\title{
EXTENDING THE DIAGNOSTIC VALUE OF CAPNOGRAPHY IN VENTILATED PATIENTS
}

\author{
Ádám László Balogh MD \\ $\mathrm{PhD}$ Thesis \\ Department of Anaesthesiology and Intensive Therapy \\ University of Szeged, Hungary
}

Doctoral School of Multidisciplinary Medical Sciences

Supervisor: Barna Babik

Szeged

2017 


\section{List of scientific papers included in this thesis}

I. Balogh AL, Petak F, Fodor GH, Tolnai J, Csorba Z, Babik B. Capnogram slope and ventilation dead space parameters: comparison of mainstream and sidestream techniques. Br J Anaesth 2016; 117: 109-17.

II. Balogh AL, Petak F, Fodor GH, Sudy R, Babik B. Sevoflurane Relieves Lung Function Deterioration After Cardiopulmonary Bypass. J Cardiothorac Vasc Anesth. 2017; (Epub ahead of print)

\section{List of related scientific papers}

III. Csorba Z, Petak F, Nevery K, Tolnai J, Balogh AL, Rarosi F, Fodor GH, Babik B. Capnographic Parameters in Ventilated Patients: Correspondence with Airway and Lung Tissue Mechanics. Anaesth Analg. 2016; 122: 1412-20. 


\section{Table of contents}

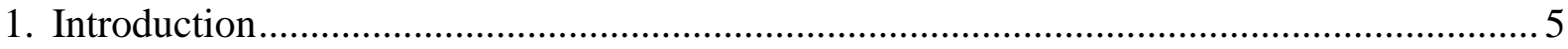

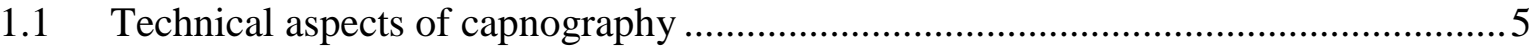

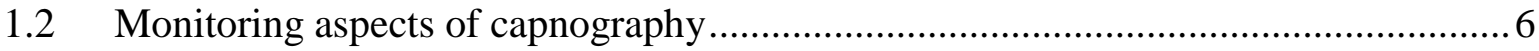

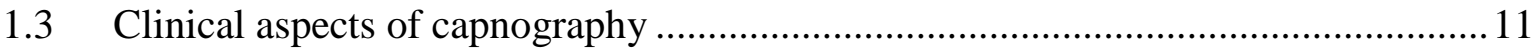

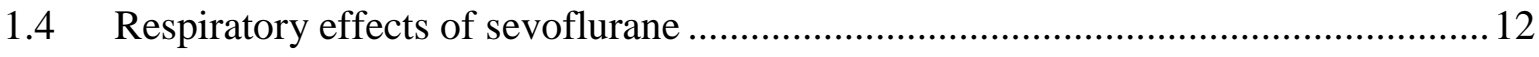

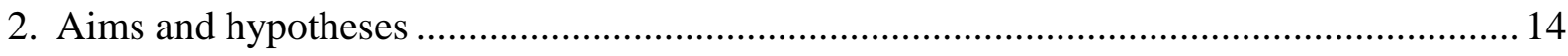

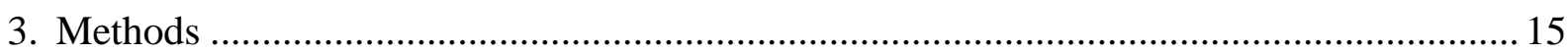

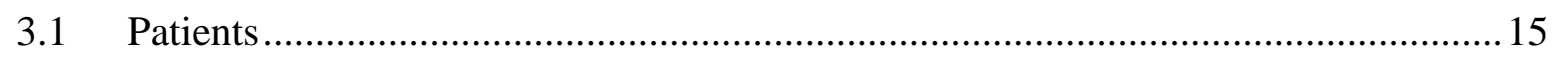

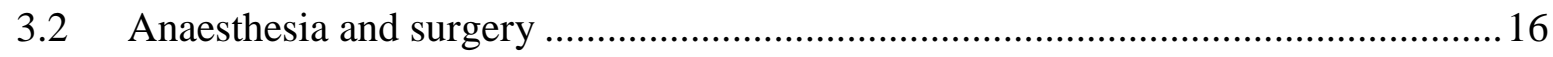

3.3 Recording and analyses of the expiratory capnogram .......................................... 16

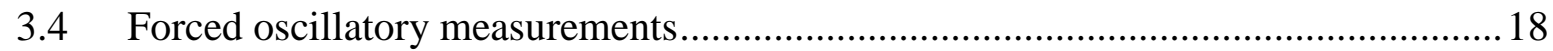

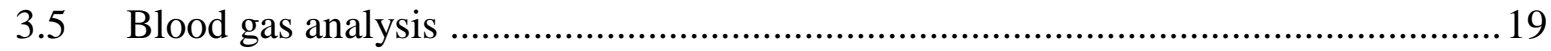

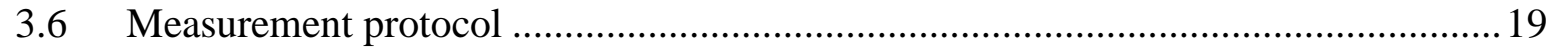

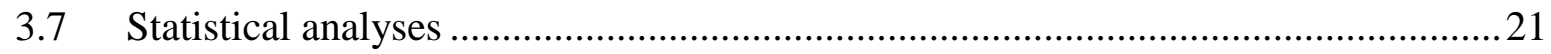

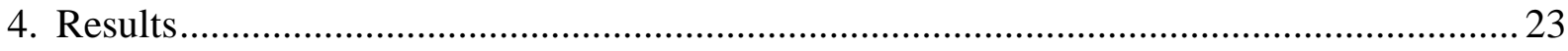

4.1 Comparison of mainstream and sidestream capnography ...................................23

4.2 The effect of sevoflurane on respiratory mechanics and gas exchange after CPB .... 31

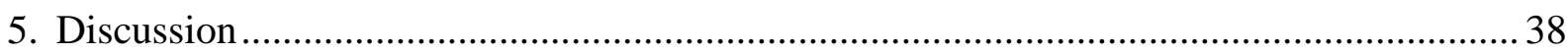

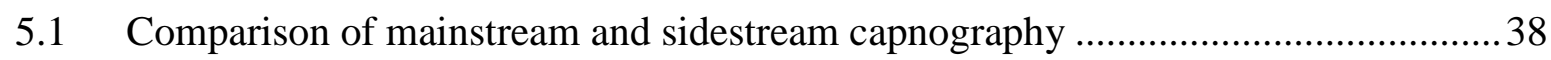

5.2 The effect of sevoflurane on respiratory mechanics and gas exchange after CPB ....40

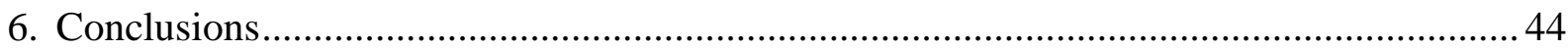

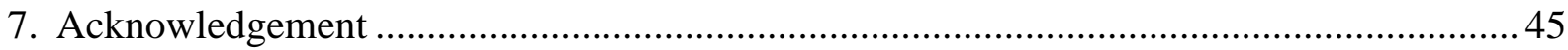

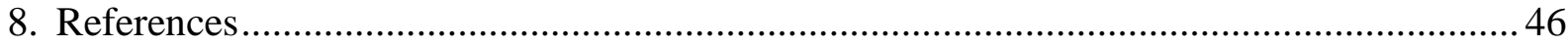




\section{Figures and tables}

Figure 1. Representative time and volumetric capnograms.

Figure 2. Volumetric capnogram with the graphical representation of the derived parameters. 9 Table 1. Demographic, anthropometric, and clinical characteristics of the patients in Study II.

Figure 3. Timeline of the experimental protocol of Study II. 21

Figure 4. Representative capnograms. 23

Figure 5. The relationship between the sidestream capnogram and the sampling flow. 24

Figure 6. Correlations and agreements between phase III slopes determined by sidestream and mainstream capnography.

Figure 7. Correlations between parameters related to phase II determined by sidestream and mainstream capnography.

Figure 8. Correlation between normalized dead space indices determined by sidestream and mainstream capnography.

Figure 9. Relative differences in normalized dead space indices by respiratory compliance determined by sidestream and mainstream capnography.

Table 2. Mainstream capnographic parameter values obtained with or without sidestream suctioning, and the corresponding p-values of paired t-tests. 31

Figure 10. Lung mechanical parameters in the groups by protocol stage. 32

Figure 11. Ventilation and shunt parameters and compliance in the groups by protocol stage.

Figure 12. Association between changes in airway resistance and phase III slope ( $\mathrm{S}_{\text {III }}$ in each patient.

Figure 13. Association between post-CPB values of the $\mathrm{PaO} 2 / \mathrm{FiO} 2$ ratio (left) and $\mathrm{Pa}-\mathrm{ETCO} 2$ (right) and their sevoflurane-induced changes. 36

Figure 14. Boxplots of indices exhibiting a difference between SEVi and SEVd subgroups.. 37 


\section{List of relevant abbreviations}

$\sim$ MS: derived from mainstream capnography

ss: derived from sidestream capnography

$\sim \mathrm{T}$ : derived from time capnography

$\sim$ v: derived from volumetric capnography

BMI: body-mass index

$\mathrm{C}$ : respiratory compliance

$\mathrm{C}_{\mathrm{aO}_{2}}:$ arterial oxygen content

$\mathrm{C}_{\mathrm{CO}_{2}}$ : pulmonary capillary oxygen content

CPB: cardiopulmonary bypass

$\mathrm{C}_{\mathrm{vO}_{2}}$ : venous oxygen content

$\mathrm{F}_{\mathrm{iO}_{2}}:$ fraction of inspired oxygen

FRC: functional residual capacity

G: tissue damping

$\mathrm{H}: \quad$ tissue elastance

Iaw: airway inertance

MAC: minimal alveolar concentration

$\mathrm{P}_{\mathrm{aCO}_{2}}$ : arterial partial pressure of $\mathrm{CO}_{2}$

$\mathrm{P}_{\mathrm{ACO}_{2}}$ : mean alveolar partial pressure of

$\mathrm{CO}_{2}$

$\mathrm{P}_{\mathrm{a}-\mathrm{ETCO}_{2}}:$ arterial to end-tidal $\mathrm{CO}_{2}$ partial pressure gradient

$\mathrm{P}_{\mathrm{aO}}:$ arterial partial pressure of $\mathrm{O}_{2}$

$\mathrm{P}_{\overline{\mathrm{E} C O}}{ }_{2}$ : mixed expired partial pressure of $\mathrm{CO}_{2}$
PEEP: positive end-expiratory pressure

$\mathrm{P}_{\mathrm{ETCO}_{2}}$ : end-tidal partial pressure of $\mathrm{CO}_{2}$

$\mathrm{P}_{\mathrm{iCO}_{2}}$ : inspired partial pressure of $\mathrm{CO}_{2}$

$\mathrm{Q}_{\mathrm{s}} / \mathrm{Q}_{\mathrm{t}}$ : shunt fraction

$\mathrm{R}$ : respiratory resistance

Raw: airway resistance

SEM: standard error of the mean

$\mathrm{S}_{\text {III }} \quad$ phase II slope

S

$\mathrm{V}_{\mathrm{CO}_{2}}:$ volume of $\mathrm{CO}_{2}$ expired in one breath

$\mathrm{V}^{\prime} \mathrm{CO}_{2}$ : volume of $\mathrm{CO}_{2}$ expired in one minute

$\mathrm{V}_{\mathrm{DB}}$ : Bohr dead space (physiological)

$\mathrm{V}_{\mathrm{DE}}$ : Enghoff dead space (physiological)

$\mathrm{V}_{\mathrm{DF}}$ : Fowler dead space (airway, anatomical)

$\mathrm{V}_{\mathrm{s}}$ : intrapulmonary shunt matched volume

$\mathrm{V}_{\mathrm{T}}$ : tidal volume

$\eta$ : $\quad$ hysteresivity 


\section{Introduction}

Capnography is a part of standard monitorization during anaesthesia and intensive care. The technique is a non-invasive, continuous, online, bedside, effort- and cooperation-independent numeric and graphic analysis of the exhaled carbon dioxide $\left(\mathrm{CO}_{2}\right)$ partial pressure in the exhaled gas mixture ${ }^{1-5}$.

\subsection{Technical aspects of capnography}

Monitoring of exhaled $\mathrm{CO}_{2}$ partial pressure in clinical practice requires a bedside method with a fast response time and ability to distinct the specific gas components. The most widespread approach possessing these requirements is the infrared spectroscopy. Carbon dioxide strongly absorbs near-infrared light with a wavelength of $4.26 \mu \mathrm{m}$, and the relationship of the $\mathrm{CO}_{2}$ partial pressure in the sample and emitted and absorbed light intensity is described by the BeerLambert law. ${ }^{1}$ Alternatively, the rarely used colorimetric method for the detection of expired $\mathrm{CO}_{2}$ is based on the effect of $\mathrm{CO}_{2}$ on $\mathrm{pH}$. The change in $\mathrm{pH}$ can be tracked using a simple mesh coated with and indicator dye, which changes its colour breath-by-breath.

In clinical practice, two techniques are available based on the measurement site of $\mathrm{CO}_{2}$. Mainstream capnography applies an infrared sensor located proximally to the patient between the tracheal tube and the Y-piece and thus, allows a rapid and accurate analysis of the $\mathrm{CO}_{2}$ partial pressure of the exhaled gas ${ }^{6-8}$. However, this method is used mainly in intensive care units, because of the disadvantages posed by the potential local heating of the head, and the weight of the sample cell increasing the risk of tracheal tube dislocation.

As an alternative, sidestream capnography is often used in the operating theatre because it is easily manageable and allows the monitoring of other gases ${ }^{9-12}$. These devices analyse the gas sample distally from the patient, and therefore have the drawbacks of a prolonged total response time $^{13-15}$, the occurrence of axial mixing ${ }^{2,16-18}$ and a variable suction flow rate ${ }^{19}$. All these processes result in a dynamic distortion of the $\mathrm{CO}_{2}$ partial pressure curve and thus, have a potential to bias the derived capnographic parameters.

Capnography can also be classified on the bases of the evaluation of the changes in $\mathrm{CO}_{2}$ values as a function of time or expired volume. In routine respiratory monitoring, the easier operated time capnography is more widely used. It can be applied in non-intubated patients, provides 
information on the inspiration as well, and it is easier to comprehend along with other signals display in the time domain, such as pressure, flow and oxygen partial pressure. The drawback of this simpler technique is the lack of information on respiratory dead spaces and the volume of expired $\mathrm{CO}_{2}\left(\mathrm{~V}_{\mathrm{CO}_{2}}\right)$. Synchronized analyses of flowmeter and mainstream capnograph signals allows $\mathrm{CO}_{2}$ partial pressure monitoring in the volumetric domain. Such volumetric capnography provides the online assessment of dead spaces and $\mathrm{V}_{\mathrm{CO}_{2}}$, and thereby allows the accurate characterization of lung ventilation, ventilation-perfusion matching and metabolic status. Therefore, there is an emerging tendency for modern ventilators and anaesthesia machines to display volumetric capnograms.

\subsection{Monitoring aspects of capnography}

\subsubsection{Shape factors of capnogram}

The expiratory capnogram can be divided into three phases. ${ }^{20}$ Phase I begins at the very end of inspiration and lasts until a rapid rise in exhaled $\mathrm{CO}_{2}$ concentration, and it reflects the expiration of the gas from the conducting airways. Phase II reflects the transition between the expiration from the airways and the alveoli, i.e. the width of the moving airway-alveolar gas front. ${ }^{21}$ Phase III indicates the emptying of the alveoli, the slope of this plateau is normally $2-3 \mathrm{mmHg} / \mathrm{s}$. The highest point of phase III denotes the end-tidal $\mathrm{CO}_{2}$ partial pressure $\left(\mathrm{P}_{\mathrm{ETCO}_{2}}\right)$, with a normal value of $30-43 \mathrm{mmHg}$. The angle between phase II and phase III is called the $\alpha$ angle, and it is generally $100-110^{\circ}$ at the standard monitoring speed of $12.5 \mathrm{~mm} / \mathrm{s}$.
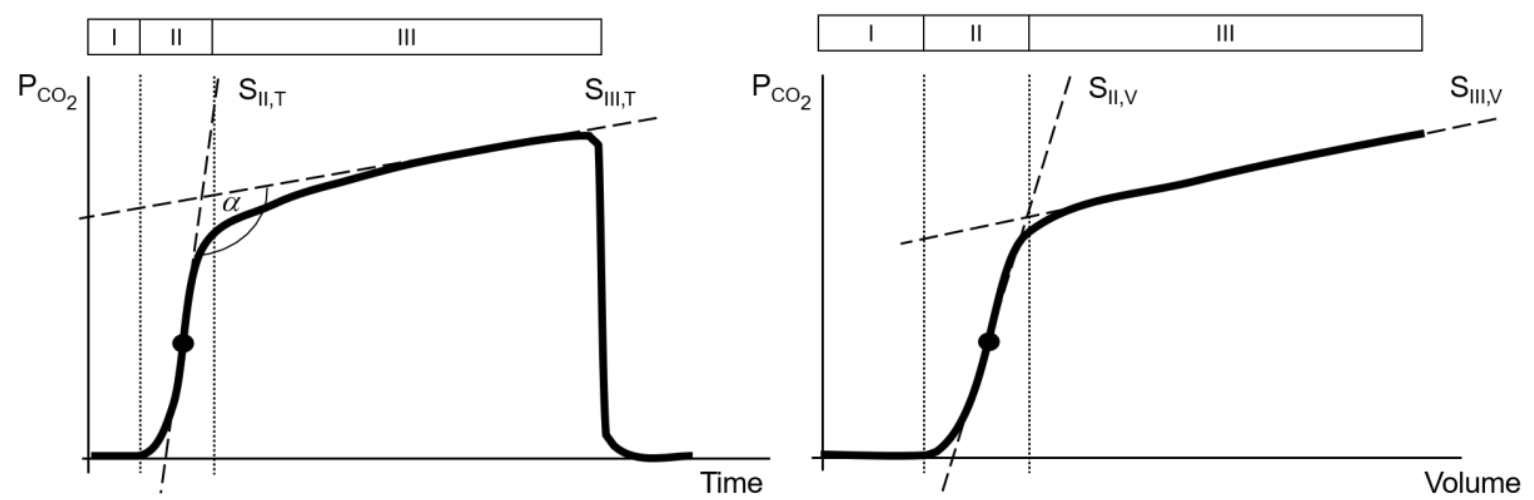

Figure 1. Representative time and volumetric capnograms.

Roman numerals denote capnogram phases. $S_{\text {II,T }}, S_{I I, V}, S_{I I I, T}$ and $S_{\text {III,V }}$ denote phase II and phase III slopes of time and volumetric capnograms, respectively. $\alpha$ signifies the angle between the lines fitted to phase II and phase III. 
Under physiological circumstances, the phase II slope $\left(\mathrm{S}_{\text {II }}\right)$ is somewhat smaller than $90^{\circ}$. This is due to the fact, that the sharp difference in $\mathrm{CO}_{2}$ partial pressure between the airway and alveolar compartments is constantly decreasing via axial diffusion on the vast total cross section of the airway-alveolar interface. ${ }^{22}$ In a previous study assessing the relationship between lung mechanical and capnogram parameters, $S_{\text {II }}$ exhibited close relation with lung elastance and compliance, independent of the $\mathrm{P}_{\mathrm{aO}_{2}} / \mathrm{F}_{\mathrm{iO}_{2}}$ ratio. ${ }^{23}$ This result is in agreement with a wider phase II in patients with emphysematous lungs. ${ }^{24}$

The physiological cause of the phase III slope $\left(\mathrm{S}_{\mathrm{III}}\right)$ is related to the fact that respiration is periodic while pulmonary circulation is continuous. Therefore, during expiration, blood in the pulmonary capillaries equilibrates with a continuously decreasing alveolar volume. Consequently, the later emptying alveoli have a higher $\mathrm{CO}_{2}$ partial pressure. ${ }^{18}$ Pathophysiological conditions give rise to ventilation heterogeneities, i.e. alveolar microcompartments with different time constants develop. The serial (e.g. in emphysema) or parallel (e.g. in asthma) sequential alveolar emptying of the heterogenous lungs is manifested in an increased phase III slope. ${ }^{2,9}$ Global alveolar emptying is governed by the contrasting effects of flow-generating and flow-limiting factors, i.e. elastic recoil indicated by respiratory compliance and lung elastance, and airway resistance. Since the role of the former factor dynamically decreases towards the end of expiration, airway resistance has a primary influence

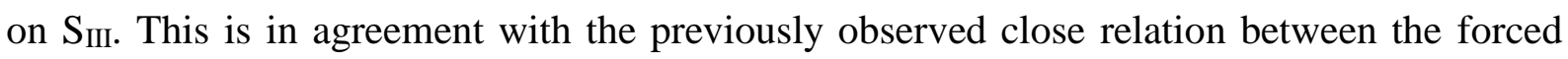
expired volume measured by spirometry and $\mathrm{S}_{\mathrm{III}} .{ }^{9}{ }^{25}$ Under physiological conditions the internal friction of the lung parenchyma did not affect $S_{\text {III }}$ substantially, while lung compliance had a lesser influence on it. However, in the presence of respiratory pathologies, such as interstitial oedema, a significantly increased tissue resistance is likely to affect $S_{\text {III. Likewise, in }}$ emphysema, a greatly decreased elastic recoil with impaired alveolar emptying is often manifested in an increased $S_{\text {III. }}$. However, a physiological $S_{\text {III }}$ may be observed in the presence of pulmonary pathologies resulting in a significantly decreased compliance, such as observed in the presence of lung congestion secondary to left ventricular failure, obesity or pleural effusion. ${ }^{10,23}$ Yet another factor influencing the absolute value of $\mathrm{S}_{\mathrm{III}}$ is $\mathrm{P}_{\mathrm{ETCO}_{2}}$. In case of a smaller $\mathrm{PETCO}_{2}$, the "shorter" capnogram exhibits a proportionally smaller absolute $\mathrm{S}_{\mathrm{III}}$; this issue can be solved by normalising $\mathrm{S}_{\mathrm{III}}$ by $\mathrm{P}_{\mathrm{ETCO}_{2}}$. Like $\mathrm{S}_{\mathrm{III}}, \mathrm{S}_{\mathrm{II}}$ is influenced by ventilation 
heterogeneity, in contrast to $\mathrm{S}_{\mathrm{III}}$, however, it is decreased in asthma or emphysema, and increased by alveolar recruitment. ${ }^{9}$

\subsubsection{Measures of characteristic gas concentrations}

Physiologically, gas partial pressures in the alveoli and the corresponding pulmonary capillaries are in equilibrium. The mean alveolar $\mathrm{CO}_{2}$ partial pressure $\left(\mathrm{P}_{\mathrm{ACO}}\right)$ is defined as the $\mathrm{CO}_{2}$ partial pressure at the midpoint of phase III of the volumetric capnogram in scientific investigations, ${ }^{3}$ but not routinely assessed in clinical practice yet. Therefore, an easier accessible surrogate, $\mathrm{PETCO}_{2}$ is used in clinical practice to assess minute ventilation and to detect severe ventilation/perfusion mismatch. Even under physiological conditions in adults, $\mathrm{P}_{\mathrm{aCO}}$ is higher than the pulmonary capillary $\mathrm{CO}_{2}$ partial pressure, due to the mixing of pulmonary capillary blood with pulmonary venous blood through extrapulmonary and intrapulmonary shunts. The difference between $\mathrm{PaCO}_{2}$ and $\mathrm{P}_{\mathrm{ACO}_{2}}$ incorporates both types of ventilation-perfusion mismatches, i.e. intrapulmonary shunt and ventilation dead space. The $\mathrm{P}_{\mathrm{a}-\mathrm{ETCO}} \mathrm{E}_{2}$ increases in case of dead space ventilation. The normal value of $\mathrm{P}_{\mathrm{a}-\mathrm{ETCO}_{2}}$ is $2-5 \mathrm{mmHg}$, and it can be increased in conditions such as pulmonary embolism, low cardiac output and bronchoconstriction, oedema or atelectasis. Under physiological circumstances, there is minimal difference between $\mathrm{PETCO}_{2}$ and $\mathrm{P}_{\mathrm{ACO}_{2}}$. However, in the presence of severe ventilation heterogeneity, a high $\mathrm{S}_{\mathrm{III}}$ leads to an increased $\mathrm{PETCO}_{2}$, which may result in a negative $\mathrm{P}_{\mathrm{a}-\mathrm{ETCO}}$, although in this case the arterial to alveolar $\mathrm{CO}_{2}$ gradient would still be positive. 


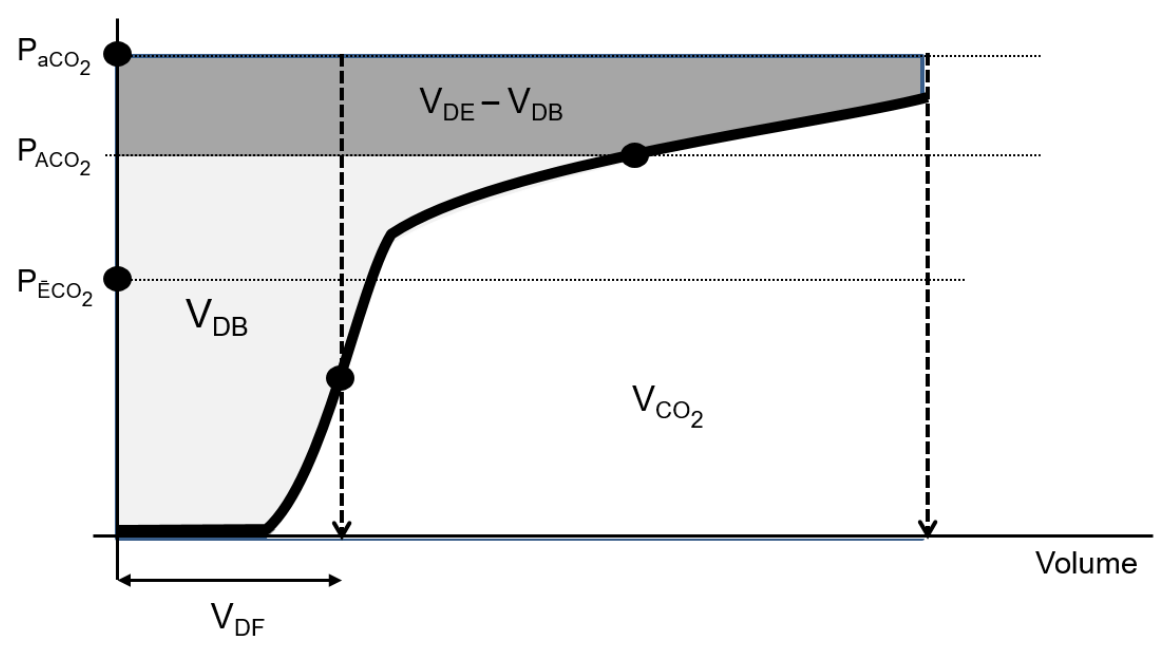

Figure 2. Volumetric capnogram with the graphical representation of the derived parameters.

$\mathrm{V}_{\mathrm{CO}_{2}}$ (volume of expired $\mathrm{CO}_{2}$ in one breath): area under curve, $\mathrm{V}_{\mathrm{DF}}$ (Fowler dead space): volume expired until the inflexion point of phase II, $\mathrm{V}_{\mathrm{DB}}$ (Bohr dead space): light grey area, $\mathrm{V}_{\mathrm{DE}}$ (Enghoff dead space): sum of light and dark grey areas. $\mathrm{P}_{\mathrm{aCO}_{2}}, \mathrm{P}_{\mathrm{ACO}_{2}}$ and $\mathrm{P}_{\overline{\mathrm{ECO}}}$ denote the arterial, mean alveolar and mean expired $\mathrm{CO}_{2}$ partial pressures, respectively.

\subsubsection{Characteristic volumes derived from volumetric capnography}

In case of volumetric capnography, the exhaled $\mathrm{CO}_{2}$ partial pressure is plotted against the exhaled volume, breath by breath. This technique requires the simultaneous use of capnography and flow-measurement. The volumetric capnogram can only display the expiration, which can be divided into the aforementioned three phases. However, phase II is wider and phase III is narrower compared to the time capnogram due the higher flow at the beginning of the expiration. The use of volumetric capnography offers important advantages against time capnography: it allows the measurement of $\mathrm{V}_{\mathrm{CO}_{2}}$ and the respiratory dead spaces.

The $\mathrm{V}_{\mathrm{CO}_{2}}$ can be determined as the area under the volumetric capnogram within an expiration. Multiplying it by the respiratory rate, the $\mathrm{CO}_{2}$ output $\left(\mathrm{V}^{\prime} \mathrm{CO}_{2}\right)$, i.e. the volume of $\mathrm{CO}_{2}$ expired in one minute can be derived. Under physiological conditions, assuming a respiratory quotient of $\sim 0.8$, the normal value of $\mathrm{V}^{\prime} \mathrm{CO}_{2}$ is $3 \mathrm{ml} / \mathrm{kg} / \mathrm{min}$ in adults, and it can be as high as $10 \mathrm{ml} / \mathrm{kg} / \mathrm{min}$ in infants. Since $\mathrm{V}^{\prime} \mathrm{CO}_{2}$ reflects the metabolic rate, its value is increased during sepsis, hyperthermia or exercise, and decreased during general anaesthesia, hypothermia or sleep.

Dead space is a fraction of tidal volume that does not participate in gas exchange. The lack of gas exchange can be attributed to anatomical, physiological and pathophysiological factors. 
During each breath, there is a volume fraction of air residing in the conducting airways and in the connective tubing system distal to the Y-piece in case of mechanical ventilation. These volumes do not participate in the gas exchange. These gas compartments form the anatomical dead space, referred often as Fowler dead space $\left(\mathrm{V}_{\mathrm{DF}}\right)$ after the first person to describe a method for its measurement. According to Fowler's concept originally described for nitrogen washout tests, ${ }^{26}$ the virtual border of the anatomical dead space is represented by the inflection point of phase II of the volumetric capnogram. Thus, $\mathrm{V}_{\mathrm{DF}}$ is determined by taking the volume expired up until that inflection point. Its normal value is around $2 \mathrm{ml} / \mathrm{kg}$.

Further causes of wasted ventilation are related to alveolar compartments not accessed by the pulmonary circulation. The three-compartment model of the heterogeneous lung proposed groups the whole spectrum of alveoli with different ventilation-perfusion (V'/Q) ratios into three isolated categories, as proposed by Riley. ${ }^{27}$ In this schematic model, gas exchange can only occur in the ideal compartment with a $V^{\prime} / Q$ ratio of 1 . The second compartment is ventilated but unperfused, thus comprises alveolar dead space with an infinitely high V'/Q ratio. The third compartment is perfused without ventilation, therefore forms an intrapulmonary shunt with a V'/Q ratio of 0 .

Bohr's proposal for dead space calculation is based on the notion, that $\mathrm{V}_{\mathrm{CO}_{2}}$ must be equal to the sum of the volume of $\mathrm{CO}_{2}$ from the physiological dead space and that from the ideal alveoli, resulting in the equation: ${ }^{28}$

$$
\mathrm{P}_{\overline{\mathrm{E} C O}} \cdot \mathrm{V}_{\mathrm{T}}=\mathrm{P}_{\mathrm{iCO}_{2}} \cdot \mathrm{V}_{\mathrm{DB}}+\mathrm{P}_{\mathrm{ACO}_{2}} \cdot\left(\mathrm{V}_{\mathrm{T}}-\mathrm{V}_{\mathrm{DB}}\right)
$$

where $\mathrm{V}_{\mathrm{T}}$ is the tidal volume, $\mathrm{V}_{\mathrm{DB}}$ is the physiological dead space according to Bohr, $\mathrm{P}_{\mathrm{aCO}}$ is the mean alveolar partial pressure of $\mathrm{CO}_{2}$, and $\mathrm{P}_{\overline{\mathrm{ECO}}}$ is the mixed expired $\mathrm{CO}_{2}$ partial pressure. $\mathrm{P}_{\mathrm{iCO}_{2}}$ is the $\mathrm{CO}_{2}$ partial pressure of the inspired gas, and since this can be considered 0 , the first product of the right side can be removed, leaving after rearrangement:

$$
\mathrm{V}_{\mathrm{DB}} / \mathrm{V}_{\mathrm{T}}=\left(\mathrm{P}_{\mathrm{ACO}_{2}}-\mathrm{P}_{\overline{\mathrm{ECO}}}\right) / \mathrm{P}_{\mathrm{ACO}_{2}}
$$

implying, that $\mathrm{V}_{\mathrm{DB}}$ represents the volume that dilutes the alveolar $\mathrm{CO}_{2}$ partial pressure to the mixed $\mathrm{CO}_{2}$ partial pressure during expiration, i.e. the "dead air" leaving the airways and the unperfused alveoli. Consequently, beyond those factors affecting $\mathrm{V}_{\mathrm{DF}}, \mathrm{V}_{\mathrm{DB}}$ is also influenced 
by alveolar hypoperfusion, such as the overdistension of the alveoli by relatively high positive pressure, pulmonary embolism, hypovolaemia, pulmonary hypertension and/or right ventricular failure. In the past, the main limitation of routine assessment of $V_{D B}$ was the lack of tools to accurately measure $\mathrm{P}_{\mathrm{ACO}_{2}}$. $\mathrm{P}_{\mathrm{ETCO}_{2}}$ was used instead, which led to an overestimation of the physiological dead space, especially in case of a ventilation heterogeneity. Furthermore, $\mathrm{V}_{\mathrm{DB}}$ does not reflect ventilation-perfusion mismatch originating from the third compartment according to Riley's model, i.e. the intrapulmonary shunt.

To facilitate the widespread utilization of the physiological dead space concept, Enghoff modified the calculation by replacing $\mathrm{P}_{\mathrm{ACO}_{2}}$ with the arterial $\mathrm{CO}_{2}$ partial pressure $\left(\mathrm{P}_{\mathrm{aCO}_{2}}\right) .{ }^{29}$

$$
\mathrm{V}_{\mathrm{DE}} / \mathrm{V}_{\mathrm{T}}=\left(\mathrm{P}_{\mathrm{aCO}_{2}}-\mathrm{P}_{\overline{\mathrm{ECO}}}\right) / \mathrm{P}_{\mathrm{aCO}}
$$

Thus, the Enghoff dead space $\left(\mathrm{V}_{\mathrm{DE}}\right)$ is influenced by all factors affecting the transfer of $\mathrm{CO}_{2}$ from the pulmonary artery to the expired gas, i.e. all sources of venous admixture. Accordingly, beyond $\mathrm{V}_{\mathrm{DB}}, \mathrm{V}_{\mathrm{DE}}$ also includes the intrapulmonary shunt, i.e. the virtual volume of perfused but unventilated alveoli. However, $\mathrm{V}_{\mathrm{DE}}$ may also be increased in the presence of a pulmonary arteriovenous malformations or right-to-left intracardiac shunts, even without an increased intrapulmonary shunt.

\subsection{Clinical aspects of capnography}

Nowadays capnography is an essential monitoring modality for the improvement of patient safety in anaesthesia and intensive therapy ${ }^{30}$. Furthermore, it serves as a diagnostic tool in emergency medicine, paediatrics, sleep medicine, during resuscitation, patient transport and pulmonology.

Besides monitoring the vital signs (i.e. fogging in the tracheal tube, chest wall movement or breath sounds), capnography is an accurate method for confirming tracheal intubation. ${ }^{31}$ The risk of unrecognized misplaced intubation is higher in emergency situations, and capnography has a potential to reveal the severe consequences. Flat capnogram curves may result from severe airway constriction. Furthermore, absence of characteristic capnogram with slopes II and III may immediately suggest intraoesophageal intubation. However, it should be kept in mind that $\mathrm{CO}_{2}$ may be detected even after oesophageal intubation if the stomach has been inflated with expired $\mathrm{CO}_{2}$ during mask ventilation, or the patient has consumed carbonated beverages or 
previously taken antacids. During cardiopulmonary resuscitation, an increase in $\mathrm{PETCO}_{2}$ can be the first indicator of the return of the spontaneous circulation reflected by restored pulmonary blood flow. Likewise, the efficiency of chest compressions can be estimated by capnographic monitoring of the $\mathrm{PETCO}_{2} \cdot{ }^{32}$ Additionally, $\mathrm{P}_{\mathrm{ETCO}_{2}}$ has been demonstrated to predict prognosis in cardiac arrest. ${ }^{33} \mathrm{P}_{\mathrm{ETCO}_{2}}$ complemented with occasional blood gas analyses also allows the continuous guidance of arterial $\mathrm{CO}_{2}$ tension, that is crucial in patients with increased intracranial pressure, since both hypercapnia and hypocapnia are detrimental for neurological outcome. $^{34}$

Despite widespread availability of capnography to assess metabolism, and to monitor ventilation and ventilation-perfusion matching, it still can be considered as an underutilised tool for anaesthesiologist, intensivists, and pulmonologists. Furthermore, the current capnogram analysis is mainly limited to the qualitative assessment of the overall shape, with the only monitored quantitative parameter is the $\mathrm{P}_{\mathrm{ETCO}_{2}}$.

While assessment of capnogram shape factors is not standard part of the patient monitoring yet, they have the promise to possess routine information concerning pathophysiological processes of lung ventilation, such as airway patency ${ }^{9}, 10,12,18$ and lung recoil tendency ${ }^{10,12}$. Furthermore, combining capnography with expired gas volume monitoring allows the assessment of ventilation-perfusion matching and the metabolic status of the body $\mathrm{y}^{3,5,17,18}$

There have been a few previous attempts to compare capnographic parameters obtained by sidestream and mainstream techniques, but they were either manufacturer's educational material ${ }^{35}$, focused only on the end-tidal $\mathrm{CO}_{2}$ value in experimental ${ }^{36}$ and clinical studies ${ }^{37-39}$, or were limited to a small cohort of infants ${ }^{40}$. However, there is a lack of information about the relationship between capnographic indices obtained by sidestream and mainstream techniques in mechanically ventilated adults.

\subsection{Respiratory effects of sevoflurane}

Volatile anaesthetics have a significant fundamental role in general anaesthesia with a marked relaxation potential on the airway smooth muscle, resulting in complex pulmonary consequences. Therefore, application of these agents is ideal to assess the monitoring value of capnography to detect changes in the lung ventilation. Their bronchodilator activity against an 
elevated bronchial tone caused by exogenous constrictor agonists has been consistently proved in experimental studies. ${ }^{41-43}$ The airway dilation by volatile agents was also confirmed after endogenous release of constrictor mediators in clinical investigations; elevations in the airway tone in these previous clinical studies were induced by administering thiopental and succinylcholine and/or performing endotracheal intubation. ${ }^{44,45}$

Another relevant trigger of perioperative bronchoconstriction is cardiopulmonary bypass (CPB) applied during open-heart surgery. ${ }^{46,47}$ The use of this technique induces well-described multimodal detrimental changes in the lungs. ${ }^{48}$ The systemic inflammatory response is initiated by contact activation, ischemia-reperfusion and endotoxemia, which are followed by the activation of complement, cytokine and coagulation/fibrinolysis cascades, ${ }^{49-51}$ which in turn result in leukocyte activation. ${ }^{52}$ Free oxygen radicals, platelet-activating factor and leukotrienes increase vascular permeability and interstitial oedema. ${ }^{53}$ Furthermore, mast cells and basophils release bronchoactive mediators, such as histamine and serotonin. ${ }^{54,55}$ The subsequent overall pulmonary dysfunction can be manifested in important clinical pathologies, such as airway constriction, atelectasis, hypoxemia, elevated right heart afterload and reduced systemic venous return.

Sevoflurane is among the most commonly used volatile anaesthetics with beneficial pharmacokinetic properties, an advantageous bronchial effect compared to other volatile anaesthetics. ${ }^{44}$ The effects of sevoflurane on lung function have been investigated extensively in humans as well as in animal models. However, in these studies simple bronchial challenges were applied, mainly inducing specific bronchoconstriction of cholinergic or histaminergic origin. ${ }^{41,56,57}$ While the beneficial pulmonary profile of sevoflurane following CPB can be anticipated, the only previous study to investigate its effects on the lungs following this complex challenge was limited to demonstrating beneficial changes in leukocyte counts and interleukin levels. ${ }^{58}$ Furthermore, the effect of sevoflurane on lung functional changes, particularly increased interstitial oedema and ventilation heterogeneity after CPB have not been investigated. To evaluate the potential additional diagnostic value of capnography, these measurements were supplemented by the simultaneously assessment of ventilation by capnography. 


\section{Aims and hypotheses}

The studies included in the present thesis aimed at extending the monitoring and diagnostic value of capnography. For this purpose, we investigated the accuracy of the easier accessible, more widespread sidestream technique in the estimation of capnogram parameters. To assess the applicability of capnography for the qualitative monitoring in a clinical model of rapidly developing pulmonary mechanical and functional deteriorations, we simultaneously measured respiratory mechanics, oxygenation and ventilation heterogeneity in a large cohort of patients intraoperatively. The specific aims of the studies included in the present thesis were:

- to validate the ability of the sidestream technique to provide adequate quantitative bedside information about uneven alveolar emptying and ventilation-perfusion mismatch;

- to determine which capnogram parameters (shape factors, respiratory dead spaces) can be reliably assessed by applying the sidestream technique by comparing the sidestream outcomes to those obtained by a mainstream technique as a reference;

- to assess the effect of respiratory compliance on the accuracy of the sidestream capnography measurement;

- to examine the effects of sampling flow and sampling tube length on the accuracy of sidestream measurement;

- to assess adverse alterations in airway and lung tissue mechanics, ventilation heterogeneity, ventilation-perfusion matching and gas exchange induced by $\mathrm{CPB}$, and to estimate the potential of sevoflurane to reverse these detrimental changes;

We hypothesized that sidestream capnography is suitable to measure indices obtained from the quasi-static phases of the capnogram, whereas phases with transient $\mathrm{CO}_{2}$ partial pressure changes are exposed to the measurement bias. We also postulated that after deleterious lung function changes to $\mathrm{CPB}$, the expected bronchodilation by sevoflurane is associated with improvements in lung tissue viscoelasticity and diminished ventilation heterogeneities, which may enhance oxygenation. 


\section{Methods}

\subsection{Patients}

The study protocols were approved by the Human Research Ethics Committee of the University of Szeged, Hungary (no. WHO 2788). Patients undergoing elective open-heart surgery were enrolled in the studies. Written informed consent was obtained from each patient. Patients with severe cardiopulmonary disorders (pleural effusion $>300 \mathrm{ml}$, ejection fraction $<30 \%$, endocarditis, $\mathrm{BMI}>35 \mathrm{~kg} / \mathrm{m}^{2}$ or intraoperative acute asthma exacerbation) were excluded.

In Study I, twenty-nine patients (female/male: 13/16, 71 (57-85) yrs.) undergoing elective cardiac surgery were enrolled in a prospective consecutive manner.

In Study II, patients were randomly assigned to the sevoflurane group (SEV) or the control group (CTRL). Measurement data of one hundred and ninety patients (SEV: n=99, CTRL: $\mathrm{n}=91 ; 107$ males, 83 females, 63 yrs. of age (range 32-85 yrs.)) were included in the analysis. Table 1 summarizes the demographic, anthropometric, and clinical characteristics of the patients.

\begin{tabular}{|c|c|c|}
\hline Group & CTRL (n=91) & SEV (n=99) \\
\hline Male/female & $54 / 37$ & $53 / 46$ \\
\hline Age (yrs.) & $65 \pm 14$ & $63 \pm 14$ \\
\hline Height $(\mathrm{cm})$ & $167 \pm 9$ & $168 \pm 10$ \\
\hline Weight (kg) & $79 \pm 16$ & $82 \pm 16$ \\
\hline \multicolumn{3}{|l|}{ Surgery } \\
\hline AVR/AVP & 58 & 58 \\
\hline $\mathrm{AVR}+\mathrm{CABG}$ & 13 & 8 \\
\hline MVM/MVP & 17 & 21 \\
\hline Other & 11 & 4 \\
\hline \multicolumn{3}{|c|}{ Respiratory comorbidities } \\
\hline Asthma & 4 & 5 \\
\hline Emphysema & 9 & 12 \\
\hline
\end{tabular}

Table 1. Demographic, anthropometric, and clinical characteristics of the patients in Study II. Anthropometric data are presented as mean \pm SD. AVR/AVP: aortic valve replacement/plasty, CABG: coronary artery bypass grafting, MVR/MVP: mitral valve replacement/plasty, Other: left atrial myxoma removal, tricuspid valve plasty, atrial septal defect closure, ascending aorta aneurysm repair. 


\subsection{Anaesthesia and surgery}

Anaesthesia was induced with intravenous midazolam $(30 \mu \mathrm{g} / \mathrm{kg})$, sufentanil $(0.4-0.5 \mu \mathrm{g} / \mathrm{kg})$ and propofol $(0.3-0.5 \mu \mathrm{g} / \mathrm{kg})$, and was maintained by an intravenous propofol infusion (50 $\mu \mathrm{g} / \mathrm{kg} / \mathrm{min}$ ). Neuromuscular blockade was achieved by intravenous boluses of rocuronium $(0.2 \mathrm{mg} / \mathrm{kg}$ every $30 \mathrm{~min})$.

After tracheal intubation with a cuffed tracheal tube with an internal diameter of 7,8 or $9 \mathrm{~mm}$ was achieved, the patients' lungs were mechanically ventilated in volume-controlled mode with descending flow (Dräger Zeus, Lübeck, Germany) by setting the tidal volume to $7 \mathrm{ml} / \mathrm{kg}$, the ventilator frequency to $9-14$ breaths per minute, and the positive end-expiratory pressure (PEEP) to $4 \mathrm{cmH}_{2} \mathrm{O}$. The fraction of inspired oxygen $\left(\mathrm{F}_{\mathrm{iO}_{2}}\right)$ was set to 0.5 before $\mathrm{CPB}$ and 0.8 after CPB.

Before $\mathrm{CPB}$, the membrane oxygenator was primed with $1500 \mathrm{ml}$ of lactated Ringer's solution. Heparin was administered at a dose of $300 \mathrm{U} / \mathrm{kg}$, with the anticoagulation time maintained at $300 \mathrm{~s}$. Moderate hypothermia was routinely induced (oesophageal temperature of $32^{\circ} \mathrm{C}$ ). During CPB, mechanical ventilation was stopped, and the ventilator was disconnected without applying positive airway pressure. Before restoring ventilation, the lungs were inflated 3-5 times to a peak airway pressure of $30 \mathrm{cmH}_{2} \mathrm{O}$ to facilitate lung recruitment.

\subsection{Recording and analyses of the expiratory capnogram}

The measurement setup was designed to allow the sampling of the mainstream (Capnogard Model 1265, Novametrix, Andover, MA, USA) and sidestream (Capnomac Ultima, Datex, Helsinki, Finland) capnographs from the same sampling site in the ventilator circuit. This was achieved by connecting the sampling port of the sidestream capnograph next to the mainstream sensor between the Y-piece and the tracheal tube. A screen pneumotachograph (Piston Ltd., Budapest, Hungary) was used to record the central airflow at the same point of the ventilator circuit. Simultaneous 15-s recordings of the $\mathrm{CO}_{2}$ signals of the mainstream and sidestream capnographs and the ventilation flow were digitized (sampling frequency $102.4 \mathrm{~Hz}$ ) and analysed with custom-made software. Volumetric capnograms were constructed from the time capnograms and the integrated flow data. To compensate for the transport delay caused by the suction of the gas into the sample cell, the sidestream time capnograms were shifted by $-1.65 \mathrm{~s}$. This value was determined by analysing the time delay between the mainstream and sidestream 
capnogram curves during stepwise changes in $\mathrm{CO}_{2}$ partial pressure, similarly as in an earlier approach $^{14}$.

The slopes of phase III of the time and volumetric capnograms determined by mainstream ( $\mathrm{S}_{\text {III,T,MS }}$ and $\mathrm{S}_{\text {III,V,MS }}$ ) and sidestream capnography ( $\mathrm{S}_{\text {III,T,SS }}$ and $\mathrm{S}_{\text {III,V,SS }}$ ) were assessed by fitting a linear regression line to the last $60 \%$ of phase $\mathrm{III}^{6,9,10}$. Similarly, regression lines were fitted to the points around the inflexion point of phase II within $\pm 20 \%$ of the time or volume of phase II, to determine their slopes in the mainstream $\left(\mathrm{S}_{\mathrm{II}, \mathrm{T}, \mathrm{MS}}\right.$ and $\left.\mathrm{S}_{\mathrm{II}, \mathrm{V}, \mathrm{MS}}\right)$ and sidestream $\left(\mathrm{S}_{\mathrm{II}, \mathrm{T}, \mathrm{SS}}\right.$ and $\mathrm{S}_{\text {II,V,SS }}$ ) measurements. The angles formed by the phase II and III limbs of the expiratory time mainstream $\left(\alpha_{M S}\right)$ and sidestream ( $\left.\alpha_{S S}\right)$ capnograms were calculated from the phase II and phase III slopes using a virtual monitoring speed of $12.5 \mathrm{mmHg} / \mathrm{s}$ ).

Additionally, dead space fractions were calculated from volumetric capnograms. Fowler dead space, reflecting the volume of the conducting airways ${ }^{59}$, was determined by taking the volume expired up to the inflexion point of phase II from the mainstream and sidestream capnograms $\left(\mathrm{V}_{\mathrm{DF}, \mathrm{MS}}\right.$ and $\left.\mathrm{V}_{\mathrm{DF}, \mathrm{SS}}\right)$. The physiological dead space according to Bohr $\left(\mathrm{V}_{\mathrm{DB}, \mathrm{MS}}\right.$ and $\left.\mathrm{V}_{\mathrm{DB}, \mathrm{SS}}\right)$ reflecting the alveolar volume with decreased or no perfusion was calculated from the mainstream and sidestream capnograms as ${ }^{60}$ :

$$
\begin{gathered}
\mathrm{V}_{\mathrm{DB}, \mathrm{MS}} / \mathrm{V}_{\mathrm{T}}=\left(\mathrm{P}_{\mathrm{ACO}_{2}, \mathrm{MS}}-\mathrm{P}_{\overline{\mathrm{ECO}}}, \mathrm{MS}\right) / \mathrm{P}_{\mathrm{ACO}_{2}, \mathrm{MS}} \\
\mathrm{V}_{\mathrm{DB}, \mathrm{SS}} / \mathrm{V}_{\mathrm{T}}=\left(\mathrm{P}_{\mathrm{ACO}_{2}, \mathrm{SS}}-\mathrm{P}_{\overline{\mathrm{ECO}}}, \mathrm{SS}\right) / \mathrm{P}_{\mathrm{ACO}_{2}, \mathrm{SS}}
\end{gathered}
$$

where $\mathrm{P}_{\mathrm{ACO}_{2}, \mathrm{MS}}$ and $\mathrm{P}_{\mathrm{ACO}_{2}}$,SS are the mean alveolar partial pressures of $\mathrm{CO}_{2}$, determined from the midpoint of phase III in the mainstream and sidestream capnograms respectively 3,8 . $\mathrm{P}_{\overline{\mathrm{E} C O}}$, MS and $\mathrm{P}_{\overline{\mathrm{ECO}}}$, SS are the mixed expired $\mathrm{CO}_{2}$ partial pressure, obtained by calculating the area under the mainstream and sidestream volumetric capnogram curves via integration and dividing the resulting values by $\mathrm{V}_{\mathrm{T}}$.

Enghoff's approach contains all ventilation-perfusion mismatch. Hence, besides the $\mathrm{V}_{\mathrm{DB}}$, it also incorporates the intrapulmonary shunt, i.e. the alveolar volume with decreased or even loss of ventilation with perfusion maintained ${ }^{61}$ :

$$
\begin{aligned}
& \mathrm{V}_{\mathrm{DE}, \mathrm{MS}} / \mathrm{V}_{\mathrm{T}}=\left(\mathrm{P}_{\mathrm{aCO}_{2}}-\mathrm{P}_{\overline{\mathrm{ECO}}}, \mathrm{MS}\right) / \mathrm{P}_{\mathrm{aCO}_{2}} \\
& \mathrm{~V}_{\mathrm{DE}, \mathrm{SS}} / \mathrm{V}_{\mathrm{T}}=\left(\mathrm{P}_{\mathrm{aCO}_{2}}-\mathrm{P}_{\overline{\mathrm{ECO}}}, \mathrm{SS}\right) / \mathrm{P}_{\mathrm{aCO}_{2}}
\end{aligned}
$$

where $\mathrm{PaCO}_{2}$ is the partial pressure of $\mathrm{CO}_{2}$ in the arterial blood. 
Additionally we calculated the normalized differences between the Enghoff and Bohr dead spaces obtained by mainstream $\left(\mathrm{V}_{\mathrm{S}, \mathrm{MS}} / \mathrm{V}_{\mathrm{T}}=\left[\mathrm{V}_{\mathrm{DE}, \mathrm{MS}}-\mathrm{V}_{\mathrm{DB}, \mathrm{MS}}\right] / \mathrm{V}_{\mathrm{T}}\right)$ and sidestream capnography $\left(\mathrm{V}_{\mathrm{s}, \mathrm{SS}} / \mathrm{V}_{\mathrm{T}}=\left[\mathrm{V}_{\mathrm{DE}, \mathrm{SS}}-\mathrm{V}_{\mathrm{DB}, \mathrm{SS}}\right] / \mathrm{V}_{\mathrm{T}}\right)$, which reflects the all the mixed venous blood entering the arterial system. These include Thebesian veins, part of the bronchial veins and intrapulmonary shunt circulation, i.e. the virtual gas volume of the alveolar units with perfusion with decreased or no ventilation.

The amount of the $\mathrm{CO}_{2}$ exhaled during each expiration was calculated as the area under the volumetric $\mathrm{CO}_{2}$ partial pressure curve obtained by mainstream $\left(\mathrm{V}_{\mathrm{CO}_{2}, \mathrm{MS}}\right)$ and sidestream $\left(\mathrm{V}_{\mathrm{CO}_{2}}, \mathrm{SS}\right)$ capnography.

The changes in the sampling flow rate during the mechanical ventilation were measured in a smaller cohort of ventilated patients $(n=5)$. The sampling flow was assessed by measuring the pressure difference between the proximal and distal ends of the sampling tube with a miniature differential pressure transducer (model 33NA002D, ICSensors, Milpitas, CA, USA). The potential variability of the sampling flow governed by the respiratory impedance can theoretically bias the accuracy of sidestream estimates. Thus, the main cohort of the patients was divided into three groups based on their compliance values into lower $\left(\mathrm{C}<37 \mathrm{ml} / \mathrm{cmH}_{2} \mathrm{O}\right)$, higher $\left(\mathrm{C}>53 \mathrm{ml} / \mathrm{cmH}_{2} \mathrm{O}\right)$ quartiles and medium interquartile range.

\subsection{Forced oscillatory measurements}

Changes in the airway and tissue mechanical properties from CPB and sevoflurane were assessed by measuring the low-frequency forced oscillatory input impedance of the lungs, as detailed previously. ${ }^{46}$ Briefly, a T-piece with two collapsible segments was attached to the distal tracheal tube, with one end connected to the ventilator and the other end to a loudspeaker-inbox system. This apparatus made it possible to switch the patient from the respirator to the forced oscillatory setup during the measurements. These were performed by introducing pseudorandom pressure excitations generated by the loudspeaker into the trachea during short (15 s) apnoeic pauses interspersed into the mechanical ventilation. The forcing signal consisted of 15 integer-multiple components of the $0.4 \mathrm{~Hz}$ fundamental frequency, between 0.4 and $6 \mathrm{~Hz}$. A $28 \mathrm{~mm}$ internal diameter screen pneumotachograph connected to a differential pressure transducer (ICS model 33NA002D; ICSensors, Milpitas, CA, USA) was used to measure tracheal airflow. An identical pressure transducer was used to detect airway opening pressure. 
Lung input impedance was computed from the power spectra of airway opening pressure and tracheal airflow, and then ensemble-averaged under each condition. The mean lung impedance data were fitted by a well-validated 4-parameter model ${ }^{62}$ containing a frequency-independent airway resistance (Raw) and inertance (Iaw) and a constant-phase tissue compartment characterized by the coefficients of damping $(\mathrm{G})$ and elastance $(\mathrm{H})$ such that the difference between measured and modelled impedance values were minimal. Lung tissue hysteresivity was calculated as $\eta=\mathrm{G} / \mathrm{H}$. Raw represents the flow resistance of the bronchial tree, and Iaw is related to the mass of the gas in the airways. The tissue parameters characterize the resistive (G) and elastic properties of the lung parenchyma $(\mathrm{H})$, while $\eta$ reflects the coupling between the resistive and elastic properties.

\subsection{Blood gas analysis}

The partial pressure of oxygen in the arterial blood $\left(\mathrm{P}_{\mathrm{aO}_{2}}\right)$ was determined from arterial blood gas samples for the $\mathrm{P}_{\mathrm{aO}} / \mathrm{F}_{\mathrm{iO}_{2}}$ ratio and the arterial to end-tidal $\mathrm{CO}_{2}$ gradient $\left(\mathrm{P}_{\mathrm{a}-\mathrm{ETCO}_{2}}\right)$. The intrapulmonary shunt fraction $\left(\mathrm{Q}_{\mathrm{s}} / \mathrm{Q}_{\mathrm{t}}\right)$ was determined by means of the Berggren equation: ${ }^{63}$

$$
\mathrm{Q}_{\mathrm{s}} / \mathrm{Q}_{\mathrm{t}}=\left(\mathrm{C}_{\mathrm{cO}_{2}}-\mathrm{C}_{\mathrm{aO}_{2}}\right) /\left(\mathrm{C}_{\mathrm{cO}_{2}}-\mathrm{C}_{\mathrm{vO}}\right),
$$

where $\mathrm{C}_{\mathrm{CO}_{2}}, \mathrm{C}_{\mathrm{aO}}$ and $\mathrm{C}_{\mathrm{vO}_{2}}$ are the oxygen contents of the pulmonary capillary and arterial and central venous blood, respectively. $\mathrm{C}_{\mathrm{CO}_{2}}$ was calculated per the alveolar gas equation, assuming the $\mathrm{O}_{2}$ saturation of haemoglobin in the pulmonary capillaries to be $100 \%$ :

$$
\mathrm{C}_{\mathrm{cO}_{2}}=1.34 \mathrm{ml} / \mathrm{g} \cdot \mathrm{Hb}+\mathrm{Sol} \cdot\left(\mathrm{F}_{\mathrm{iO}_{2}} \cdot 713 \mathrm{mmHg}-\mathrm{P}_{\mathrm{aCO}_{2}} / 0.8\right) \text {, }
$$

where $1.34 \mathrm{ml} / \mathrm{g}$ is Hüfner's constant, $\mathrm{Hb}$ is the haemoglobin concentration in $\mathrm{g}$, Sol is the solubility of $\mathrm{CO}_{2}$ in blood, $0.0031 \mathrm{ml} / 100 \mathrm{ml} / \mathrm{mmHg}, 713 \mathrm{mmHg}$ is the total dry gas pressure, $\mathrm{P}_{\mathrm{aCO}_{2}}$ is the partial pressure of $\mathrm{CO}_{2}$ in the arterial blood, and 0.8 is the respiratory exchange ratio.

\subsection{Measurement protocol}

\subsubsection{Measurement protocol of Study I}

Mainstream and sidestream capnographic signals were recorded simultaneously during different stages of cardiac surgery: before sternotomy, 5 min before and after cardiopulmonary bypass, and immediately after sternal closure. Two pairs of 15-s traces were recorded in each 
stage, producing 8 recordings per patient (approximately 20 pairs of expirations). For the assessment of $\mathrm{PaCO}_{2}$, arterial blood gas samples were taken under each measurement condition, and the resistance $(\mathrm{R})$ and compliance $(\mathrm{C})$ values displayed by the ventilator were also registered.

To assess whether sidestream capnography affects the mainstream results via gas suctioning, an additional protocol was performed with a setup identical to that used in the main study group in a smaller cohort of patients $(n=8)$. A total number of 87 mainstream measurements, each lasting 60-s, were performed with the sidestream sampling flow switched on randomly during either the first or second half of the recordings. Separate analyses of first and second halves allowed pairwise comparisons of mainstream capnogram parameters obtained with and without gas suctioning by the sidestream device.

\subsubsection{Measurement protocol of Study II}

The scheme of the experimental protocol is outlined in Figure 3. When stable hemodynamic and respiratory mechanical conditions had been reached after sternotomy, baseline measurements were performed $5 \mathrm{~min}$ before starting CPB. Measurements included recordings of four 15-s capnogram traces, analyses of arterial and central venous blood gas samples (Radiometer ABLTM 505, Copenhagen, Denmark), registration of the dynamic respiratory compliance displayed by the ventilator (C) and collection of four impedance data epochs. The same set of data was gathered 5 min after weaning from $\mathrm{CPB}$, when stable circulatory and ventilator conditions were re-established. Subsequently, in group SEV, 1 age-related minimal alveolar concentration (MAC) ${ }^{64}$ of sevoflurane was achieved by setting the vaporizer to $1.4-$ $1.9 \%$ and the fresh gas flow to $16 \mathrm{l} / \mathrm{min}$, and maintained for 5 minutes with a fresh gas flow of $21 /$ min. This interval was chosen based on a previous study, where respiratory mechanics were found to reach a steady-state condition after administering $1 \mathrm{MAC}$ sevoflurane for 5 minutes following the peak effect an allergen provocation in rabbits. ${ }^{56}$ Ventilation was maintained without intervention in the patients in group CTRL for a matching period. The third data collection step was taken in the same manner as detailed earlier in both groups of patients. 


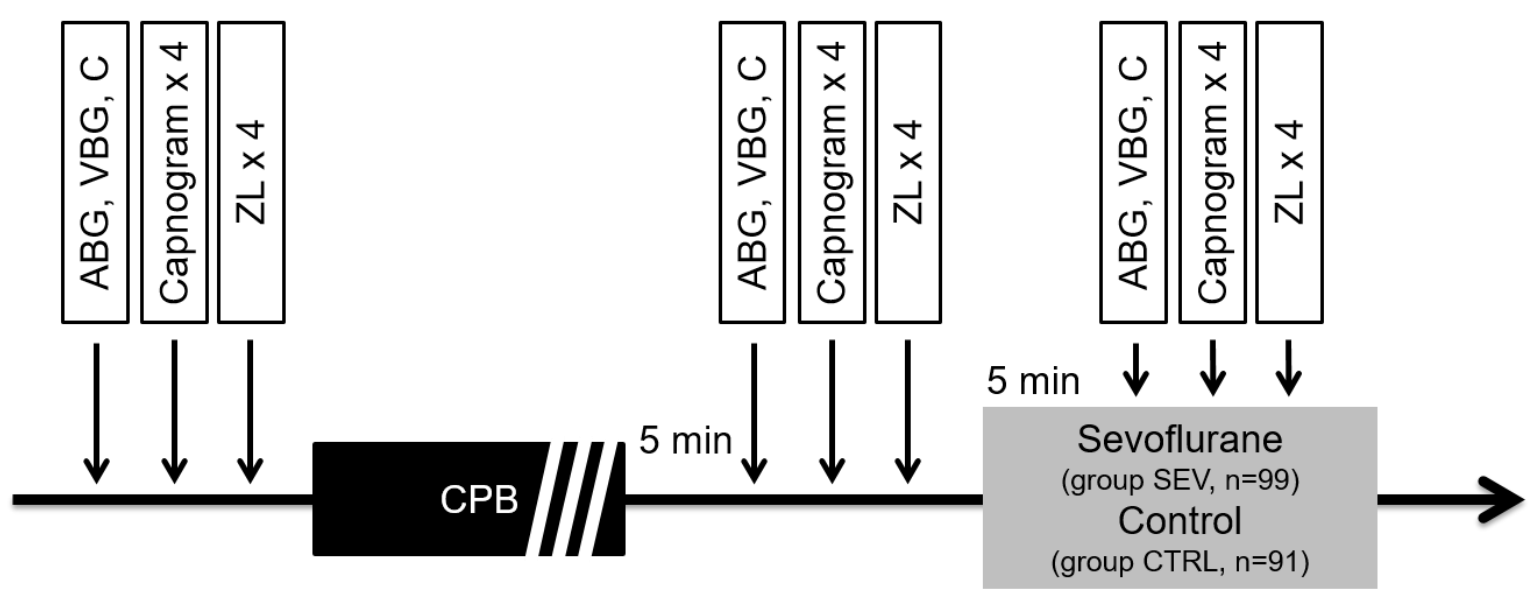

Figure 3. Timeline of the experimental protocol of Study II.

Measurements were carried out with open chest condition at three stages of cardiac surgery: before starting cardiopulmonary bypass (CPB), 5 min after weaning from CPB and after 5 min intervention (administration of sevoflurane at 1 MAC (group SEV) or unaltered anaesthesia management (group CTRL)). At each stage, arterial $(\mathrm{ABG})$ and central venous blood gas samples (VBG) were analysed, the dynamic lung compliance displayed by the ventilator was documented, four 15-s capnogram traces were recorded and four impedance measurements (ZL) were carried out

\subsection{Statistical analyses}

\subsubsection{Statistical analyses of Study I}

Sample size estimation was based on the aim to determine the $95 \%$ limits of agreement with great reliability according to the corresponding recommendation ${ }^{65}$. The correlations between the mainstream and sidestream variants of individual variables were analysed with the Pearson test. If the regression lines were close to the line of identity for a corresponding mainstream and sidestream value pair, Bland-Altman analysis was performed to assess the extent of their agreement $^{66}$. In the event of normality, paired t-tests were used to assess the statistical significance of the difference between the results of the mainstream and sidestream methods. The effects of compliance on the sidestream and mainstream dead space and shunt parameters were assessed by using one-way analysis of variance (ANOVA) tests on ranks. A p value $<0.05$ was considered significant. The reported values are expressed as mean (SEM) in case of normality, or as median $\left[1^{\text {st }}\right.$ quartile $-3^{\text {rd }}$ quartile $]$ otherwise.

\subsubsection{Statistical analyses of Study II}

Sample size was estimated for a two-way repeated measures ANOVA on $\mathrm{H}$ as the primary outcome variable with an expected effect size of 0.2 (i.e. an approximately $20 \%$ change after 
sevoflurane), a power of 0.8 and two-sided alpha error of $0.05 .{ }^{67}$ The estimation resulted in a required sample size of 97 for each group.

Two-sample t-tests were applied to compare mean age, height and weight between the protocol groups. Chi-square test was used to test the independence of group allocation and gender, and the distribution of surgery types within each group.

Scatters in measured variables are expressed as SEM. The normality of the data was tested with the Kolmogorov-Smirnov test with a Lilliefors correction. Two-way repeated measures ANOVA with the inclusion of an interaction term was used for all measured variables with the protocol stage as within-subject factor (before $\mathrm{CPB}$, after $\mathrm{CPB}$ and after intervention) and group allocation as between-subject factor (group SEV or group CTRL) to establish the effects of $\mathrm{CPB}$ and the subsequent administration of sevoflurane. The Holm-Sidak multiple comparison procedure was adopted to compare the variables in the various study groups at different protocol stages. When comparing two samples, the Student's t-test was used for normality and the Mann-Whitney rank sum test otherwise. The statistical tests were performed with a SigmaPlot statistical software package (Version 13, Systat Software, Inc., Chicago, IL, USA). All reported p-values are two-sided. 


\section{Results}

\subsection{Comparison of mainstream and sidestream capnography}

Figure 4 shows representative time and volumetric capnograms obtained with simultaneous mainstream and sidestream capnography. In both the time and volume domains the mainstream capnograms exhibited a steeper phase II, smaller $\alpha$ angles and an earlier transition into phase III. Moreover, a later transition into the inspiratory phase was observed in the time domain mainstream capnogram. These shape differences result in a lower area under the sidestream capnograms as compared with the corresponding mainstream capnogram.
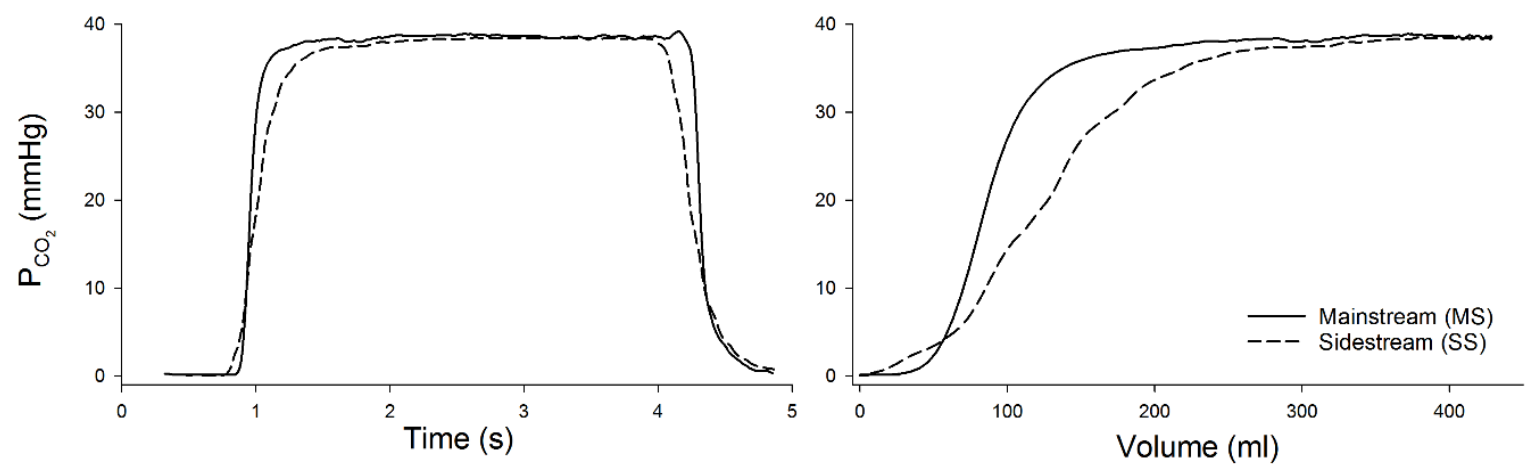

Figure 4. Representative capnograms.

Time (left) and volumetric (right) mainstream (continuous) and sidestream (dashed) capnograms.

Figure 5 illustrates the temporal relationship between the sidestream capnogram and the sampling flow variability in a representative patient. The transient spikes in the sampling flow coincide with the cyclic changes in the breathing phases. 


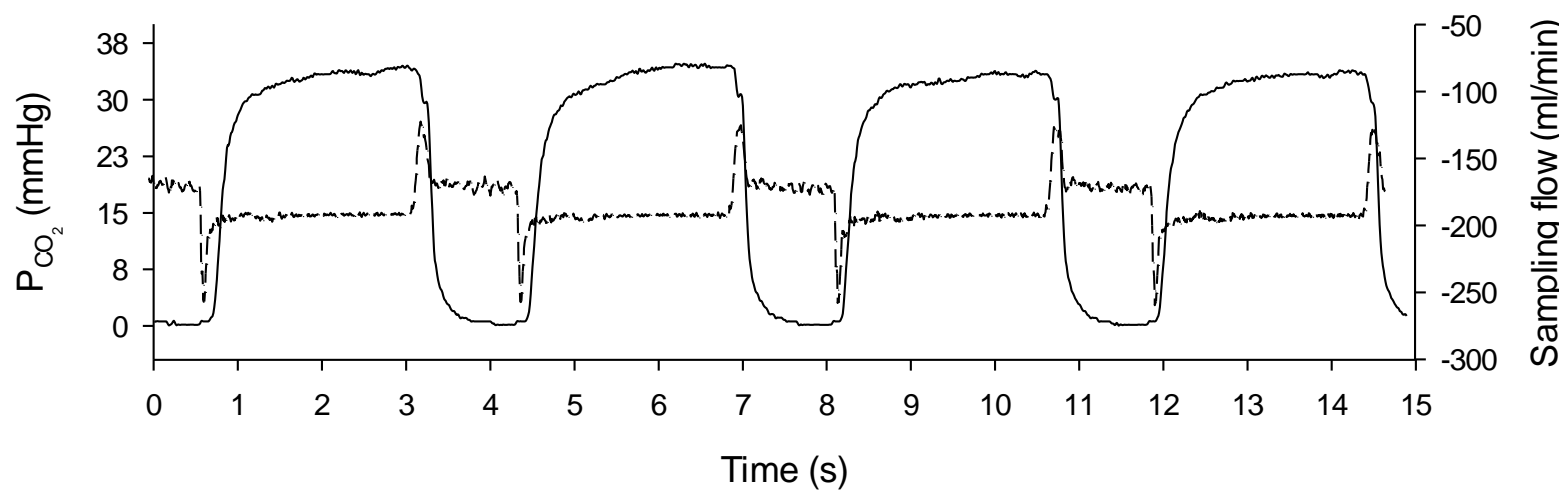

Figure 5. The relationship between the sidestream capnogram and the sampling flow.

Sidestream capnogram curve (solid line, left axis) together with the flow in the sampling tube (dashed line, right axis) in a representative patient.

The difference in mainstream and sidestream $\mathrm{PETCO}_{2}(32.0 \pm 0.14$ vs. $31.8 \pm 0.16 \mathrm{mmHg})$ was small, although statistically significantly higher with the former technique $(\mathrm{p}<0.001)$. The $\mathrm{V}_{\mathrm{CO}_{2}}$ was systematically underestimated by the sidestream method $\left(\mathrm{V}_{\mathrm{CO}_{2}, \mathrm{SS}} / \mathrm{V}_{\mathrm{CO}_{2}, \mathrm{MS}}=0.895 \pm 0.3\right.$, $\mathrm{p}<0.0001)$, despite the presence of good correlation between these variables $\left(\mathrm{R}^{2}=0.91\right.$, $\mathrm{p}<0.0001)$.

Correlations between the phase III slopes obtained by the mainstream and sidestream methods, and the corresponding Bland-Altman plots are demonstrated in Fig. 6. An excellent correlation $\left(\mathrm{R}^{2}=0.92, \mathrm{p}<0.0001\right)$ and good agreement were observed between $\mathrm{S}_{\text {III,T,MS }}$ and $\mathrm{S}_{\text {III,T,SS, although }}$ the sidestream method slightly but significantly overestimated $\mathrm{S}_{\text {III,T }}\left(\mathrm{S}_{\text {III,T,SS}} / \mathrm{S}_{\text {III,T,MS }}=1.05 \pm 0.16\right.$, $\mathrm{p}<0.0001)$. Strong correlation and good agreement were found between the volumetric $\mathrm{S}_{\mathrm{III}}$ values $\left(\mathrm{R}^{2}=0.93, \mathrm{p}<0.0001\right)$, with a systematic overestimation of $\mathrm{S}_{\text {III,V,MS }}$ by $\mathrm{S}_{\text {III,V,SS }}$ $\left(\mathrm{S}_{\mathrm{III}, \mathrm{V}, \mathrm{SS}} / \mathrm{S}_{\mathrm{III}, \mathrm{V}, \mathrm{MS}}=1.32\right.$ [1.21-1.49], $\left.\mathrm{p}<0.0001\right)$. The limits of agreements were $-0.11-$ $0.4 \mathrm{mmHg} / \mathrm{s}$ and $0.2-7.92 \mathrm{ml} / \mathrm{s}$ for the time and volumetric phase III slopes, respectively. 
A

B
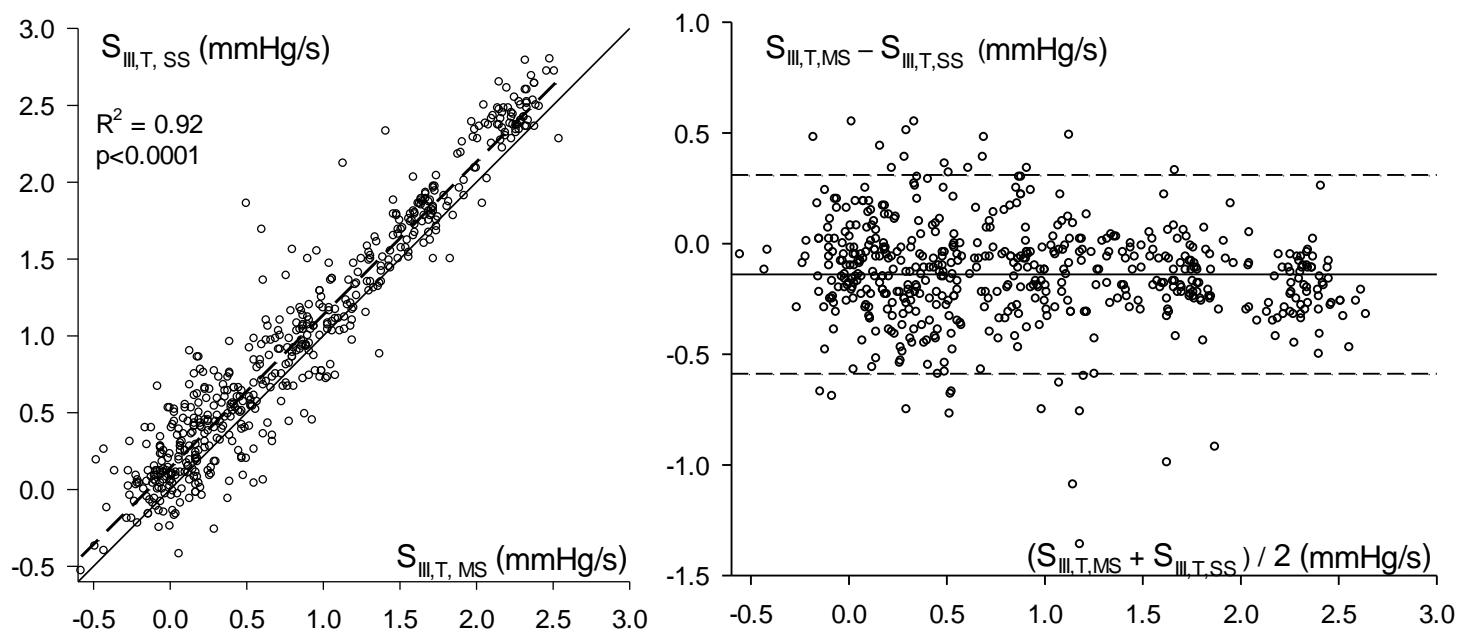

C
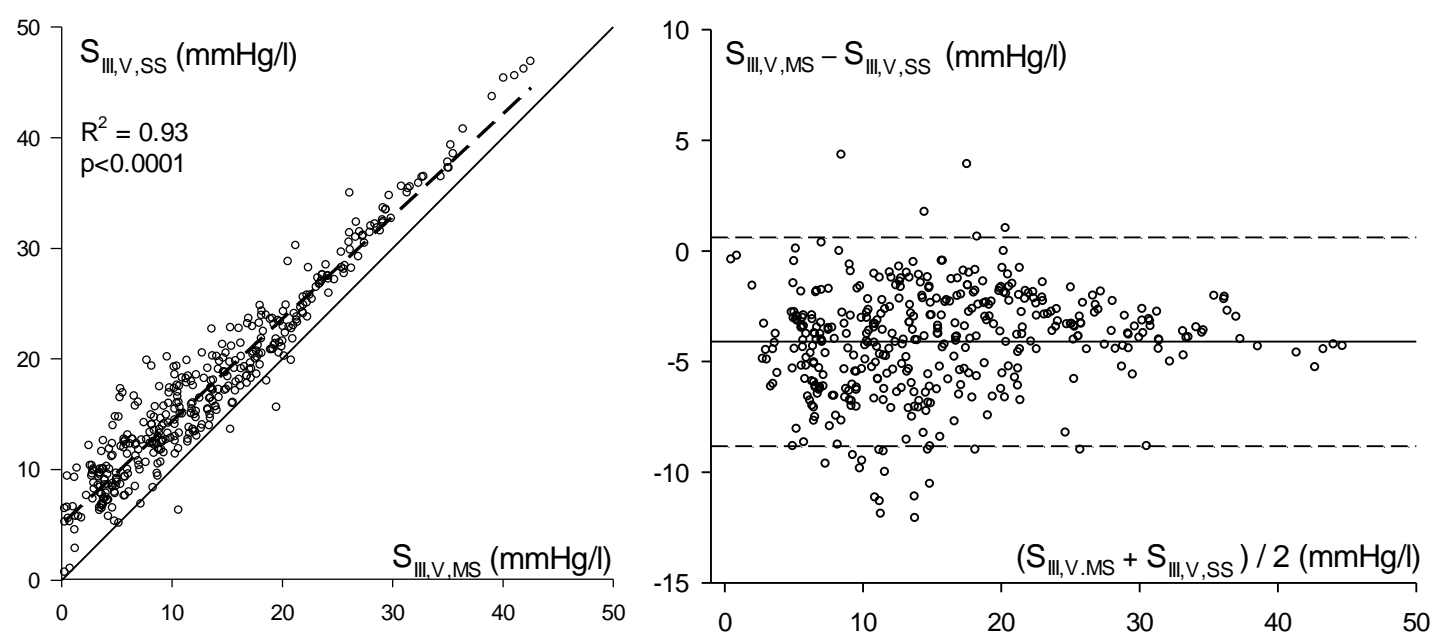

Figure 6. Correlations and agreements between phase III slopes determined by sidestream and mainstream capnography.

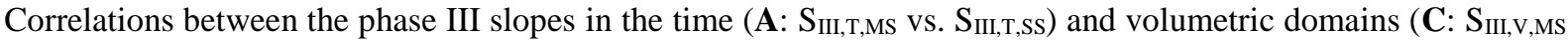
vs. SIII,V,SS) obtained by mainstream (horizontal axis) and sidestream capnography (vertical axis) with the regression lines (dashed) and the lines of identity (continuous). Regression equations: $\mathrm{S}_{\mathrm{III}, \mathrm{T}, \mathrm{SS}}=0.142+0.996 \cdot \mathrm{S}_{\mathrm{IIIT,MS}}$

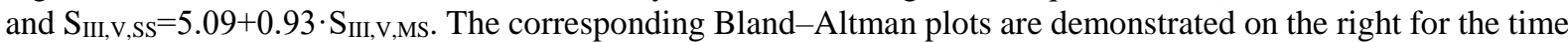

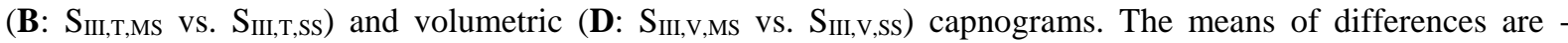
$0.14 \mathrm{mmHg} / \mathrm{s}$ and $-4,13 \mathrm{mmHg} / \mathrm{l}$ (continuous), and the limits of agreement are $0.45 \mathrm{mmHg} / \mathrm{s}$ and $4.73 \mathrm{mmHg} / \mathrm{l}$ (dashed) for the time and volumetric capnograms, respectively. Each data point represents one expiration.

Figure 7 depicts the correlations between the shape factors and the dead space fractions associated with phase II of the capnogram $\left(\mathrm{V}_{\mathrm{DF}}\right)$. Although $\mathrm{S}_{\mathrm{II}, \mathrm{T}, \mathrm{SS}}$ correlates significantly with $\mathrm{S}_{\mathrm{II}, \mathrm{T}, \mathrm{MS}}\left(\mathrm{R}^{2}=0.58, \mathrm{p}<0.0001\right)$, there is no agreement between these slopes because of the substantial underestimation by the sidestream method $\left.\left(\mathrm{S}_{\text {II,T,SS }} / \mathrm{S}_{\text {II,T,MS }}=0.48 \pm 0.004\right), \mathrm{p}<0.0001\right)$. A rather poor correlation and a lack of agreement were observed between the phase II slopes in 
the volume domain $\left(\mathrm{R}^{2}=0.02, \mathrm{p}<0.002\right)$, with a similar underestimation by sidestream capnography $\left(\mathrm{S}_{\mathrm{II}, \mathrm{V}, \mathrm{SS}} / \mathrm{S}_{\mathrm{II}, \mathrm{V}, \mathrm{MS}}=0.44 \pm 0.008, \mathrm{p}<0.0001\right)$. Significant correlation but poor agreement was found between the two types of $\alpha$ angle $\left(R^{2}=0.89, p<0.0001\right)$, with $\alpha_{\text {ss }}$ slightly but consistently overestimating $\alpha_{\mathrm{MS}}(1.04 \pm 0.001, \mathrm{p}<0.0001)$. Although $\mathrm{V}_{\mathrm{DF}, \mathrm{MS}}$ and $\mathrm{V}_{\mathrm{DF}, \mathrm{SS}}$ correlated moderately $\left(\mathrm{R}^{2}=0.56, \mathrm{p}<0.0001\right)$, their agreement was rather poor, and the sidestream method overestimated the mainstream values $\left(\mathrm{V}_{\mathrm{DF}, \mathrm{SS}} / \mathrm{V}_{\mathrm{DF}, \mathrm{MS}}=1.3 \pm 0.013, \mathrm{p}<0.0001\right)$. 
A

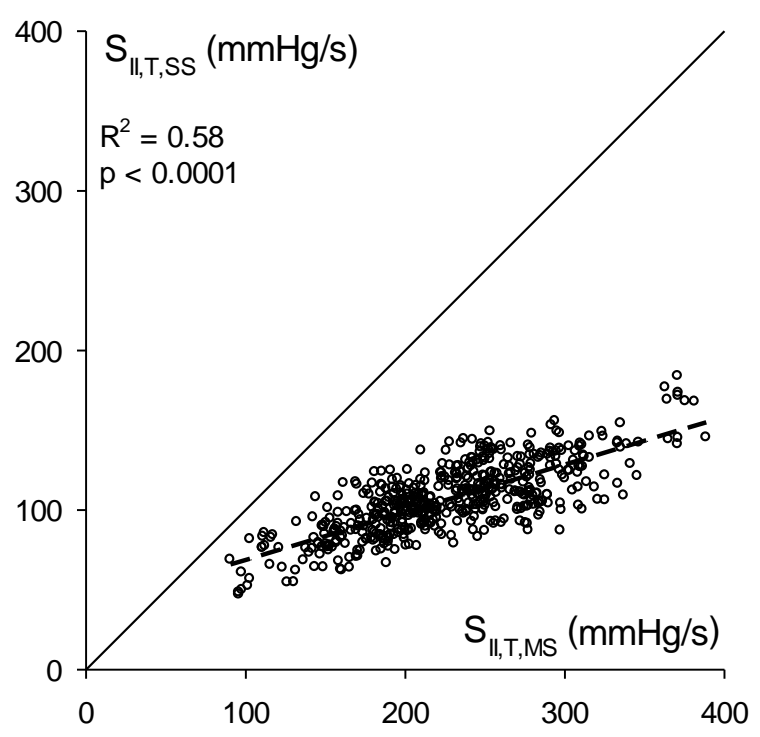

C

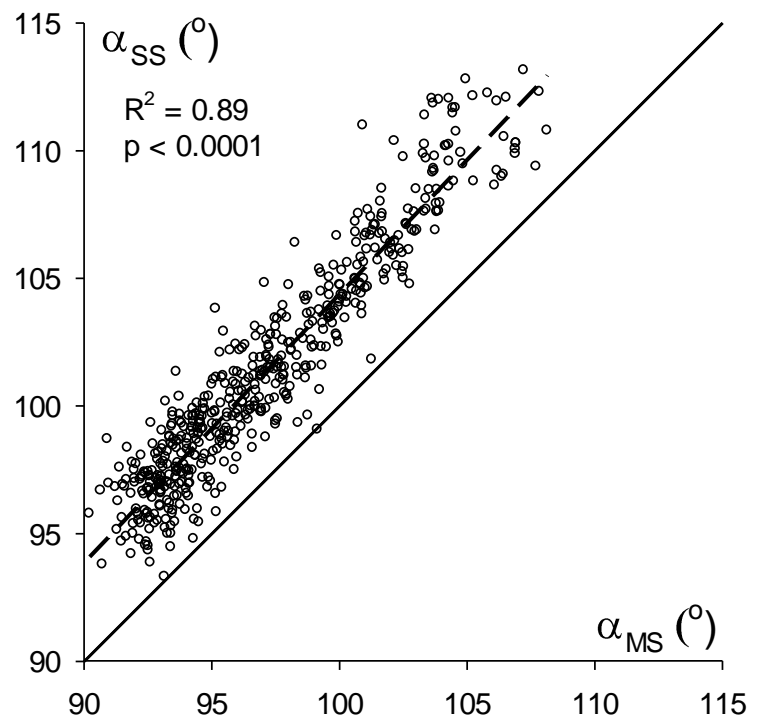

B
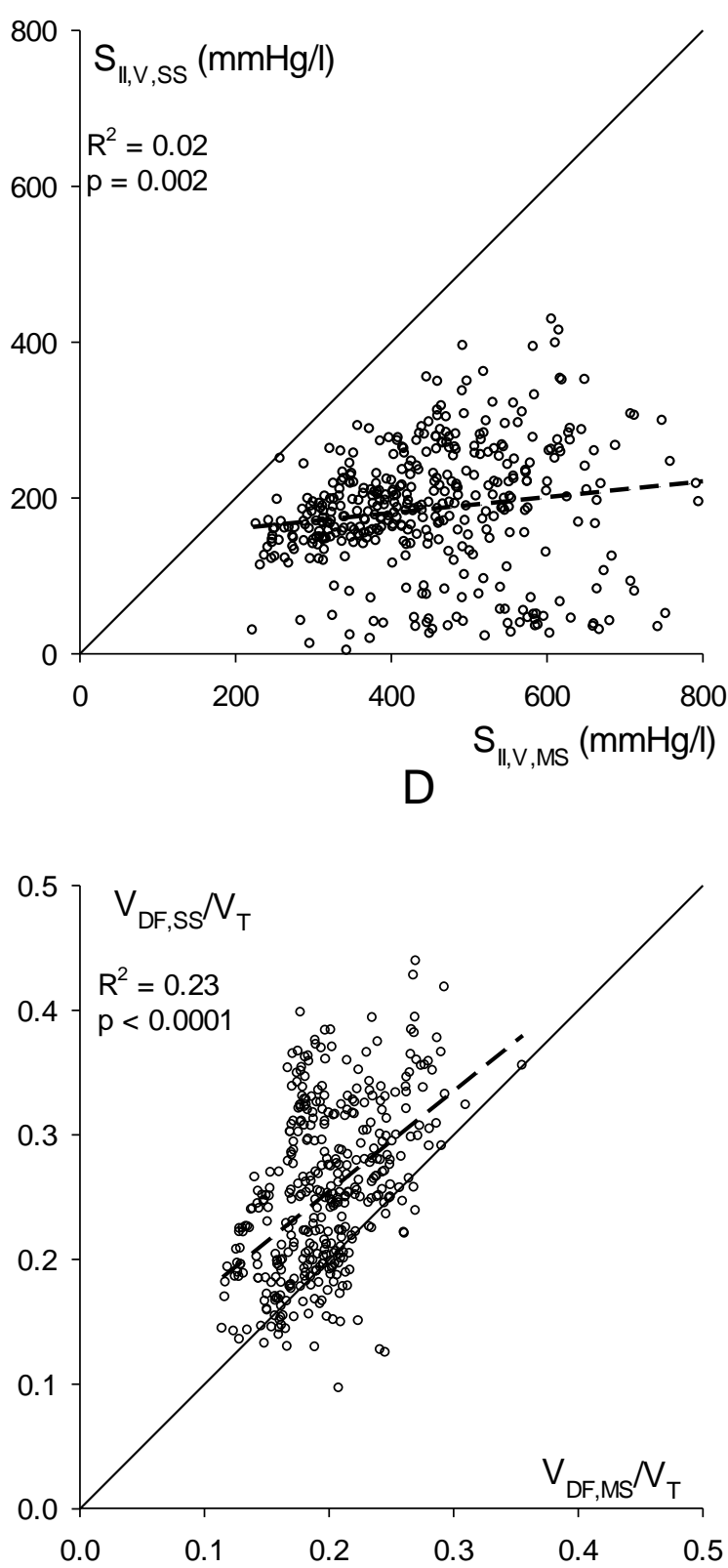

Figure 7. Correlations between parameters related to phase II determined by sidestream and mainstream capnography.

Correlations between phase II slopes in the time (A: $\mathrm{S}_{\mathrm{II}, \mathrm{T}, \mathrm{MS}}$ vs. $\left.\mathrm{S}_{\mathrm{II}, \mathrm{T}, \mathrm{SS}}\right)$ and volume domain (B: $\mathrm{S}_{\mathrm{II}, \mathrm{V}, \mathrm{MS}}$ vs. $\mathrm{S}_{\mathrm{II}, \mathrm{V}, \mathrm{SS}}$ ), angles $\alpha\left(\mathbf{C}: \alpha_{M S}\right.$ vs. $\left.\alpha_{S S}\right)$ and Fowler dead space indices obtained by mainstream (horizontal) and sidestream (vertical) capnography, with the regression lines (dashed) and the lines of identity (continuous). Regression equations: $\quad \mathrm{S}_{\mathrm{II}, \mathrm{T}, \mathrm{SS}}=39+0.298 \cdot \mathrm{S}_{\mathrm{II}, \mathrm{T}, \mathrm{MS}}, \quad \mathrm{S}_{\mathrm{II}, \mathrm{V}, \mathrm{SS}}=140.2+0.1 \cdot \mathrm{S}_{\mathrm{II}, \mathrm{V}, \mathrm{MS}}, \quad \alpha_{\mathrm{SS}} \quad=-0.84+1.05 \cdot \alpha_{\mathrm{MS}}$ and $\mathrm{V}_{\mathrm{DF}, \mathrm{SS}} / \mathrm{V}_{\mathrm{T}}=-22.3+1.52 \cdot \mathrm{V}_{\mathrm{DF}, \mathrm{MS}} / \mathrm{V}_{\mathrm{T}}$. Each data point represents one expiration.

Figure 8 illustrates the correlations between respiratory dead space indices measured by the two methods. Moderate, but statistically significant correlation was found between the normalized dead space parameters $\mathrm{V}_{\mathrm{DB}, \mathrm{MS}} / \mathrm{V}_{\mathrm{T}}$ and $\mathrm{V}_{\mathrm{DB}, \mathrm{SS}} / \mathrm{V}_{\mathrm{T}}\left(\mathrm{R}^{2}=0.37\right.$, $\left.\mathrm{p}<0.0001\right)$, with overestimation of 
mainstream Bohr dead space by the sidestream method ( $\left.\mathrm{V}_{\mathrm{DB}, \mathrm{SS}} / \mathrm{V}_{\mathrm{DB}, \mathrm{MS}}=1.37 \pm 0.01, \mathrm{p}<0.0001\right)$. In the measurement of the Enghoff dead space, the two methods exhibited good correlation $\left(\mathrm{R}^{2}=0.61, \quad \mathrm{p}<0.0001\right)$ and a slight overestimation by the sidestream capnograph $\left(\mathrm{V}_{\mathrm{DE}, \mathrm{SS}} / \mathrm{V}_{\mathrm{DE}, \mathrm{MS}}=1.16 \pm 0.004, \mathrm{p}<0.0001\right)$. Since $\mathrm{P}_{\mathrm{aCO}}$, shows excellent agreement between the two techniques $\left(\mathrm{R}^{2}=0.95\right.$ and mainstream/sidestream ratio $\left.=1.01 \pm 0.02, \mathrm{p}<0.0001\right)$, the dissociations between physiological dead space parameters can be ascribed to the discrepancies in $\mathrm{P}_{\overline{\mathrm{E}} \mathrm{CO}_{2}}\left(\mathrm{R}^{2}=0.77\right.$ and mainstream/sidestream ratio $\left.=1.12 \pm 0.08, \mathrm{p}<0.0001\right)$. The overestimations of $\mathrm{V}_{\mathrm{DE}}$ and $\mathrm{V}_{\mathrm{DB}}$ by the sidestream technique resulted in a strong correlation in their difference (i.e. the lung volume with the intrapulmonary shunt; $R^{2}=0.92, p<0.0001$ between $V_{s, S S} / V_{T}$ and $\mathrm{V}_{\mathrm{s}, \mathrm{MS}} / \mathrm{V}_{\mathrm{T}}$ ). This relationship was associated with good agreement between the shunt volumes, with the sidestream method only slightly underestimating the mainstream values $\left(\mathrm{V}_{\mathrm{s}, \mathrm{SS}} / \mathrm{V}_{\mathrm{s}, \mathrm{MS}}=0.97 \pm 0.004, \mathrm{p}<0.0001\right)$. The limit of agreement was $24 \mathrm{ml}$. 
A

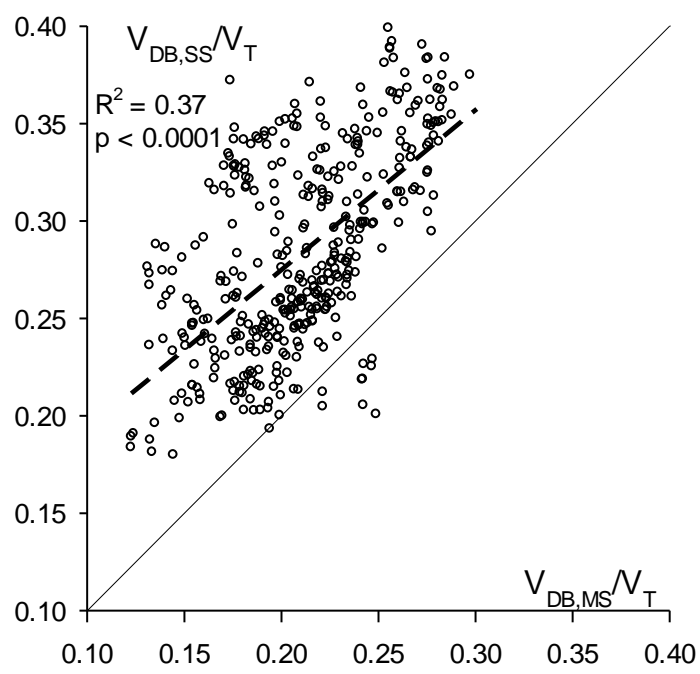

C

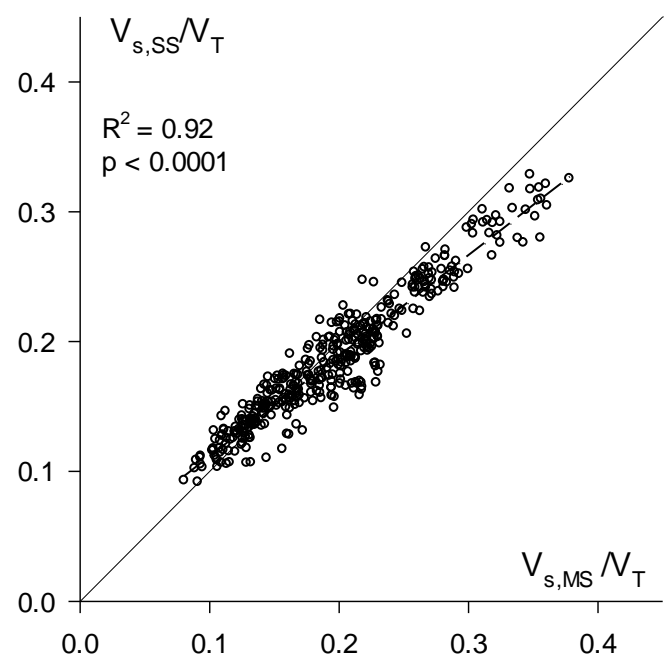

B

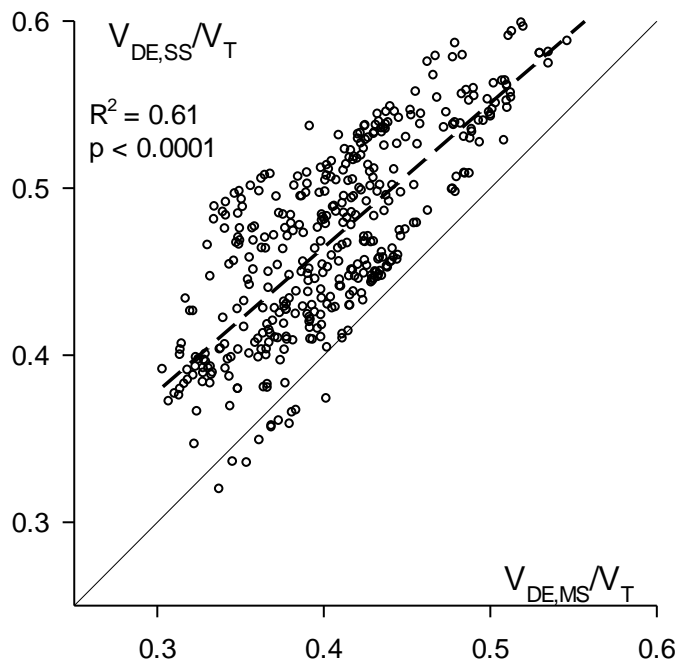

D

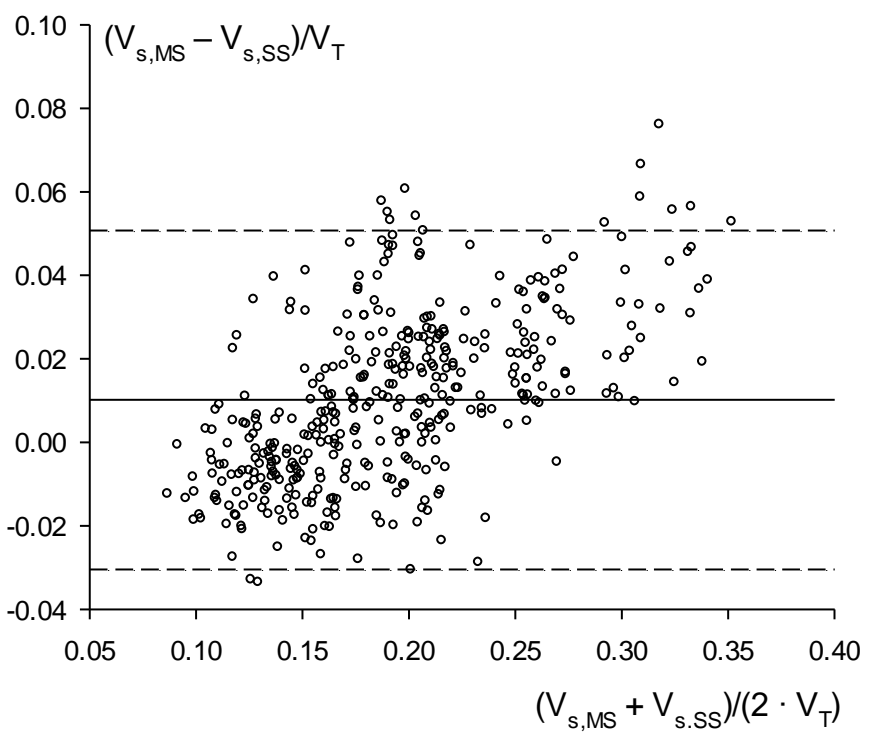

Figure 8. Correlation between normalized dead space indices determined by sidestream and mainstream capnography.

Correlation between normalized dead space indices calculated according to Bohr $\left(\mathbf{A}: \mathrm{V}_{\mathrm{DB}, \mathrm{MS}} / \mathrm{V}_{\mathrm{T}} \mathrm{Vs}\right.$. $\left.\mathrm{V}_{\mathrm{DB}, \mathrm{SS}} / \mathrm{V}_{\mathrm{T}}\right)$ and Enghoff (B: $V_{\mathrm{DE}, \mathrm{MS}} / \mathrm{V}_{\mathrm{T}} \mathrm{Vs}$. $\left.\mathrm{V}_{\mathrm{DE}, \mathrm{SS}} / \mathrm{V}_{\mathrm{T}}\right)$, and their difference $\left(\mathbf{C}: \mathrm{V}_{\mathrm{s}, \mathrm{MS}} / \mathrm{V}_{\mathrm{T}}=\left[\mathrm{V}_{\mathrm{DE}, \mathrm{MS}}-\mathrm{V}_{\mathrm{DB}, \mathrm{MS}} / \mathrm{V}_{\mathrm{T}}\right] \mathrm{vs} . \mathrm{V}_{\mathrm{S}, \mathrm{SS}} / \mathrm{V}_{\mathrm{T}}=\left[\mathrm{V}_{\mathrm{DE}, \mathrm{SS}}-\right.\right.$ $\left.\mathrm{V}_{\mathrm{DB}, \mathrm{SS}}\right] / \mathrm{V}_{\mathrm{T}}$ ) obtained by mainstream (horizontal) and sidestream (vertical) capnography, with the regression line (dashed) and the line of identity (continuous). Regression equations: $\mathrm{V}_{\mathrm{DB}, \mathrm{SS}} / \mathrm{V}_{\mathrm{T}}=0.11+0.82 \cdot \mathrm{V}_{\mathrm{DB}, \mathrm{MS}} / \mathrm{V}_{\mathrm{T}}$, $\mathrm{V}_{\mathrm{DE}, \mathrm{SS}} / \mathrm{V}_{\mathrm{T}}=0.12+0.86 \cdot \mathrm{V}_{\mathrm{DE}, \mathrm{MS}} / \mathrm{V}_{\mathrm{T}}$ and $\mathrm{V}_{\mathrm{s}, \mathrm{SS}} / \mathrm{V}_{\mathrm{T}}=0.034+0.774 \cdot \mathrm{V}_{\mathrm{S}, \mathrm{MS}} / \mathrm{V}_{\mathrm{T}}$. The corresponding Bland-Altman plot is demonstrated for $\mathrm{V}_{\mathrm{s}, \mathrm{MS}} / \mathrm{V}_{\mathrm{T}}$ and $\mathrm{V}_{\mathrm{s}, \mathrm{SS}} / \mathrm{V}_{\mathrm{T}}$ (D). The mean of differences is 6.17 (continuous), and the limit of agreement is 24.2 (dashed). Each data point represents one expiration

To reveal the effect of lung stiffness on the difference between the dead space and pulmonary shunt parameters determined by the mainstream and sidestream methods, Fig. 9 depicts the differences between mainstream and sidestream values as a function of C. Decreasing 
compliance resulted in an increasing overestimation of dead space and shunt parameters assessed by using the sidestream technique $(\mathrm{p}<0.0001)$.
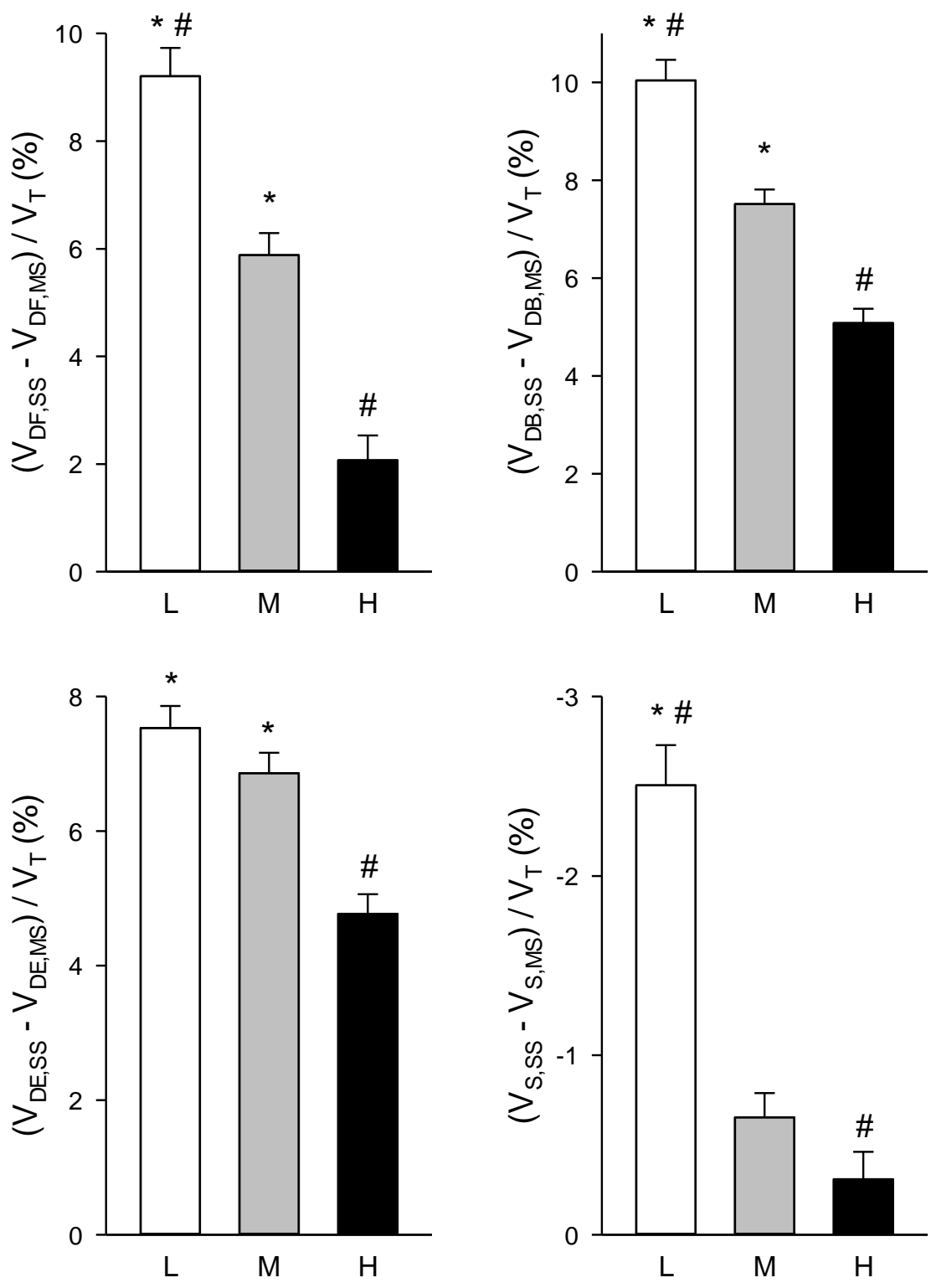

Figure 9. Relative differences in normalized dead space indices by respiratory compliance determined by sidestream and mainstream capnography.

Relative differences in dead space and intrapulmonary shunt parameters obtained with the two methods in patients with the lower $\left(\mathrm{L}, \mathrm{C}<37 \mathrm{ml} / \mathrm{cmH}_{2} \mathrm{O}\right)$, higher $\left(\mathrm{H}, \mathrm{C}>53 \mathrm{ml} / \mathrm{cmH}_{2} \mathrm{O}\right)$ quartiles and medium $(\mathrm{M})$ interquartile range. *: $\mathrm{p}<0.05$ vs. $\mathrm{H} ; \#$ : $\mathrm{p}<0.05$ vs. $\mathrm{M}$.

In the supplemental measurements assessing the potential biasing effect of sidestream sampling flow on the mainstream parameters, no statistically significant differences were found 
in any of the mainstream capnogram parameters obtained with or without suctioning (Table 2; $\mathrm{p}>0.11)$, while a $3.64(1.22) \mathrm{ml}$ difference was found in $\mathrm{V}_{\mathrm{T}}(\mathrm{p}<0.004)$.

\begin{tabular}{|c|c|c|c|}
\hline Sidestream sampling & On & Off & p-value \\
\hline $\mathrm{S}_{\text {III.T,MS }}(\mathrm{mmHg} / \mathrm{s})$ & $0.795 \pm 0.81$ & $0.818 \pm 0.78$ & 0.4 \\
\hline $\mathrm{S}_{\text {III,V,MS }}(\mathrm{mmHg} / \mathrm{l})$ & $13.65 \pm 6.9$ & $13.88 \pm 6.9$ & 0.19 \\
\hline $\mathrm{S}_{\text {II,T,MS }}(\mathrm{mmHg} / \mathrm{s})$ & $173.5 \pm 40.65$ & $217.73 \pm 40.2$ & 0.39 \\
\hline $\mathrm{S}_{\text {III, }, \mathrm{MS}}(\mathrm{mmHg} / \mathrm{l})$ & $472.2 \pm 107.3$ & $471.9 \pm 106.7$ & 0.18 \\
\hline $\mathrm{V}_{\mathrm{DF}, \mathrm{MS}} / \mathrm{V}_{\mathrm{T}}$ & $0.196 \pm 0.037$ & $0.195 \pm 0.036$ & 0.21 \\
\hline $\mathrm{V}_{\mathrm{DB}, \mathrm{MS}} / \mathrm{V}_{\mathrm{T}}$ & $0.198 \pm 0.04$ & $0.198 \pm 0.04$ & 0.11 \\
\hline $\mathrm{V}_{\mathrm{DE}, \mathrm{MS}} / \mathrm{V}_{\mathrm{T}}$ & $0.4 \pm 0.059$ & $0.4 \pm 0.058$ & 0.13 \\
\hline $\mathrm{V}_{\mathrm{S}, \mathrm{MS}} / \mathrm{V}_{\mathrm{T}}$ & $0.198 \pm 0.067$ & $0.2 \pm 0.065$ & 0.4 \\
\hline $\mathrm{V}_{\mathrm{T}}(\mathrm{ml})$ & $586 \pm 116$ & $590 \pm 116$ & 0.003 \\
\hline
\end{tabular}

Table 2. Mainstream capnographic parameter values obtained with or without sidestream suctioning, and the corresponding p-values of paired t-tests.

Values are expressed as mean \pm SD.

\subsection{The effect of sevoflurane on respiratory mechanics and gas exchange after CPB}

No significant difference was found between the protocol groups in age, height or weight. The distribution of gender, surgery types and respiratory comorbidities were independent of group allocation (Table 1).

Airway and lung tissue mechanical parameters in both protocol groups at the different stages of the study protocol are demonstrated in Fig. 10. The CPB-induced changes in any of the measured parameters in group CTRL were not significantly different from those in group SEV. CPB induced a significant change in all the mechanical parameters, with the most pronounced elevations in Raw (pooled changes of $287 \pm 17 \%$ ), marked decreases in Iaw $\left(-0.025 \pm 0.002 \mathrm{cmH}_{2} \mathrm{O}_{\mathrm{s}} \mathrm{s}^{2} / \mathrm{l}\right)$ and increases in $\mathrm{G}(98 \pm 27 \%)$, while rises in $\mathrm{H}$ and $\eta$ were smaller $(15 \pm 2.3 \%$ and $86 \pm 32 \%, \mathrm{p}<0.0005$ for all). Sevoflurane induced marked drops in Raw $(-43 \pm 1.9 \%, \mathrm{p}<0.001)$, rises in Iaw $\left(-0.024 \pm 0.003 \mathrm{cmH}_{2} \mathrm{O} . \mathrm{s}^{2} / \mathrm{l}\right)$, reductions in $\mathrm{G}(-23 \pm 2.9 \%$, $\mathrm{p}<0.001$ for all $)$ and moderate decreases in $\mathrm{H}(-10 \pm 2.0 \%, \mathrm{p}<0.001)$ and $\eta(9.0 \pm 4.0 \%, \mathrm{p}<0.02)$. There was no evidence of a statistically significantly detectable change in any of the parameters in the corresponding time-matched changes in group CTRL. 

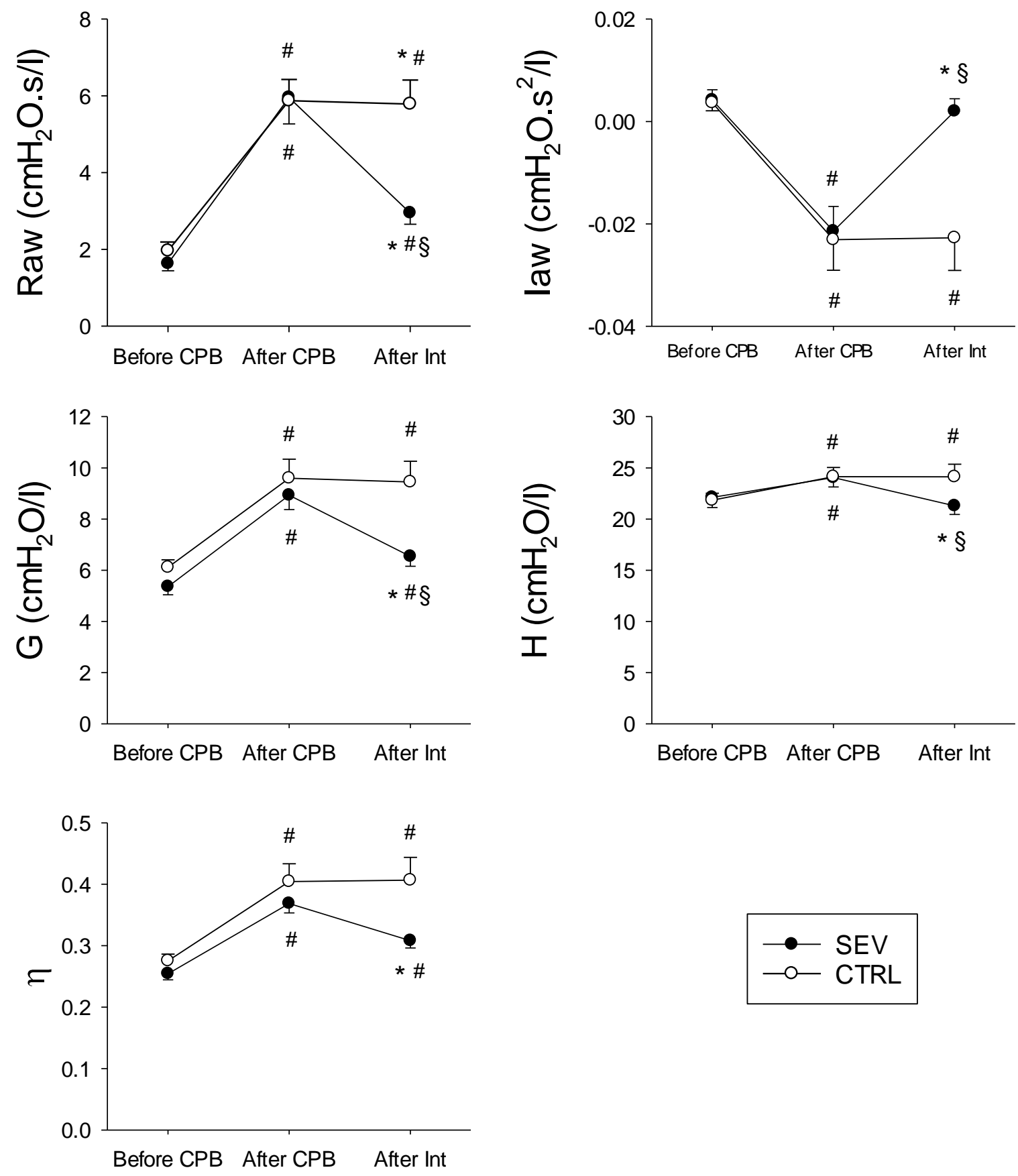

Figure 10. Lung mechanical parameters in the groups by protocol stage.

Forced oscillatory airway (Raw: airway resistance; Iaw: airway inertance) and tissue (G: tissue damping; H: tissue elastance; $\eta$ : tissue hysteresivity) parameters in the group treated with sevoflurane at 1 MAC for 5 min (SEV) and the control group with IV anaesthesia maintained (CTRL). Error bars represent SEM. *: $p<0.05$ vs. condition "After CPB" within a group; \#: $\mathrm{p}<0.05$ vs. condition "Before CPB" within a group; $\S: \mathrm{p}<0.05$ between protocol groups within a stage. 
Capnogram phase slopes, lung compliance and parameters associated with oxygenation are demonstrated in Fig. 11. The phase III slope of the capnogram exhibited markedly significant increases following CPB in both protocol groups, with pooled changes of $0.46 \pm 0.04 \mathrm{mmHg} / \mathrm{s}$ $(\mathrm{p}<0.0001)$. After application of sevoflurane, $S_{\text {III }}$ decreased $(-0.15 \pm 0.036 \mathrm{mmHg} / \mathrm{s}, \mathrm{p}<0.02)$, whereas it did not change significantly in group CTRL. No significant difference was found in $\mathrm{S}_{\text {II }}$ between the protocol groups at any stage $(\mathrm{p}>0.13)$. The phase II slope decreased markedly after CPB $(28 \pm 1.5 \%, \mathrm{p}<0.0001)$ and increased slightly at the last stage in both groups $(9.8 \pm 1.8 \%, \mathrm{p}<0.02)$. The changes in the $\mathrm{P}_{\mathrm{aO}_{2}} / \mathrm{F}_{\mathrm{iO}_{2}}$ ratio, $\mathrm{C}, \mathrm{Q}_{\mathrm{S}} / \mathrm{Q}_{\mathrm{t}}$ and $\mathrm{P}_{\mathrm{a}-\mathrm{ETCO}_{2}}$ subsequent to CPB did not differ significantly between the protocol groups. The $\mathrm{P}_{\mathrm{aO}_{2}} / \mathrm{FiO}_{2}$ ratio and $\mathrm{C}$ exhibited significant decreases post CPB (pooled changes of $-9.3 \pm 2.1 \%$ and $-13 \pm 1.0 \%$, respectively), while $\mathrm{Q}_{\mathrm{s}} / \mathrm{Q}_{\mathrm{t}}$ and $\mathrm{P}_{\mathrm{a}-\mathrm{ETCO}}$ increased $(119 \pm 9 \%$ and $32 \pm 9 \% \mathrm{p}<0.0001$ for all). Sevoflurane reversed the decreases in the $\mathrm{P}_{\mathrm{aO}_{2}} / \mathrm{F}_{\mathrm{iO}}$ ratio and $\mathrm{C}(15 \pm 1.7 \%$ and $17 \pm 1.4 \%, \mathrm{p}<0.0001$ for both $)$ and reduced $\mathrm{Q}_{\mathrm{s}} / \mathrm{Q}_{\mathrm{t}}$ and $\mathrm{P}_{\mathrm{a}-\mathrm{ETCO}}(-20 \pm 1.5 \%$ and $-9.7 \pm 3.3 \%, \mathrm{p}<0.03)$. The corresponding changes in the $\mathrm{P}_{\mathrm{aO}_{2}} / \mathrm{F}_{\mathrm{iO}_{2}}$ ratio, $\mathrm{C}$ and $\mathrm{Q}_{\mathrm{s}} / \mathrm{Q}_{\mathrm{t}}$ in group CTRL were not significant. 

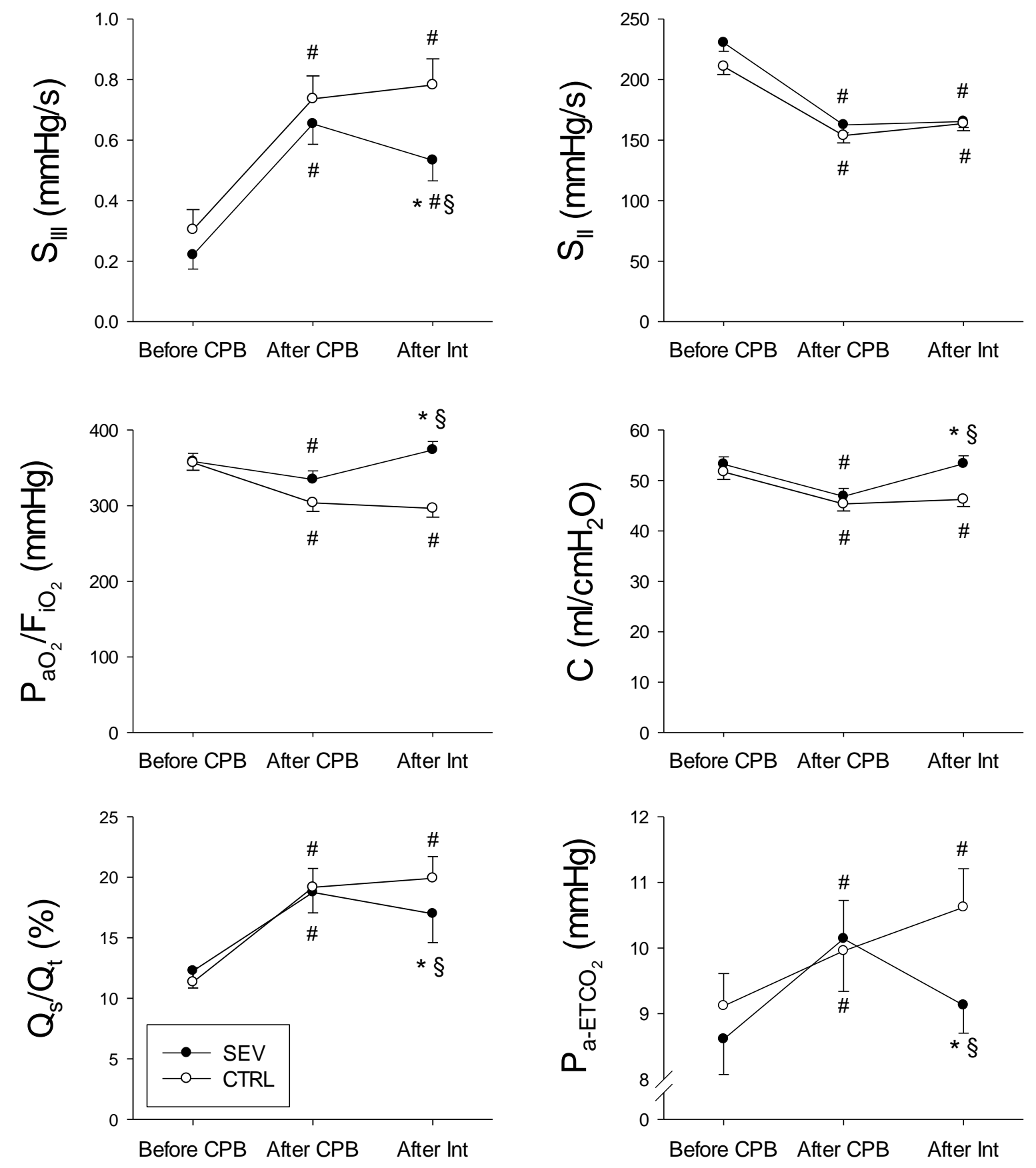

Figure 11. Ventilation and shunt parameters and compliance in the groups by protocol stage.

Phase III ( $\left.\mathrm{S}_{\mathrm{III}}\right)$ and phase II slopes $\left(\mathrm{S}_{\mathrm{II}}\right)$ of time capnograms, lung compliance $(\mathrm{C}), \mathrm{P}_{\mathrm{aO}_{2}} / \mathrm{F}_{\mathrm{iO}_{2}}$ ratio, intrapulmonary shunt fraction $\left(\mathrm{Q}_{\mathrm{s}} / \mathrm{Q}_{\mathrm{t}}\right)$ and arterial to end-tidal $\mathrm{CO}_{2}$ gradient $\left(\mathrm{P}_{\mathrm{a}-\mathrm{ETCO}}\right)$ in the group treated with sevoflurane at 1 MAC for $5 \mathrm{~min}$ (SEV) and the control group with IV anaesthesia maintained (CTRL). Error bars represent SEM. *: $\mathrm{p}<0.05$ vs. condition "After CPB" within a group; \#: $\mathrm{p}<0.05$ vs. condition "Before CPB" within a group; $\S$ : $\mathrm{p}<0.05$ between protocol groups within a stage. 
Figure 12 depicts the associations between the changes in Raw and $S_{\text {III }}$ after the interventions. Sevoflurane decreased Raw in all but one patient, whereas the changes in $S_{\text {III }}$ were far less uniform; the administration of sevoflurane resulted in further elevations in $\mathrm{S}_{\mathrm{III}}$ in 36 out of 99 cases. In contrast, 28 out of the 91 patients in group CTRL exhibited further elevations in Raw during the corresponding period, and $\mathrm{S}_{\mathrm{III}}$ increased in 35 cases.
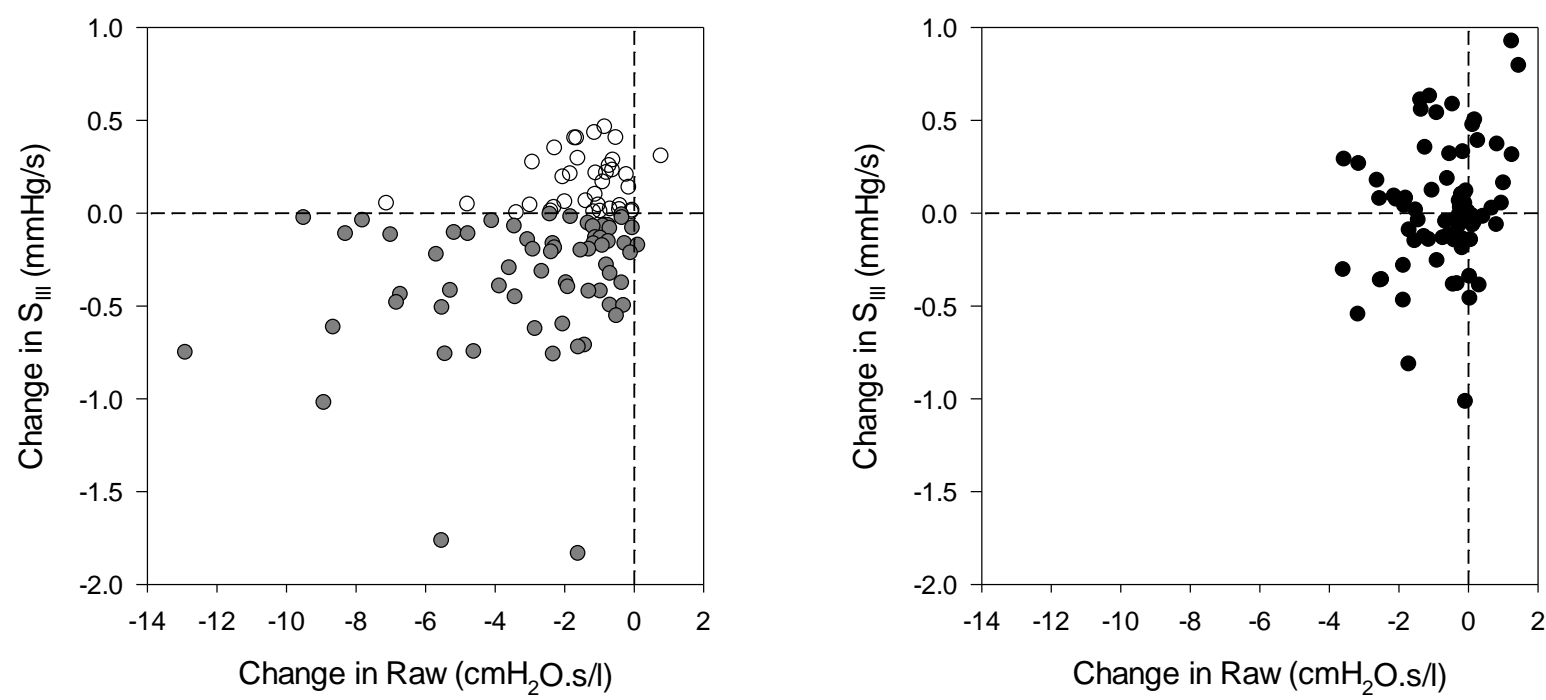

Figure 12. Association between changes in airway resistance and phase III slope ( $\left.\mathrm{S}_{\mathrm{III}}\right)$ in each patient.

Sevoflurane was administered at 1 MAC for 5 min (group SEV, left) or IV anaesthesia was maintained (group CTRL, right). In the left panel, empty symbols represent patients with increasing $S_{\text {III }}$, while filled symbols represent patients with decreasing $\mathrm{S}_{\mathrm{III}}$ from sevoflurane.

The association of post-CPB values of the $\mathrm{P}_{\mathrm{aO}_{2}} / \mathrm{F}_{\mathrm{iO}}$ ratio and $\mathrm{P}_{\mathrm{a}-\mathrm{ETCO}_{2}}$ and their sevofluraneinduced changes are demonstrated in Fig. 13. No statistically significant correlation was observed between the $\mathrm{P}_{\mathrm{aO}_{2}} / \mathrm{F}_{\mathrm{iO}_{2}}$ ratio and its change after sevoflurane $\left(\mathrm{R}^{2}=0.05\right)$, whereas strong negative correlation was found between $\mathrm{P}_{\mathrm{a}-\mathrm{ETCO}_{2}}$ and its change after sevoflurane $\left(\mathrm{R}^{2}=0.51\right.$, $\mathrm{p}<0.001)$. 

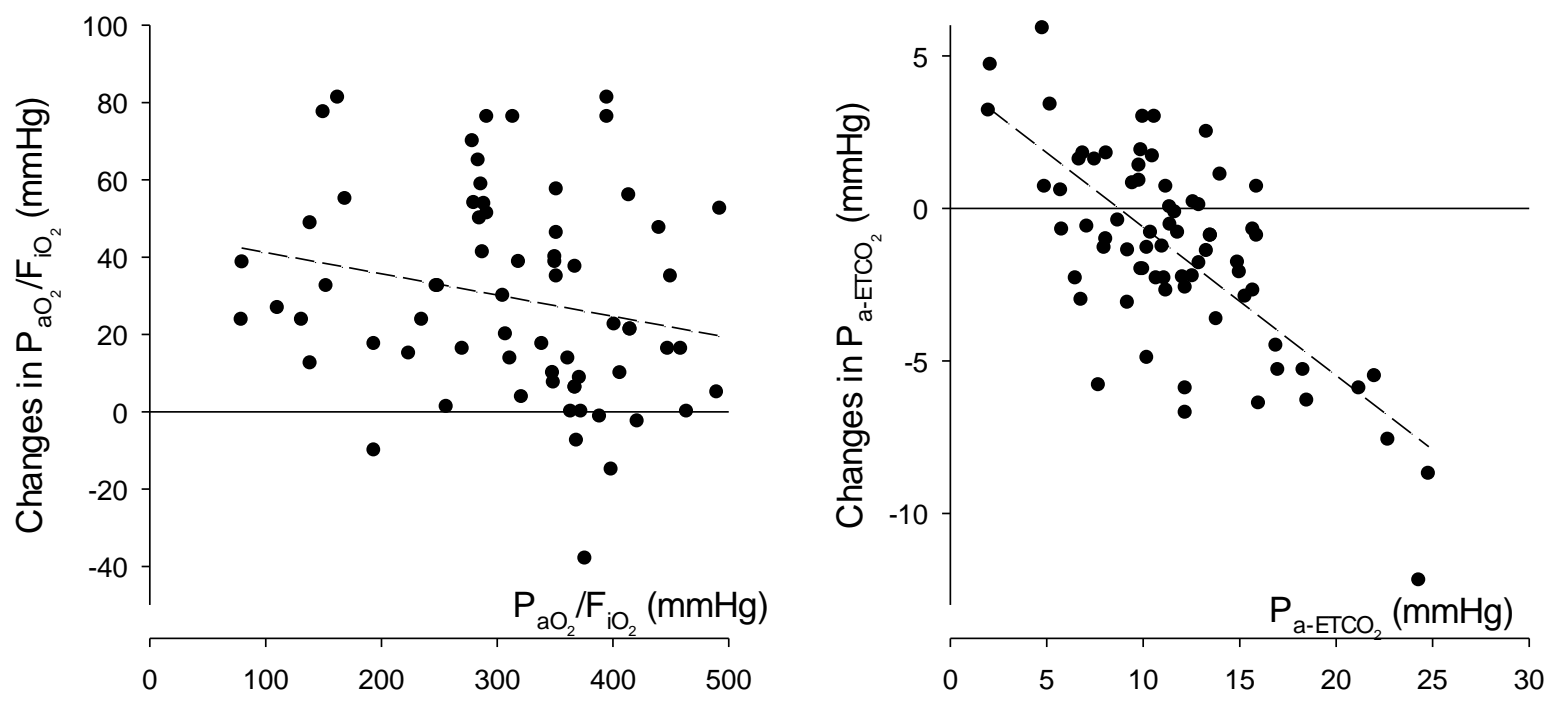

Figure 13. Association between post-CPB values of the $\mathrm{PaO} 2 / \mathrm{FiO} 2$ ratio (left) and $\mathrm{Pa}-\mathrm{ETCO} 2$ (right) and their sevoflurane-induced changes.

Each symbol represents a patient, dashed lines denote linear regressions.

Group SEV was divided into two subgroups based on the sign of the change in $\mathrm{S}_{\text {III }}$ (i.e. increase or decrease). Subgroup $\mathrm{SEV}_{\mathrm{i}}$ exhibited an average increase of $0.19 \pm 0.03 \mathrm{mmHg} / \mathrm{s}(\mathrm{n}=36)$, while subgroup $\mathrm{SEV}_{\mathrm{d}}$ showed an average decrease of $-0.33 \pm 0.04 \mathrm{mmHg} / \mathrm{s} \quad(\mathrm{n}=63)$. Figure 14 demonstrates parameters in which significant differences were found between these two subgroups. After CPB, $S_{\text {III }}$ was still lower in subgroup $\mathrm{SEV}_{\mathrm{i}}$ than in $\mathrm{SEV}_{\mathrm{d}}(\mathrm{p}<0.01)$. The baseline $C$ values normalized to body weight were lower in group $\operatorname{SEV}_{i}(p<0.05)$, whereas increments elicited by sevoflurane were greater in this group $(p<0.02)$. These changes were associated with smaller changes in $S_{I I}(p<0.05)$ and $\eta(p<0.002)$ in group $S E V_{i}$. 

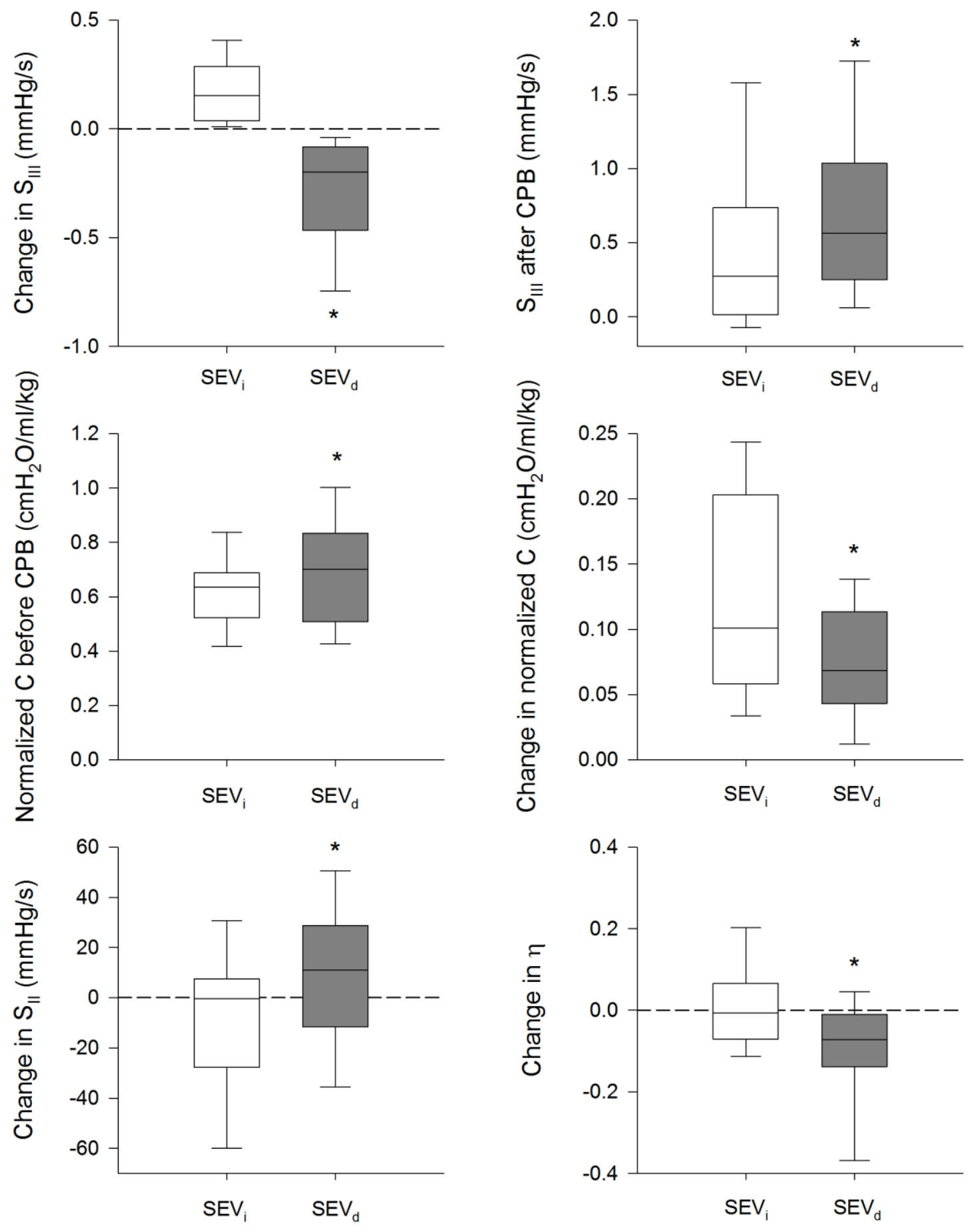

Figure 14. Boxplots of indices exhibiting a difference between SEVi and SEVd subgroups.

Boxplots of changes in $\mathrm{S}_{\text {III }}$ from sevoflurane, phase III slope $\left(\mathrm{S}_{\mathrm{III}}\right)$ after CPB, normalized compliance $(\mathrm{C})$ before CPB, changes in normalized $C$, changes in phase II slope $\left(S_{\text {II }}\right)$ and alterations in tissue hysteresivity $(\eta)$ after sevoflurane treatment in the subgroup with increasing $\left(\mathrm{SEV}_{\mathrm{i}}\right.$, empty) and decreasing $\left(\mathrm{SEV}_{\mathrm{d}}\right.$, filled $) \mathrm{S}_{\text {III. }}$ *: $\mathrm{p}<0.05$ between subgroups. 


\section{Discussion}

\subsection{Comparison of mainstream and sidestream capnography}

The results of the Study I revealed that the sidestream capnography led to a dynamic distortion of the $\mathrm{CO}_{2}$ partial pressure curve compared with the mainstream approach regarded as a reference technique ${ }^{68}$. Thus, the sidestream method biased the solid indices obtained from capnogram regions in which rapid changes in $\mathrm{CO}_{2}$ partial pressure occur (i.e. phase II slopes, the transition from phase II to III, the end-tidal portion, $\mathrm{V}_{\mathrm{CO}_{2}}$ and derived parameters such as the Fowler and Bohr dead spaces). However, the sidestream technique does provide a good approximation of capnogram parameters characterizing periods of low rates of change in $\mathrm{CO}_{2}$ (phase III slopes) and intrapulmonary shunt.

The differences between the sidestream and mainstream techniques can be explained by physical principles. The transport delay of the gas in the sampling tube is a well described characteristic of the sidestream measurement system ${ }^{14}$. This phenomenon introduces a predictable time lag in the detection of the $\mathrm{CO}_{2}$ partial pressure , and gives rise to axial mixing of the gas residing in the sampling tube $\mathrm{e}^{2,16-18}$. Axial in-line diffusion in both space and time occurs during the transport, depending on the $\mathrm{CO}_{2}$ gradient ${ }^{68}$. This blurring process equilibrates the partial pressure differences between the gas compartments ${ }^{40}$. Theoretically, the biasing effects of this adverse process can be diminished by shortening the sampling tube and/or increasing the suction flow rate. Shortening the sampling tube (from 3 to $1.5 \mathrm{~m}$ ) in 5 additional patients led to fairly proportional improvements in the sidestream estimates to the ratio of the tube lengths $\left(\mathrm{S}_{\mathrm{II}, \mathrm{T}, \mathrm{SS}} / \mathrm{S}_{\mathrm{II}, \mathrm{T}, \mathrm{MS}}\right.$ of $37.4 \%$ and $60.2 \%$; $\mathrm{V}_{\mathrm{DF}, \mathrm{SS}} / \mathrm{V}_{\mathrm{DF}, \mathrm{MS}}$ of $154.2 \%$ and $128.5 \%$ with long and short tubes, respectively). Similarly, increasing the sampling flow rate decreased the difference between sidestream and mainstream estimates $\left(\mathrm{S}_{\mathrm{II}, \mathrm{T}, \mathrm{SS}} / \mathrm{S}_{\mathrm{II}, \mathrm{T}, \mathrm{MS}}\right.$ of $47 \%$ and $76 \%$; $\mathrm{S}_{\text {III,T,SS }} / \mathrm{S}_{\text {III,T,MS }}$ of $146 \%$ and $99 \%$ for suction rates of 100 and $350 \mathrm{ml} / \mathrm{min}$, respectively). These results suggest the possibility of improving the accuracy of shape factor estimates by using sidestream capnography.

A further factor contributing to the distortion of the sidestream capnogram is the variable sampling flow rate resulting from the alternating positive airway pressure during mechanical ventilation $^{16,19}$. Since this phenomenon acts during inspiratory/expiratory phase transitions, it ultimately modifies the ascending and descending limbs of the capnograms ${ }^{16,19}$. 
The physical principles described above are of less importance in the assessment of the capnogram phase III slope. The reason for the good correlation and agreement (Fig. 6A, B) is the relatively steady-state $\mathrm{CO}_{2}$ partial pressure (Fig. 4) and constant gas sampling flow during this period (Fig. 5). In the only previous study, where the sidestream and mainstream phase III slopes were compared, substantially greater differences were observed in infants, which can be attributed to the higher ventilation rate $(\sim 32 / \mathrm{min}){ }^{40}$.

The initial part of the capnogram comprising the phase II slopes, angle $\alpha$ and $\mathrm{V}_{\mathrm{DF}}$, coincides with a high rate of change in the $\mathrm{CO}_{2}$ partial pressure and with sudden pressure alterations in the breathing circuit causing variable sampling flow rate ${ }^{19}$ in the tube of the sidestream capnograph. Consequently, in agreement with previous results on ventilated infants ${ }^{40}$, the phase II slope of the sidestream capnogram is lower than that obtained by the mainstream technique (Fig. 4, right, Fig. 7B). This drop in $\mathrm{S}_{\mathrm{II}, \mathrm{T}, \mathrm{SS}}$ of necessity infers weak relationships between the anatomic dead spaces $\mathrm{V}_{\mathrm{DF}, \mathrm{MS}}$ and $\mathrm{V}_{\mathrm{DF}, \mathrm{SS}}$ (Fig. 7D), and the sidestream-derived $\alpha_{\mathrm{SS}}$ (Fig. 7C).

The ventilation-perfusion mismatch can be divided into alveolar dead space ventilation and shunt perfusion ${ }^{3,8}$. We obtained fairly weak correlations and agreements of both the normalized Bohr and Enghoff dead space fractions. The correlation analyses revealed that these dissociations can be ascribed to the discrepancies in the $\mathrm{P}_{\overline{\mathrm{E}} \mathrm{CO}_{2}}$, resulting from the dynamic distortion of the sidestream capnogram (e.g. Fig. 5). Taking the difference between the Enghoff and Bohr dead spaces eliminates these discrepancies, which explains the excellent correlations and good agreement between $\mathrm{V}_{\mathrm{s}, \mathrm{MS}}$ and $\mathrm{V}_{\mathrm{s}, \mathrm{SS}}$ (Fig. 8C, D). The differences between the two estimates in the dead space and shunt parameters depend on the level of $\mathrm{C}$, with greatest deviations in patients with low compliance (Fig. 9). Around the ventilation frequency, the respiratory system impedance is dominated by the elastic forces. Since low compliance involves higher airway pressures, variations in sampling flow rate are expected to be augmented within the respiratory cycle in the presence of increased stiffness. This implies that the use of dead space parameters determined by sidestream technique may result in false interpretations. Conversely, the assessment of the intrapulmonary shunt is feasible by using sidestream capnography, though a slight underestimation is expected in patients with a less compliant respiratory system. 
Our measurements demonstrate that the most frequently utilized capnogram parameter, the $\mathrm{PETCO}_{2}$, is underestimated by a value with clinically minimal relevance $(0.2 \mathrm{mmHg})$. This concordance between the two techniques supports the conclusions of previous studies ${ }^{37,39}$.

As a methodological aspect, we assessed whether gas sampling to the sidestream capnograph affects the shape of the mainstream capnogram resulting from the juxtaposed position of the mainstream sensor. However, the lack of differences in any of the mainstream parameters revealed that this effect has negligible impact on the mainstream parameters. This lack of sensitivity can also be anticipated from the amount of aspirated volume being about two orders of magnitude smaller than the $\mathrm{V}_{\mathrm{T}}$.

\subsection{The effect of sevoflurane on respiratory mechanics and gas exchange after CPB}

The results of Study II demonstrated the ability of sevoflurane to reverse detrimental changes in lung function induced by extracorporeal circulation in a large cohort of cardiac surgery patients. Administration of sevoflurane led to marked airway dilations uniformly in almost all the patients, resulting in improved function of the lung as an oxygenator. Conversely, this beneficial profile of sevoflurane was reflected in distinctly different changes in the capnogram parameter related to ventilation heterogeneities $\left(\mathrm{S}_{\mathrm{III}}\right)$. While the parameters presented improved unanimously after the administration of sevoflurane, none of them showed significant changes in group CTRL during the matching period.

\subsubsection{Airway and lung tissue mechanics}

Sevoflurane induced significant improvements in the airway and tissue mechanics compromised by CPB. This finding is in accordance with previous results, where the beneficial profile of sevoflurane was demonstrated against bronchoconstriction induced by exogenous cholinergic agonists ${ }^{41,42}$ or following a release of endogenous mediators. ${ }^{43}$ Since Raw mainly reflects the flow resistance of the central conducting airways, ${ }^{69}$ the marked drops in this parameter are likely to reflect the prominent dilation of proximal airway regions. This idea is supported by the complete return of Iaw to pre-CPB levels in group SEV, which may have resulted from the rise of bronchial volume as a consequence of bronchodilation ${ }^{69}$ as well as from the homogenization of airway calibres. ${ }^{70}$ The drops in lung tissue parameters $\mathrm{G}$ and $\mathrm{H}$ after the administration of sevoflurane may reflect an improvement in the parenchymal viscoelasticity, since sevoflurane is reported to have pulmonary anti-inflammatory effects. ${ }^{71,72}$ 
However, such a process was not likely to evolve due to the relatively short time frame (5 min). Another, more probable mechanism responsible for the improvement in tissue parameters may be due to alveolar recruitment secondary to bronchodilation and homogenization of alveolar ventilation. Accordingly, the drops in $\mathrm{G}$ can be explained by decreasing time constant inequalities arising from the heterogeneous constriction of small airways. Since sevoflurane induced greater drops in $\mathrm{G}$ than in $\mathrm{H}$, their ratio $\eta$ decreased after the administration of sevoflurane, supporting the notion of lung homogenization. ${ }^{73}$ The improved lung aeration from sevoflurane is also supported by the increases in a routinely assessed mechanical parameter reflecting overall lung tissue stiffness $(\mathrm{C})$.

\subsubsection{Ventilation and oxygenation}

The phase III slope of the capnogram is determined by the ventilation and perfusion of the lungs, although the latter process only accounts for $\sim 20 \%$ of the change in $\mathrm{S}_{\mathrm{III}}{ }^{21}$ Furthermore, the slope of $\mathrm{CO}_{2}$ partial pressure during alveolar emptying is governed primarily by Raw. ${ }^{23}$ Accordingly, increment in $\mathrm{S}_{\text {III }}$ mainly reflects the maldistribution of ventilation, as observed in asthma, ${ }^{25}$ in obstructive lung disease ${ }^{9}$ or after $\mathrm{CPB},{ }^{23}$ while bronchodilator therapy ${ }^{74}$ or an

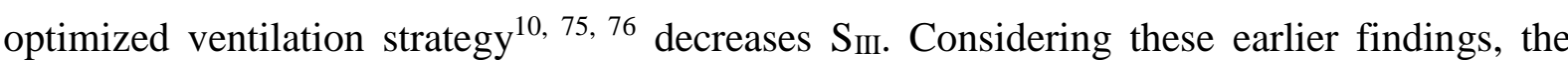
decrement in the mean $S_{\text {III }}$ in the present study implies the reduction of ventilation heterogeneity from sevoflurane. This result is in accordance with the beneficial lung mechanical changes, as described above.

The lack of difference in the change in $S_{\text {II }}$ between the protocol groups can be explained by the dependence of this parameter on various lung mechanical properties. In a previous study, the change in $\mathrm{S}_{\text {II }}$ exhibited a negative correlation with the change in Raw and a positive correlation with the change in $\mathrm{C}^{23}$ Since sevoflurane induced changes in both of these mechanical parameters, their effects on $\mathrm{S}_{\text {II }}$ may have been counterbalanced.

The improvement of ventilation from sevoflurane was manifested in better ventilationperfusion matching as reflected by the decreased $\mathrm{Q}_{s} / \mathrm{Q}_{t}$ and a related, easier accessible parameter, $\mathrm{P}_{\mathrm{a}-\mathrm{ETCO}}$. Several studies have investigated the effect of sevoflurane on the intrapulmonary shunt fraction, but they were focused on the potential inhibition of hypoxic pulmonary vasoconstriction by this volatile agent during one-lung ventilation. Abe et al. reported a decrease in $\mathrm{Q}_{\mathrm{s}} / \mathrm{Q}_{\mathrm{t}}$ after switching from sevoflurane to propofol, ${ }^{77}$ while Beck et al. 
observed similar changes in $\mathrm{Q}_{\mathrm{s}} / \mathrm{Q}_{\mathrm{t}}$ among patients receiving either sevoflurane or propofol. ${ }^{78}$ The discrepancies in these findings can be attributed to the dual action of sevoflurane; although it inhibits hypoxic pulmonary vasoconstriction via vascular smooth muscle relaxation, it also decreases ventilation-perfusion mismatch by facilitating a more uniformly distributed ventilation. In the present study, the striking bronchodilation from sevoflurane opened shunted alveolar regions with sustained perfusion in both lungs. The resultant improvement in ventilation-perfusion matching most likely outweighed the potential loss of protective hypoxic pulmonary vasoconstriction, as reflected in the decreased $\mathrm{Q}_{\mathrm{s}} / \mathrm{Q}_{\mathrm{t}}$ and $\mathrm{P}_{\mathrm{a}-\mathrm{ETCO}_{2}}$. These beneficial changes ultimately resulted in better oxygenation, as reflected by the increased $\mathrm{P}_{\mathrm{aO}_{2}} / \mathrm{F}_{\mathrm{iO}_{2}}$ ratio. A further noteworthy observation is that the higher the $\mathrm{P}_{\mathrm{a}-\mathrm{ETCO}}$ after CPB the greater its improvement to sevoflurane. While this relationship is less apparent for the absolute changes in $\mathrm{P}_{\mathrm{aO}_{2}} / \mathrm{F}_{\mathrm{iO}_{2}}$ to sevoflurane, this is of greater importance in patients with low $\mathrm{P}_{\mathrm{aO}_{2}} / \mathrm{F}_{\mathrm{iO}_{2}}$ post-CPB. These findings indicate the particular benefit of sevoflurane in patients with severely compromised gas exchange.

\subsubsection{Effect of sevoflurane on ventilation heterogeneity}

Despite the association between airway calibre and $\mathrm{S}_{\mathrm{III}},{ }^{23}$ the magnitude of the decrement in $\mathrm{S}_{\mathrm{III}}$ following the administration of sevoflurane did not match that in Raw. Thus, we sought to elucidate the origin of this discrepancy by investigating the association between the changes in Raw and in $\mathrm{S}_{\text {III }}$ after the post-CPB intervention in both protocol groups. While Raw decreased spontaneously in about two-thirds of the patients in group CTRL after CPB, bronchodilation was observed in all the patients in group SEV but one. Despite this uniform change in Raw in the latter group, $\mathrm{S}_{\mathrm{III}}$ exhibited diverse changes, with further elevations in more than one-third of the patients. This suggests that in these cases airway dilation resulted in a more heterogeneous alveolar emptying. It is noteworthy that oxygenation was equally improved in both subgroups $\left(\mathrm{P}_{\mathrm{aO}_{2}} / \mathrm{F}_{\mathrm{iO}_{2}}\right.$ in subgroups $\mathrm{SEV}_{\mathrm{i}}$ and $\mathrm{SEV}_{\mathrm{d}}$ of $37 \pm 7$ and $40 \pm 6 \mathrm{mmHg}$, respectively).

To explain the different behaviour of $\mathrm{S}_{\text {III }}$ between the two subgroups with similar improvements in oxygenation capabilities, differences in the lung functional parameters were examined. Patients in subgroup $\mathrm{SEV}_{\mathrm{i}}$ may originally have had closed dependent lung regions and homogeneously open, less compliant areas after CPB. In these patients, administration of sevoflurane induced bronchodilation and opened some alveolar units, thus giving rise to $\mathrm{C}$ and 
$\mathrm{P}_{\mathrm{aO}_{2}} / \mathrm{F}_{\mathrm{iO}_{2}}$. Nevertheless, alveolar re-openings increased the heterogeneity of ventilation indicated by the rise in $S_{\text {III, }}$ i.e., creating a cycle of unstable alveoli opening and closing. Consequently, monitoring the changes in $S_{\text {III }}$ offers a possibility to recognize alveolar recruitment within the respiratory cycle.

\subsubsection{Limitations of Study II and future directions}

Since the low-frequency forced oscillation technique requires general anaesthesia and mechanical ventilation, this study was limited to the assessment of intraoperative changes in pulmonary mechanics, ventilation and oxygenation. Systematic evaluation of the duration of the pulmonary effects of sevoflurane and its possible postoperative benefits (e.g. shorter extubation time and ICU stay, lower frequency and severity of respiratory morbidities) may be a subject of a future investigation. A further research may focus on the characterization of the preventive potential of sevoflurane administered into the oxygenator during $\mathrm{CPB}$ in patients with airway susceptibilities. Another possible direction for forthcoming research is the investigation of the potential respiratory benefit of sevoflurane in ICU patients with respiratory complications, where its administration can be achieved by using the anaesthetic conserving device (AnaConDa; Sendana Medical, Kirdare, Ireland). 


\section{Conclusions}

In conclusion, we evidenced that the sidestream capnography allows reliable measurement of $\mathrm{PETCO}_{2}$, time and volumetric phase III slopes, and the intrapulmonary shunt. Thus, sidestream capnography is suitable for quantification of the unevenness of the alveolar ventilation, and the ventilation-perfusion mismatch. However, the anatomical and physiological dead space parameters were considerably overestimated by the sidestream technique, especially in patients with low pulmonary compliance. Although the accuracy of sidestream capnography can be improved by increasing the sampling flow or shortening the sampling tube, these measures have limited feasibility due to patient safety and practical reasons. Therefore, reliable assessments of the phase II slope, the anatomical and physiological dead spaces, and the rate of elimination of $\mathrm{CO}_{2}$ necessitate the combined application of mainstream volumetric capnography and sophisticated bedside information technology tools.

Furthermore, we demonstrated that bronchoconstriction with subsequent development of atelectasis and intrapulmonary shunt triggered by CPB can be effectively alleviated with the application of sevoflurane. This benefit may be of particular importance in patients with airway hyperresponsiveness, where severe bronchoconstriction is likely to develop following CPB. In such cases, switching anaesthesia management from a total intravenous approach to an inhalational technique may be recommended. The potential increase in ventilation heterogeneity after sevoflurane may necessitate the elevation of PEEP and/or applying recruitment manoeuvres. 


\section{Acknowledgement}

I would like to express my gratitude to my supervisor, Dr. Barna Babik, for introducing me into clinical research and guiding me ever since. I am grateful for his mentoring and the trust he placed in me.

I am thankful to Professor Dr. Ferenc Peták for sharing his extensive expertise and skillset on research methodology and providing everyday guidance in my years as a $\mathrm{PhD}$ student.

I greatly appreciate the opportunities they provided me.

I am grateful to Professor Dr. Ferenc Bari for the support to participate in the research activity and to the possibility to advance my educational skill at the Department of Medical Physics and Informatics. I thank Professor Dr. Zsolt Molnár for the encouragement to conduct research at the Department of Anaesthesiology and Intensive Therapy and its collaborative institutes.

I would like to express my acknowledgement to Dr. József Tolnai for creating a data analysis software. I am thankful for Dr. Gergely Fodor for greatly facilitating my work by constantly sharing his research experience, and Dr. Roberta Südy for helping me in the data analysis with unbreakable enthusiasm.

I would like to thank Dr. Gábor Bogáts, the Head of Department of Cardiac Surgery in University of Szeged and all his staff for their contribution and help throughout the construction of the studies.

I am grateful to my parents and grandparents for their continuous encouragement, and for providing immense support and stability to pursue my $\mathrm{PhD}$ studies. 


\section{References}

1 Ortega R, Connor C, Kim S, Djang R, Patel K. Monitoring ventilation with capnography. N Engl J Med 2012; 367: e27

2 Thompson JE, Jaffe MB. Capnographic waveforms in the mechanically ventilated patient. Respir Care 2005; 50: 100-8; discussion 8-9

3 Tusman G, Sipmann FS, Bohm SH. Rationale of dead space measurement by volumetric capnography. Anesth Analg 2012; 114: 866-74

4 Bhavani-Shankar K, Moseley H, Kumar AY, Delph Y. Capnometry and anaesthesia. Can J Anaesth 1992; 39: 617-32

5 Walsh BK, Crotwell DN, Restrepo RD. Capnography/Capnometry during mechanical ventilation: 2011. Respir Care 2011; 56: 503-9

6 Blanch L, Lucangelo U, Lopez-Aguilar J, Fernandez R, Romero PV. Volumetric capnography in patients with acute lung injury: effects of positive end-expiratory pressure. Eur Respir J 1999; 13: 1048-54

7 Tusman G, Suarez-Sipmann F, Bohm SH, et al. Monitoring dead space during recruitment and PEEP titration in an experimental model. Intensive Care Med 2006; 32: 1863-71

8 Tusman G, Sipmann FS, Borges JB, Hedenstierna G, Bohm SH. Validation of Bohr dead space measured by volumetric capnography. Intensive Care Med 2011; 37: 870-4

9 Krauss B, Deykin A, Lam A, et al. Capnogram shape in obstructive lung disease. Anesth Analg 2005; 100: 884-8

10 Babik B, Csorba Z, Czovek D, Mayr PN, Bogats G, Petak F. Effects of respiratory mechanics on the capnogram phases: importance of dynamic compliance of the respiratory system. Crit Care 2012; 16: R177

11 Tusman G, Bohm SH, Sipmann FS, Maisch S. Lung recruitment improves the efficiency of ventilation and gas exchange during one-lung ventilation anesthesia. Anesth Analg 2004; 98: $1604-9$

12 Ioan I, Demoulin B, Duvivier C, et al. Frequency dependence of capnography in anesthetized rabbits. Respir Physiol Neurobiol 2014; 190: 14-9

13 Brunner JX, Westenskow DR. How the rise time of carbon dioxide analysers influences the accuracy of carbon dioxide measurements. Br J Anaesth 1988; 61: 628-38

14 Breen PH, Mazumdar B, Skinner SC. Capnometer transport delay: measurement and clinical implications. Anesth Analg 1994; 78: 584-6

15 Schena J, Thompson J, Crone RK. Mechanical influences on the capnogram. Crit Care Med 1984; 12: 672-4

16 Epstein RA, Reznik AM, Epstein MA. Determinants of distortions in CO2 catheter sampling systems: a mathematical model. Respir Physiol 1980; 41: 127-36

17 Anderson CT, Breen PH. Carbon dioxide kinetics and capnography during critical care. Crit Care 2000; 4: 207-15

18 Stromberg NO, Gustafsson PM. Ventilation inhomogeneity assessed by nitrogen washout and ventilation-perfusion mismatch by capnography in stable and induced airway obstruction. Pediatr Pulmonol 2000; 29: 94-102

19 Farmery AD, Hahn CE. A method of reconstruction of clinical gas-analyzer signals corrupted by positive-pressure ventilation. J Appl Physiol 2001; 90: 1282-90

20 Bhavani-Shankar K, Philip JH. Defining segments and phases of a time capnogram. Anesth Analg 2000; 91: 973-7 
21 Tusman G, Areta M, Climente C, et al. Effect of pulmonary perfusion on the slopes of single-breath test of CO2. J Appl Physiol (1985) 2005; 99: 650-5

22 Crawford AB, Makowska M, Paiva M, Engel LA. Convection- and diffusion-dependent ventilation maldistribution in normal subjects. J Appl Physiol (1985) 1985; 59: 838-46

23 Csorba Z, Petak F, Nevery K, et al. Capnographic Parameters in Ventilated Patients: Correspondence with Airway and Lung Tissue Mechanics. Anesth Analg 2016; 122: $1412-$ 20

24 Kars AH, Bogaard JM, Stijnen T, de Vries J, Verbraak AF, Hilvering C. Dead space and slope indices from the expiratory carbon dioxide tension-volume curve. Eur Respir J 1997; 10: $1829-36$

25 You B, Peslin R, Duvivier C, Vu VD, Grilliat JP. Expiratory capnography in asthma: evaluation of various shape indices. Eur Respir J 1994; 7: 318-23

26 Fowler WS. Lung function studies. II. The respiratory dead space. American Journal of Physiology 1948; 154: 405-16

27 Riley RL, Cournand A. Ideal alveolar air and the analysis of ventilation-perfusion relationships in the lungs. J Appl Physiol 1949; 1: 825-47

28 Bohr C. Über die Lungenatmung. Skandinavisches Archiv fur Physiologie 1891; 2: 236-68

29 Enghoff H. Volumen inefficax: Bemerkungen zur Frage des schädlichen Raumes. Upsala Läkareforen Forhandl 1938; 44: 191-218

30 American Society of Anesthesiologists. Standards for basic anesthetic monitoring. 2015. Available

from http://www.asahq.org/ /media/Sites/ASAHQ/Files/Public/Resources/standardsguidelines/standards-for-basic-anesthetic-monitoring.pdf

31 Knapp S, Kofler J, Stoiser B, et al. The assessment of four different methods to verify tracheal tube placement in the critical care setting. Anesth Analg 1999; 88: 766-70

32 Falk JL, Rackow EC, Weil MH. End-tidal carbon dioxide concentration during cardiopulmonary resuscitation. N Engl J Med 1988; 318: 607-11

33 Sanders AB, Kern KB, Otto CW, Milander MM, Ewy GA. End-tidal carbon dioxide monitoring during cardiopulmonary resuscitation. A prognostic indicator for survival. JAMA 1989; 262: 1347-51

34 Donald MJ, Paterson B. End tidal carbon dioxide monitoring in prehospital and retrieval medicine: a review. Emerg Med J 2006; 23: 728-30

35 Jaffe MB. Mainstream or Sidestream Capnography? Respironics White Paper 2002: 1012102 SB 8/23/02

36 Teixeira Neto FJ, Carregaro AB, Mannarino R, Cruz ML, Luna SP. Comparison of a sidestream capnograph and a mainstream capnograph in mechanically ventilated dogs. $J$ Am Vet Med Assoc 2002; 221: 1582-5

37 McEvedy BA, McLeod ME, Kirpalani H, Volgyesi GA, Lerman J. End-tidal carbon dioxide measurements in critically ill neonates: a comparison of side-stream and mainstream capnometers. Can J Anaesth 1990; 37: 322-6

38 Pekdemir M, Cinar O, Yilmaz S, Yaka E, Yuksel M. Disparity between mainstream and sidestream end-tidal carbon dioxide values and arterial carbon dioxide levels. Respir Care 2013; 58: 1152-6

39 Sakata DJ, Matsubara I, Gopalakrishnan NA, et al. Flow-through versus sidestream capnometry for detection of end tidal carbon dioxide in the sedated patient. J Clin Monit Comput 2009; 23: 115-22 
40 Pascucci RC, Schena JA, Thompson JE. Comparison of a sidestream and mainstream capnometer in infants. Crit Care Med 1989; 17: 560-2

41 Habre W, Petak F, Sly PD, Hantos Z, Morel DR. Protective effects of volatile agents against methacholine-induced bronchoconstriction in rats. Anesthesiology 2001; 94: 34853

42 Myers CF, Fontao F, Janosi TZ, Boda K, Petak F, Habre W. Sevoflurane and desflurane protect cholinergic-induced bronchoconstriction of hyperreactive airways in rabbits. Can J Anaesth 2011; 58: 1007-15

43 Wiklund CU, Lindsten U, Lim S, Lindahl SG. Interactions of volatile anesthetics with cholinergic, tachykinin, and leukotriene mechanisms in isolated Guinea pig bronchial smooth muscle. Anesth Analg 2002; 95: 1650-5

44 von Ungern-Sternberg BS, Saudan S, Petak F, Hantos Z, Habre W. Desflurane but not sevoflurane impairs airway and respiratory tissue mechanics in children with susceptible airways. Anesthesiology 2008; 108: 216-24

45 Rooke GA, Choi JH, Bishop MJ. The effect of isoflurane, halothane, sevoflurane, and thiopental/nitrous oxide on respiratory system resistance after tracheal intubation. Anesthesiology 1997; 86: 1294-9

46 Babik B, Asztalos T, Petak F, Deak ZI, Hantos Z. Changes in respiratory mechanics during cardiac surgery. Anesth Analg 2003; 96: 1280-7

47 Albu G, Babik B, Kesmarky K, Balazs M, Hantos Z, Petak F. Changes in airway and respiratory tissue mechanics after cardiac surgery. Ann Thorac Surg 2010; 89: 1218-26

48 Wan S, LeClerc JL, Vincent JL. Inflammatory response to cardiopulmonary bypass: mechanisms involved and possible therapeutic strategies. Chest 1997; 112: 676-92

49 Steinberg JB, Kapelanski DP, Olson JD, Weiler JM. Cytokine and complement levels in patients undergoing cardiopulmonary bypass. J Thorac Cardiovasc Surg 1993; 106: 100816

50 Chenoweth DE, Cooper SW, Hugli TE, Stewart RW, Blackstone EH, Kirklin JW. Complement activation during cardiopulmonary bypass: evidence for generation of C3a and C5a anaphylatoxins. N Engl J Med 1981; 304: 497-503

51 Tanaka K, Takao M, Yada I, Yuasa H, Kusagawa M, Deguchi K. Alterations in coagulation and fibrinolysis associated with cardiopulmonary bypass during open heart surgery. $J$ Cardiothorac Anesth 1989; 3: 181-8

52 Laffey JG, Boylan JF, Cheng DC. The systemic inflammatory response to cardiac surgery: implications for the anesthesiologist. Anesthesiology 2002; 97: 215-52

53 Downing SW, Edmunds LH, Jr. Release of vasoactive substances during cardiopulmonary bypass. Ann Thorac Surg 1992; 54: 1236-43

54 Fayaz KM, Pugh S, Balachandran S, Sudheer PS, Hall JE. Histamine release during adult cardiopulmonary bypass. Anaesthesia 2005; 60: 1179-84

55 Neuhof C, Walter O, Dapper F, et al. Bradykinin and histamine generation with generalized enhancement of microvascular permeability in neonates, infants, and children undergoing cardiopulmonary bypass surgery. Pediatr Crit Care Med 2003; 4: 299-304

56 Lele E, Petak F, Carnesecchi S, Virag K, Argiroffo CB, Habre W. The protective effects of volatile anesthestics against the bronchoconstriction induced by an allergic reaction in sensitized rabbit pups. Anesth Analg 2013; 116: 1257-64

57 Schutz N, Petak F, Barazzone-Argiroffo C, Fontao F, Habre W. Effects of volatile anaesthetic agents on enhanced airway tone in sensitized guinea pigs. Br J Anaesth 2004; 92: $254-60$ 
58 Cho EJ, Yoon JH, Hong SJ, Lee SH, Sim SB. The effects of sevoflurane on systemic and pulmonary inflammatory responses after cardiopulmonary bypass. J Cardiothorac Vasc Anesth 2009; 23: 639-45

59 Fowler W. The respiratory dead space Am J Physiol 1948; 54: 405-16

60 Bohr C. Über die Lungenatmung. Skan Arch Physiol 1891; 53: 236-8

61 Enghoff H. Volumen inefficax. Uppsala Laekareforen Forh 1938; 44

62 Hantos Z, Daroczy B, Suki B, Nagy S, Fredberg JJ. Input impedance and peripheral inhomogeneity of dog lungs. J Appl Physiol (1985) 1992; 72: 168-78

63 Berggren S. The oxygen deficit of arterial blood caused by non-ventilating parts of the lung. Acta Physiol Scand 1942; 4

64 Nickalls RW, Mapleson WW. Age-related iso-MAC charts for isoflurane, sevoflurane and desflurane in man. Br J Anaesth 2003; 91: 170-4

65 Bland M. How can I decide the sample size for a study of agreement between two methods of measurement? . 2004. Available from https://wwwusers.york.ac.uk/ mb55/meas/sizemeth.htm

66 Bland JM, Altman DG. Statistical methods for assessing agreement between two methods of clinical measurement. Lancet 1986; 1: 307-10

67 Bausell RB, Li Y-F. Power analysis for experimental research: a practical guide for the biological, medical, and social sciences. Cambridge University Press, 2002

68 Gravenstein JS, Jaffe MB, Gravenstein N, Paulus DA. Technical Perpectives. Capnography. Cambridge: Cambridge University Press, 2011; 381-96

69 Peslin R, Fredberg JJ. Oscillation Mechanics of the Respiratory System. Comprehensive Physiology. Hoboken, NJ, USA: John Wiley \& Sons, Inc., 2011; 145-77

70 Lanteri CJ, Petak F, Gurrin L, Sly PD. Influence of inertance on respiratory mechanics measurements in mechanically ventilated puppies. Pediatr Pulmonol 1999; 28: 130-8

71 Suter D, Spahn DR, Blumenthal S, et al. The immunomodulatory effect of sevoflurane in endotoxin-injured alveolar epithelial cells. Anesth Analg 2007; 104: 638-45

72 Sugasawa Y, Yamaguchi K, Kumakura S, et al. Effects of sevoflurane and propofol on pulmonary inflammatory responses during lung resection. J Anesth 2012; 26: 62-9

73 Lutchen KR, Hantos Z, Petak F, Adamicza A, Suki B. Airway inhomogeneities contribute to apparent lung tissue mechanics during constriction. J Appl Physiol (1985) 1996; 80: 1841-9

74 Blanch L, Fernandez R, Saura P, Baigorri F, Artigas A. Relationship Between Expired Capnogram and Respiratory System Resistance in Critically III Patients During Total Ventilatory Support. Chest 1994; 105: 219-23

75 Blanch L, Lucangelo U, Lopez-Aguilar J, Fernandez R, Romero PV. Volumetric capnography in patients with acute lung injury: effects of positive end-expiratory pressure. The European respiratory journal 1999; 13: 1048-54

76 Böhm SH, Maisch S, von Sandersleben A, et al. The effects of lung recruitment on the Phase III slope of volumetric capnography in morbidly obese patients. Anesthesia and Analgesia 2009; 109: 151-9

77 Abe K, Shimizu T, Takashina M, Shiozaki H, Yoshiya I. The effects of propofol, isoflurane, and sevoflurane on oxygenation and shunt fraction during one-lung ventilation. Anesth Analg 1998; 87: 1164-9

78 Beck DH, Doepfmer UR, Sinemus C, Bloch A, Schenk MR, Kox WJ. Effects of sevoflurane and propofol on pulmonary shunt fraction during one lung ventilation for thoracic surgery. Br J Anaesth 2001; 86: 38-43 
I. 


\title{
Capnogram slope and ventilation dead space parameters: comparison of mainstream and sidestream techniques
}

\author{
A. L. Balogh ${ }^{1,2}$, F. Petak ${ }^{2, *}$, G. H. Fodor ${ }^{2}$, J. Tolnai' ${ }^{2}$ Z. Csorba ${ }^{1}$ and B. Babik ${ }^{1}$ \\ ${ }^{1}$ Department of Anaesthesiology and Intensive Therapy, University of Szeged, 6 Semmelweis u. H-6725, Szeged, \\ Hungary, and ${ }^{2}$ Department of Medical Physics and Informatics, University of Szeged, 9 Koranyi fasor, H-6720, \\ Szeged, Hungary \\ *Corresponding author. E-mail: petak.ferenc@med.u-szeged.hu
}

\begin{abstract}
Background: Capnography may provide useful non-invasive bedside information concerning heterogeneity in lung ventilation, ventilation-perfusion mismatching and metabolic status. Although the capnogram may be recorded by mainstream and sidestream techniques, the capnogram indices furnished by these approaches have not previously been compared systematically.

Methods: Simultaneous mainstream and sidestream time and volumetric capnography was performed in anaesthetized, mechanically ventilated patients undergoing elective heart surgery. Time capnography was used to assess the phase II ( $\left.\mathrm{S}_{\mathrm{II}, \mathrm{T}}\right)$ and III slopes $\left(\mathrm{S}_{\text {III,T) }}\right.$. The volumetric method was applied to estimate phase II $\left(\mathrm{S}_{\text {II, }}\right)$ and III slopes $\left(\mathrm{S}_{\text {III,V }}\right)$, together with the dead space values according to the Fowler $\left(\mathrm{V}_{\mathrm{DF}}\right), \mathrm{Bohr}\left(\mathrm{V}_{\mathrm{DB}}\right)$, and Enghoff $\left(\mathrm{V}_{\mathrm{DE}}\right)$ methods and the volume of $\mathrm{CO}_{2}$ eliminated per breath $\left(\mathrm{VCO}_{2}\right)$. The partial pressure of end-tidal $\mathrm{CO}_{2}\left(\mathrm{PET}_{\mathrm{CO}_{2}}\right)$ was registered.

Results: Excellent correlation and good agreement were observed in $S_{\text {III,T }}$ measured by the mainstream and sidestream techniques [ratio $=1.05$ (SEM 0.16), $R^{2}=0.92, P<0.0001$ ]. Although the sidestream technique significantly underestimated $\mathrm{VcO}_{2}$ and overestimated $S_{\text {III, }}\left[1.32(0.28), R^{2}=0.93, P<0.0001\right], V_{D F}, V_{D B}$, and $V_{D E}$, the agreement between the mainstream and sidestream techniques in the difference between $V_{D E}$ and $V_{D B}$, reflecting the intrapulmonary shunt, was excellent $\left[0.97(0.004), R^{2}=0.92\right.$, $P<0.0001]$. The $P \mathrm{PET}_{\mathrm{CO}_{2}}$ exhibited good correlation and mild differences between the mainstream and sidestream approaches [0.025 (0.005) kPa].

Conclusions: Sidestream capnography provides adequate quantitative bedside information about uneven alveolar emptying and ventilation-perfusion mismatching, because it allows reliable assessments of the phase III slope, $\mathrm{PET}_{\mathrm{CO}_{2}}$ and intrapulmonary shunt. Reliable measurement of volumetric parameters (phase II slope, dead spaces, and eliminated $\mathrm{CO}_{2}$ volumes) requires the application of a mainstream device.
\end{abstract}

Key words: capnography; carbon dioxide; intraoperative monitoring; mechanical ventilation; ventilation-perfusion ratio

Capnography is a non-invasive method for the numerical and graphical analysis of the exhaled $\mathrm{CO}_{2}$ concentration, ${ }^{1-5}$ and a valuable tool for the improvement of patient safety. ${ }^{6}$ Although assessment of capnogram shape factors is not yet a standard part of patient monitoring, it has the promise to provide routine information concerning pathophysiological processes of lung ventilation, such as airway patency ${ }^{7-10}$ and lung recoil tendency. ${ }^{8}$ Furthermore, combination of capnography with expired gas volume 


\section{Editor's key points}

- It is not clear which factors sidestream capnography can indicate as accurately as mainstream capnography.

- Mainstream and sidestream time and volumetric capnography were performed to compare several factors in anaesthetized, mechanically ventilated patients undergoing elective heart surgery.

- Sidestream capnography provides adequate quantitative bedside information about uneven alveolar emptying and ventilation-perfusion mismatch, but mainstream capnography is required for a reliable measurement of volumetric parameters.

monitoring allows the assessment of ventilation-perfusion matching and the metabolic status of the body. ${ }^{35} 1011$

In clinical practice, two techniques are available, based on the measurement site of $\mathrm{CO}_{2}$. Mainstream capnography applies an infrared sensor located proximally to the patient between the tracheal tube and the Y-piece, and thus, allows a rapid and accurate analysis of the $\mathrm{CO}_{2}$ concentration of the exhaled gas. ${ }^{12-14}$ However, this method is used mainly in intensive care units, because of the disadvantages posed by the local heating of the head and the weight of the sample cell, which increases the risk of tracheal tube dislocation.

As an alternative, sidestream capnography is often used in the operating theatre because it is easily manageable and allows the monitoring of other gases. ${ }^{7-915}$ These devices analyse the gas sample distally from the patient, and therefore, have the drawbacks of a prolonged total response time, ${ }^{16-18}$ the occurrence of axial mixing, ${ }^{2} 10^{11} 19$ and a variable suction flow rate. ${ }^{20}$ All these processes result in a dynamic distortion of the $\mathrm{CO}_{2}$ concentration curve, and thus, have a potential to bias the derived capnographic parameters.

There have been a few previous attempts to compare capnographic parameters obtained by sidestream and mainstream techniques, but they were the manufacturer's educational material, ${ }^{21}$ focused only on the end-tidal $\mathrm{CO}_{2}$ value in experimen$\mathrm{tal}^{22}$ and clinical studies, ${ }^{23-25}$ or were limited to a small cohort of infants. ${ }^{26}$ However, there is a lack of information about the relationship between capnographic indices obtained by sidestream and mainstream techniques in mechanically ventilated adults. Therefore, the aim of the present study was to validate the ability of the sidestream technique to provide adequate quantitative bedside information about uneven alveolar emptying and ventilation-perfusion mismatching. Therefore, we determined which of the capnogram parameters (shape factors, respiratory dead space) can be assessed reliably by applying the sidestream technique. We hypothesized that sidestream capnography is suitable to measure indices obtained from the quasi-static phases of the capnogram, whereas phases with transient $\mathrm{CO}_{2}$ concentration changes are exposed to measurement bias.

\section{Methods}

\section{Patients}

Twenty-nine patients [female/male: 13/16, 71 (57-85) yr old] undergoing elective cardiac surgery were enrolled into the study in a prospective consecutive manner. The study protocol was approved by the Human Research Ethics Committee of the University of Szeged, Hungary (no. WHO 2788). Written informed consent was obtained from each patient. Patients with severe cardiopulmonary disorders (pleural effusion $>300 \mathrm{ml}$, ejection fraction $<30 \%, \mathrm{BMI}>35 \mathrm{~kg} \mathrm{~m}^{-2}$, or intraoperative acute asthma exacerbation) were excluded.

\section{Anaesthesia and surgery}

Anaesthesia was induced with i.v. midazolam $\left(30 \mu \mathrm{g} \mathrm{kg}^{-1}\right)$, sufentanil (0.4-0.5 $\left.\mu \mathrm{gg}^{-1}\right)$, and propofol $\left(0.3-0.5 \mu \mathrm{kg}^{-1}\right)$, and was maintained by an i.v. propofol infusion $\left(50 \mu \mathrm{g} \mathrm{kg}^{-1} \mathrm{~min}^{-1}\right)$. Neuromuscular block was achieved by i.v. boluses of rocuronium (0.2 $\mathrm{mg} \mathrm{kg}^{-1}$ every $30 \mathrm{~min}$ ).

After tracheal intubation, the patients' lungs were mechanically ventilated in volume-controlled mode with descending flow (Dräger Zeus, Lübeck, Germany) by setting the tidal volume to $7 \mathrm{ml} \mathrm{kg}{ }^{-1}$, the ventilator frequency to 9-14 bpm, and the PEEP to $4 \mathrm{~cm} \mathrm{H}_{2} \mathrm{O}$, and maintaining the inspired oxygen fraction at 0.5 .

\section{Recording and analyses of the expiratory capnogram}

The measurement set-up was designed to allow the sampling of the mainstream (Capnogard ${ }^{\circledR}$; Novametrix, Andover, MA, USA) and sidestream (Ultima ${ }^{\mathrm{TM}}$; Datex/Instrumentarium, Helsinki, Finland) capnographs from the same sampling site in the ventilator circuit. This was achieved by connecting the sampling port of the sidestream capnograph next to the mainstream sensor between the Y-piece and the tracheal tube. A screen pneumotachograph (Piston Ltd, Budapest, Hungary) was used to record the central airflow at the same point of the ventilator circuit. Simultaneous $15 \mathrm{~s}$ recordings of the $\mathrm{CO}_{2}$ signals of the mainstream and sidestream capnographs and the ventilation flow were digitized (sampling frequency $102.4 \mathrm{~Hz}$ ) and analysed with custommade software. Volumetric capnograms were constructed from the time capnograms and the integrated flow data. To compensate for the transport delay caused by the suction of the gas into the sample cell, the sidestream time capnograms were shifted by $-1.65 \mathrm{~s}$. This value was determined by analysing the time delay between the mainstream and sidestream capnogram curves during stepwise changes in $\mathrm{CO}_{2}$ concentration, in a similar manner to an earlier approach. ${ }^{17}$

The slopes of phase III of the time and volumetric capnograms determined by mainstream ( $\mathrm{S}_{\text {III,T,MS }}$ and $\mathrm{S}_{\text {III,V,MS }}$ ) and sidestream ( $\mathrm{S}_{\text {III,T,SS }}$ and $\mathrm{S}_{\text {III,V,SS }}$ capnography were assessed by fitting a linear regression line to the last $60 \%$ of phase III. ${ }^{7}{ }^{12}$ Likewise, regression lines were fitted to the points around the inflexion point of phase II within $20 \%$ of the time or volume of phase II, to determine their slopes in the mainstream (SII,T,MS and $\mathrm{S}_{\mathrm{II}, \mathrm{V}, \mathrm{MS}}$ ) and sidestream $\left(\mathrm{S}_{\mathrm{II}, \mathrm{T}, \mathrm{SS}}\right.$ and $\left.\mathrm{S}_{\mathrm{II}, \mathrm{V}, \mathrm{SS}}\right)$ measurements. The angles formed by the phase II and III limbs of the expiratory time mainstream $\left(\alpha_{\mathrm{MS}}\right)$ and sidestream $\left(\alpha_{\mathrm{SS}}\right)$ capnograms were calculated from the phase II and phase III slopes using a monitoring speed of $1.67 \mathrm{kPa} \mathrm{s}^{-1}\left(12.5 \mathrm{~mm} \mathrm{Hg} \mathrm{s}^{-1}\right)$.

Additionally, dead space fractions were calculated from volumetric capnograms. Fowler's dead space, reflecting the volume of the conducting airways, ${ }^{27}$ was determined by taking the volume expired up to the inflexion point of phase II from the mainstream and sidestream capnograms $\left(\mathrm{V}_{\mathrm{DF}, \mathrm{MS}}\right.$ and $\left.\mathrm{V}_{\mathrm{DF}, \mathrm{SS}}\right)$. The physiological dead space according to $\mathrm{Bohr}\left(\mathrm{V}_{\mathrm{DB}, \mathrm{MS}}\right.$ and $\left.\mathrm{V}_{\mathrm{DB}, \mathrm{SS}}\right)$, reflecting the alveolar volume with decreased or no perfusion, was calculated from the mainstream and sidestream capnograms as follows: ${ }^{28}$

$$
\begin{aligned}
\mathrm{V}_{\mathrm{DB}, \mathrm{MS}} / \mathrm{V}_{\mathrm{T}} & =\left(\mathrm{Pa}_{\mathrm{CO}_{2}, \mathrm{MS}}-\mathrm{PE}_{\mathrm{CO}_{2}, \mathrm{MS}}\right) / \mathrm{Pa}_{\mathrm{CO}_{2}, \mathrm{MS}} \\
\mathrm{V}_{\mathrm{DB}, \mathrm{SS}} / \mathrm{V}_{\mathrm{T}} & =\left(\mathrm{Pa}_{\mathrm{CO}_{2}, \mathrm{SS}}-\mathrm{PE}_{\mathrm{CO}_{2}, \mathrm{SS}}\right) / \mathrm{Pa}_{\mathrm{CO}_{2}, \mathrm{SS}}
\end{aligned}
$$

where $\mathrm{Pa}_{\mathrm{CO}_{2}, \mathrm{MS}}$ and $\mathrm{Pa}_{\mathrm{CO}_{2}, \mathrm{Ss}}$ are the mean alveolar partial 
pressures of $\mathrm{CO}_{2}$ determined from the midpoint of phase III in the mainstream and sidestream capnograms, respectively, ${ }^{314}$ and $P \overline{\mathrm{E}}_{\mathrm{CO}_{2}, \mathrm{MS}}$ and $P \overline{\mathrm{E}}_{\mathrm{CO}_{2}, \mathrm{sS}}$ are the mixed expired $\mathrm{CO}_{2}$ partial pressure obtained by calculating the area under the mainstream and sidestream volumetric capnogram curves, respectively, via integration and dividing the resulting values by $\mathrm{V}_{\mathrm{T}}$.

Enghoff's approach contains all of the ventilation-perfusion mismatching. Hence, besides the $V_{\mathrm{DB}}$, it also incorporates the intrapulmonary shunt (i.e. the alveolar volume with decreased or even loss of ventilation with perfusion maintained), as follows: ${ }^{29}$

$$
\begin{aligned}
\mathrm{V}_{\mathrm{DE}, \mathrm{MS}} / \mathrm{V}_{\mathrm{T}} & =\left(\mathrm{Pa}_{\mathrm{CO}_{2}}-\mathrm{P} \overline{\mathrm{E}}_{\mathrm{CO}_{2}}, \mathrm{MS}\right) / \mathrm{Pa}_{\mathrm{CO}_{2}} \\
\mathrm{~V}_{\mathrm{DE}, \mathrm{SS}} / \mathrm{V}_{\mathrm{T}} & =\left(\mathrm{Pa}_{\mathrm{CO}_{2}}-\mathrm{P}_{\mathrm{E}_{2}}, \mathrm{SS}\right) / \mathrm{Pa}_{\mathrm{CO}_{2}}
\end{aligned}
$$

where $\mathrm{Pa}_{\mathrm{CO}_{2}}$ is the partial pressure of $\mathrm{CO}_{2}$ in the arterial blood.

Additionally, we calculated the normalized differences between the Enghoff and Bohr dead spaces obtained by mainstream $\left[\mathrm{V}_{\mathrm{S}, \mathrm{MS}} / \mathrm{V}_{\mathrm{T}}=\left(\mathrm{V}_{\mathrm{DE}, \mathrm{MS}}-\mathrm{V}_{\mathrm{DB}, \mathrm{MS}}\right) / \mathrm{V}_{\mathrm{T}}\right]$ and sidestream capnography $\left[\mathrm{V}_{\mathrm{S}, \mathrm{SS}} / \mathrm{V}_{\mathrm{T}}=\left(\mathrm{V}_{\mathrm{DE}, \mathrm{SS}}-\mathrm{V}_{\mathrm{DB}, \mathrm{SS}}\right) / \mathrm{V}_{\mathrm{T}}\right]$, which reflects the all the mixed venous blood entering the arterial system, including Thebesian veins, part of the bronchial veins, and intrapulmonary shunt circulation (i.e. the virtual gas volume of the alveolar units with perfusion with decreased or no ventilation).

The amount of the $\mathrm{CO}_{2}$ exhaled during each expiration was calculated as the area under the volumetric $\mathrm{CO}_{2}$ concentration curve obtained by mainstream $\left(\mathrm{V}_{\mathrm{CO}_{2}, \mathrm{MS}}\right)$ and sidestream $\left(\mathrm{V}_{\mathrm{CO}_{2}, \mathrm{SS}}\right)$ capnography.

The changes in the sampling flow rate during the mechanical ventilation were measured in a smaller cohort of ventilated patients $(n=5)$. The sampling flow was assessed by measuring the pressure difference between the proximal and distal ends of the sampling tube with a miniature differential pressure transducer (model 33NA002D; ICSensors, Milpitas, CA, USA). The potential variability of the sampling flow governed by the respiratory impedance can theoretically bias the accuracy of sidestream estimates. Thus, the main cohort of patients was divided into three groups based on their compliance $(C)$ values into lower $\left(C<37 \mathrm{ml} \mathrm{cm} \mathrm{H}_{2} \mathrm{O}^{-1}\right)$ and higher $\left(\mathrm{C}>53 \mathrm{ml} \mathrm{cm} \mathrm{H}_{2} \mathrm{O}^{-1}\right)$ quartiles and medium interquartile range.

\section{Measurement protocol}

Mainstream and sidestream capnographic signals were recorded simultaneously during different stages of cardiac surgery: before sternotomy, $5 \mathrm{~min}$ before and after cardiopulmonary bypass, and immediately after sternal closure. Two pairs of $15 \mathrm{~s}$ traces were recorded in each stage, producing eight recordings per patient ( 20 pairs of expirations). For the assessment of $\mathrm{Pa}_{\mathrm{CO}_{2}}$, arterial blood gas samples were obtained during each measurement condition, and the resistance $(R)$ and compliance $(C)$ values displayed by the ventilator were also registered.

\section{Supplemental measurements}

To assess whether sidestream capnography affects the mainstream results via gas suctioning, an additional protocol was performed with a set-up identical to that used in the main study group in a smaller cohort of patients $(n=8)$. A total number of 87 mainstream measurements, each lasting $60 \mathrm{~s}$, were performed with the sidestream sampling flow switched on randomly during either the first or second half of the recordings. Separate analyses of first and second halves allowed pairwise comparisons of mainstream capnogram parameters obtained with and without gas suctioning by the sidestream device.

\section{Statistical analyses}

Sample size estimation was based on the aim to determine the $95 \%$ limits of agreement with great reliability according to the corresponding recommendation. ${ }^{30}$ The correlations between the mainstream and sidestream variants of individual variables were analysed with the Pearson test. If the regression lines were close to the line of identity for a corresponding mainstream and sidestream value pair, Bland-Altman analysis was performed to assess the extent of their agreement. ${ }^{31}$ In the event of normality, Student's paired t-tests were used to assess the statistical significance of the difference between the results of the mainstream and sidestream methods. The effects of compliance on the sidestream and mainstream dead space and shunt parameters were assessed by using one-way ANOva tests on ranks. A $P$-value $<0.05$ was considered significant. The reported values are expressed as the mean (SEM) in case of normality, or as the median [first quartile-third quartile] otherwise.

\section{Results}

Figure 1 shows representative time and volumetric capnograms obtained with simultaneous mainstream and sidestream capnography. In both the time and volume domains, the mainstream capnograms exhibited a steeper phase II, smaller $\alpha$ angles, and an earlier transition into phase III. Moreover, a later transition into the inspiratory phase was observed in the time domain mainstream capnogram. These shape differences result in a lower area under the sidestream capnogram compared with the corresponding mainstream capnogram.

Figure 2 illustrates the temporal relationship between the sidestream capnogram and the sampling flow variability in a representative patient. The transient spikes in the sampling flow coincide with the cyclic changes in the breathing phases.

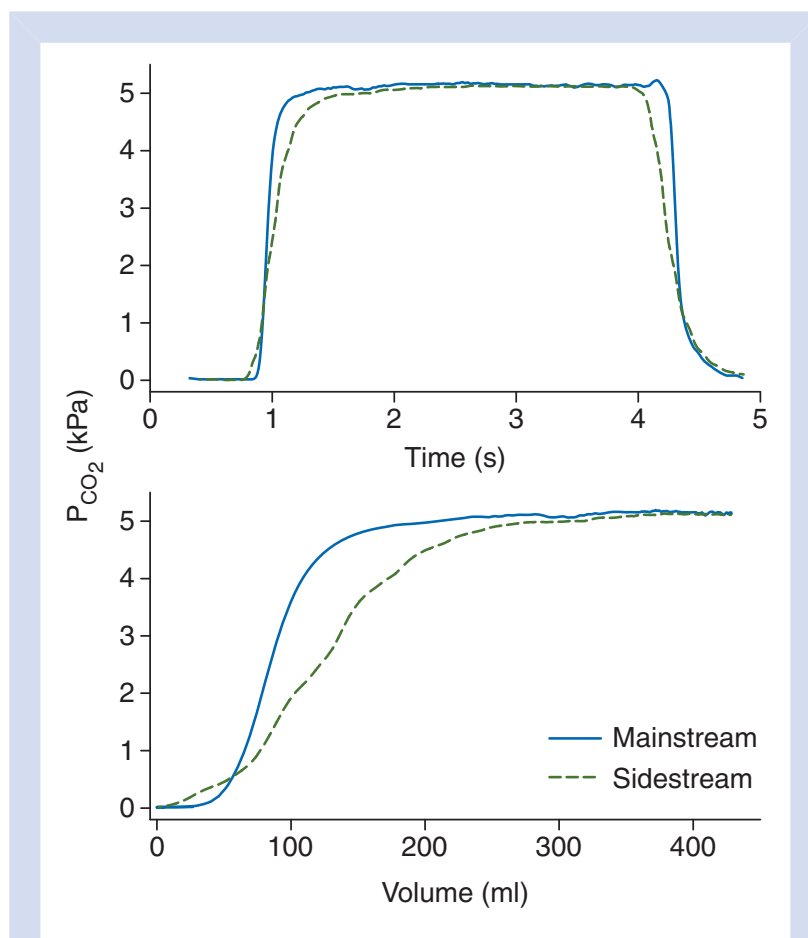

Fig 1 Representative time (top) and volumetric (bottom) mainstream (continuous traces) and sidestream (dashed traces) capnograms. 


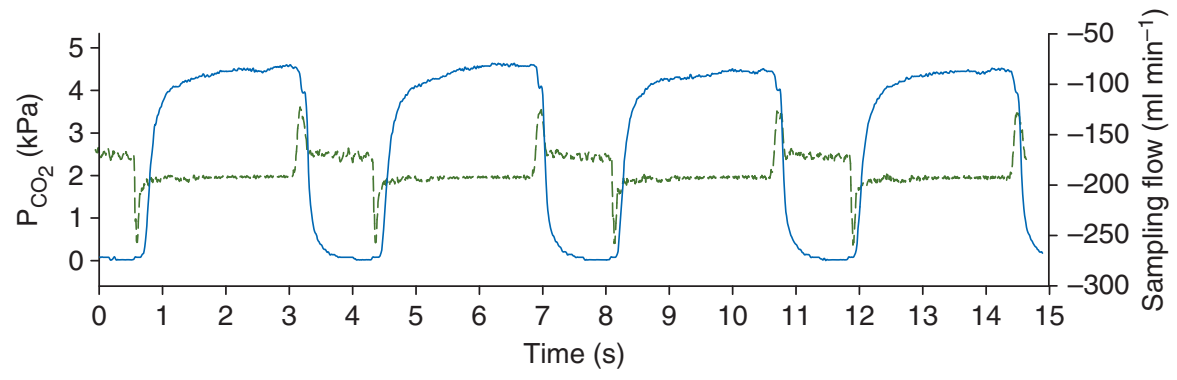

Fig 2 Sidestream capnogram curve (continuous line, left axis) together with the flow in the sampling tube (dashed line, right axis) in a representative patient.

A

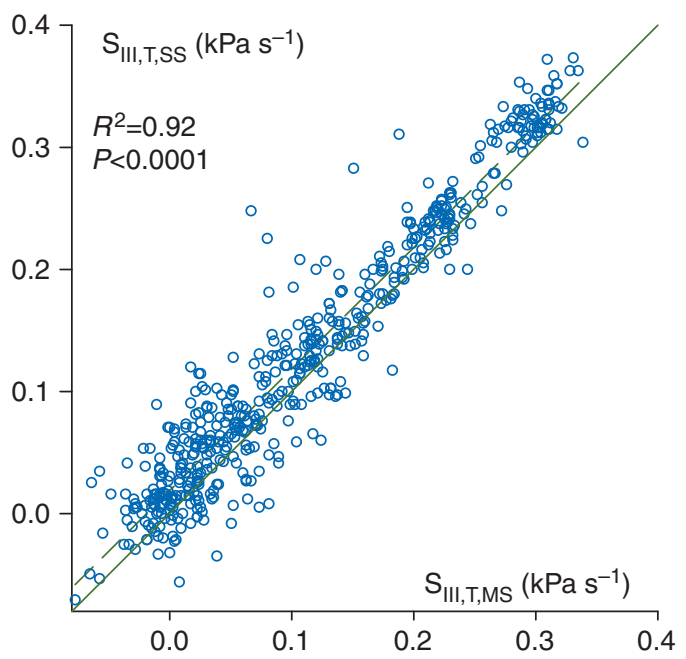

C

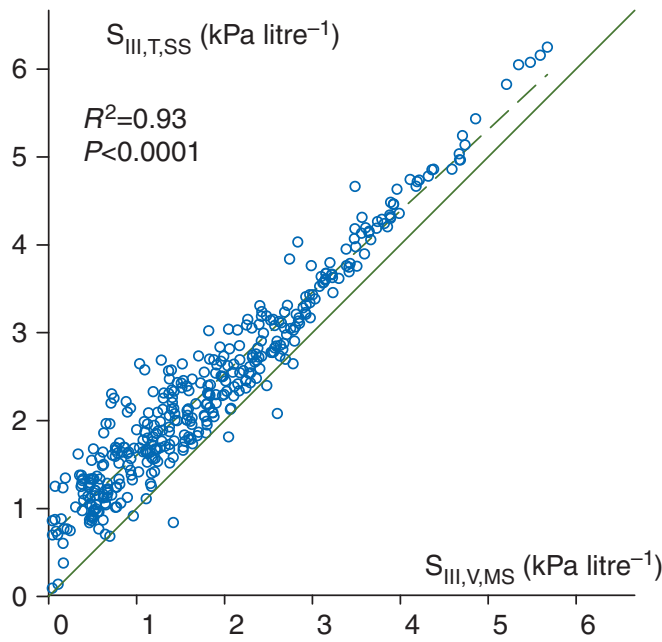

B

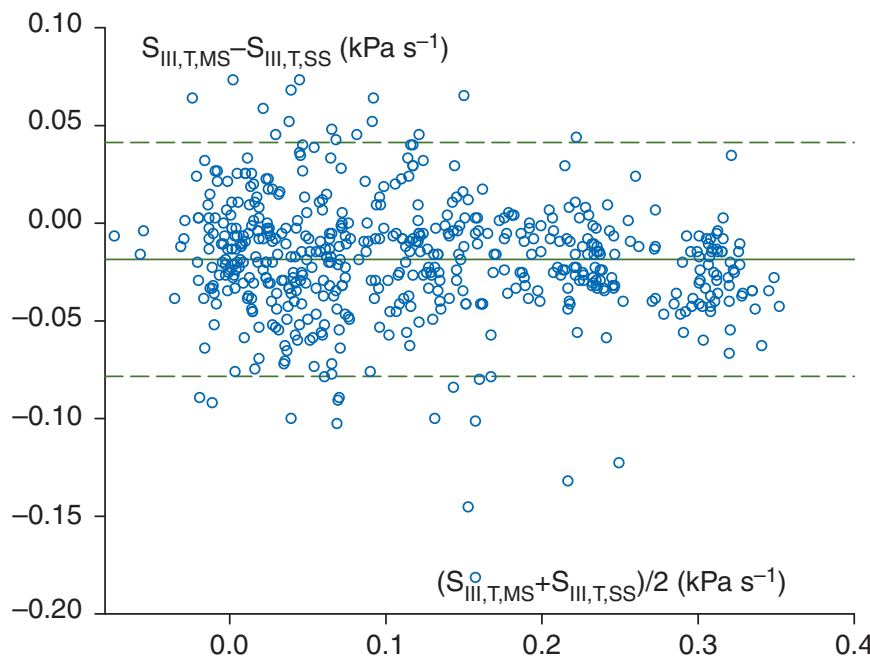

D

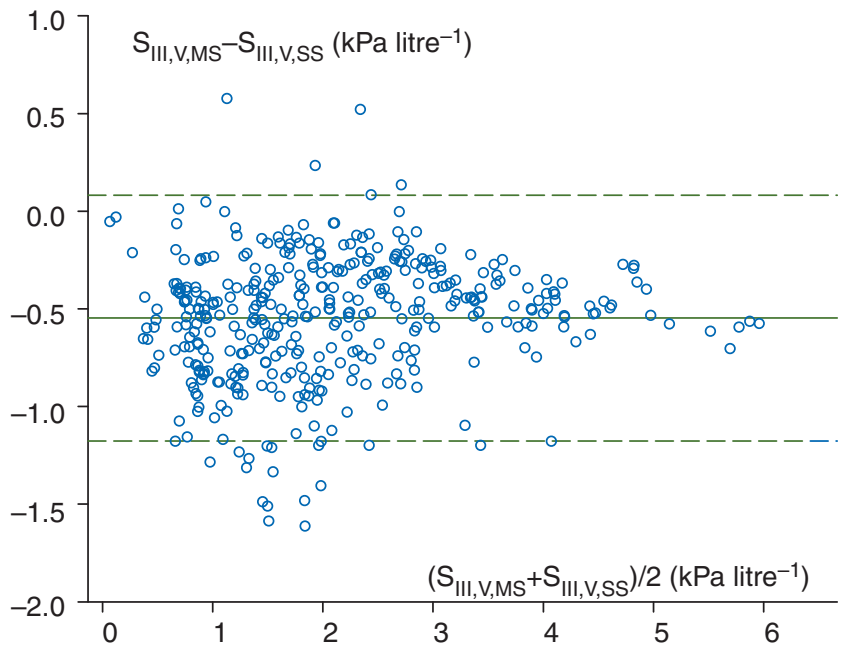

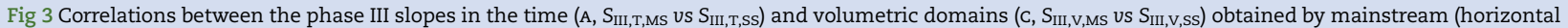

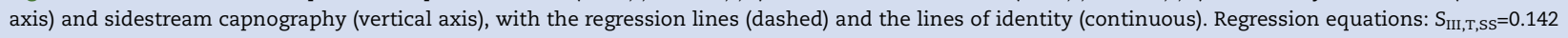

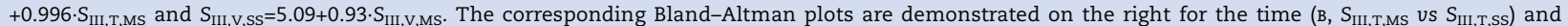
volumetric ( $\mathrm{D}, \mathrm{S}_{\mathrm{III}, \mathrm{V}, \mathrm{MS}}$ Us $\mathrm{S}_{\mathrm{III}, \mathrm{V}, \mathrm{SS}}$ ) capnograms. The means of differences are $-0.019 \mathrm{kPa} \mathrm{s}^{-1}$ and $-0.55 \mathrm{kPa}$ litre $\mathrm{P}^{-1}$ (continuous), and the limits of agreement are $0.06 \mathrm{kPa} \mathrm{s}^{-1}$ and $0.63 \mathrm{kPa}$ litre ${ }^{-1}$ (dashed) for the time and volumetric capnograms, respectively. Each data point represents one expiration. $\mathrm{S}_{\text {III,T,Ms, }}$ phase III slope of time capnogram; $\mathrm{S}_{\mathrm{II}, \mathrm{V}, \mathrm{MS}}$, phase III slope of volumetric capnogram; $\mathrm{S}_{\mathrm{II}, \mathrm{T}, \mathrm{MS}}$, phase II slope of time capnogram; $\mathrm{S}_{\mathrm{II}, \mathrm{v}, \mathrm{MS}}$, phase II slope of volumetric capnogram; $V_{\mathrm{DF}, \mathrm{MS}} / \mathrm{V}_{\mathrm{T}}$, normalized Fowler dead space; $\mathrm{V}_{\mathrm{DB}, \mathrm{MS}} / \mathrm{V}_{\mathrm{T}}$, normalized Bohr dead space; $\mathrm{V}_{\mathrm{DE}, \mathrm{MS}} / \mathrm{V}_{\mathrm{T}}$, normalized Enghoff dead space; $\mathrm{V}_{\mathrm{S}, \mathrm{MS}} / \mathrm{V}_{\mathrm{T}}$, normalized difference between the Enghoff and Bohr dead spaces; $\mathrm{V}_{\mathrm{T}}$, tidal volume. 
The difference in mainstream and sidestream partial pressure of end-tidal $\mathrm{CO}_{2}\left[\mathrm{PET}_{\mathrm{CO}_{2}} ; 4.27\right.$ (0.02) us $\left.4.24(0.02) \mathrm{kPa}\right]$ was small, although statistically significantly higher with the former technique $(P<0.001)$. The $\mathrm{V}_{\mathrm{CO}_{2}}$ was systematically underestimated

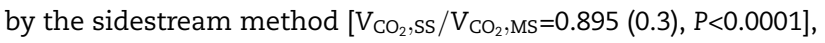
despite the presence of good correlation between these variables $\left(R^{2}=0.91, P<0.0001\right)$.

Correlations between the phase III slopes obtained by the mainstream and sidestream methods, and the corresponding Bland-Altman plots, are demonstrated in Fig. 3. An excellent correlation $\left(R^{2}=0.92, P<0.0001\right)$ and good agreement were observed between $\mathrm{S}_{\mathrm{II}, \mathrm{T}, \mathrm{MS}}$ and $\mathrm{S}_{\mathrm{III}, \mathrm{T}, \mathrm{SS}}$, although the sidestream method slightly but significantly overestimated $\mathrm{S}_{\mathrm{III}, \mathrm{T}}\left[\mathrm{S}_{\mathrm{III}, \mathrm{T}, \mathrm{SS}} / \mathrm{S}_{\mathrm{III}, \mathrm{T}, \mathrm{MS}}=1.05\right.$
(0.16), $P<0.0001]$. Strong correlation and good agreement were found between the volumetric $S_{\text {III }}$ values $\left(R^{2}=0.93, P<0.0001\right)$, with a systematic overestimation of $\mathrm{S}_{\text {III,V,MS }}$ by $\mathrm{S}_{\text {III,V,SS }}\left(\mathrm{S}_{\text {III,V,SS }} /\right.$ $\mathrm{S}_{\text {III,V,MS }}=1.32$ [1.21-1.49], $P<0.0001$ ). The limits of agreements were -0.08 to $0.04 \mathrm{kPa} \mathrm{s}^{-1}$ and -0.07 to $1.16 \mathrm{kPa}$ litre ${ }^{-1}$ for the time and volumetric phase III slopes, respectively.

Figure 4 depicts the correlations between the shape factors and the dead space fractions associated with phase II of the capnogram $\left(V_{\mathrm{DF}}\right)$. Although $\mathrm{S}_{\mathrm{II}, \mathrm{T}, \mathrm{SS}}$ correlates significantly with $\mathrm{S}_{\mathrm{II}, \mathrm{T}, \mathrm{MS}}$ $\left(R^{2}=0.58, P<0.0001\right)$, there is no agreement between these slopes because of the substantial underestimation by the sidestream method $\left[\mathrm{S}_{\mathrm{II}, \mathrm{T}, \mathrm{SS}} / \mathrm{S}_{\mathrm{II}, \mathrm{T}, \mathrm{MS}}=0.48\right.$ (0.004), $\left.\mathrm{P}<0.0001\right]$. A rather poor correlation and a lack of agreement were observed between the

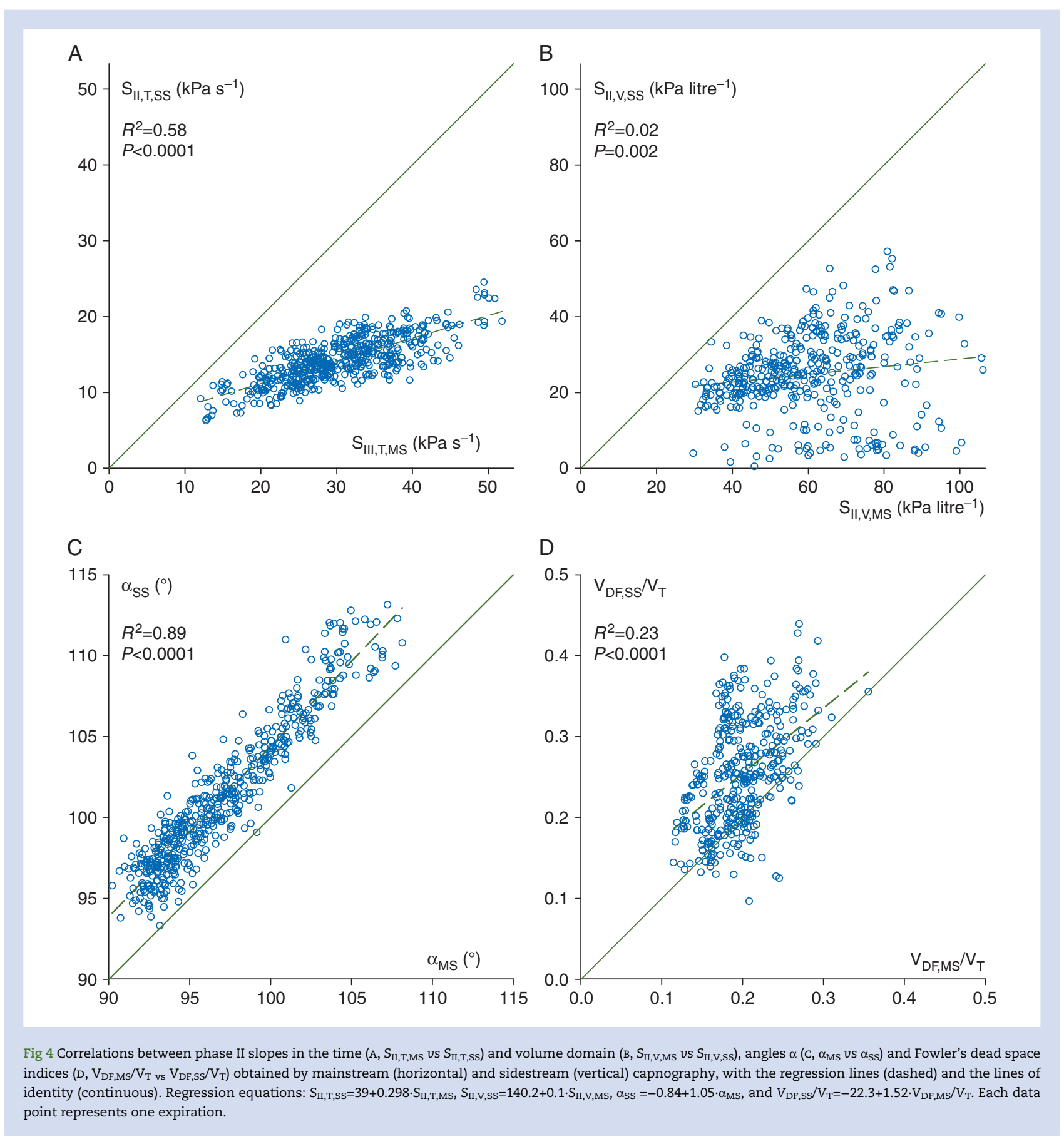




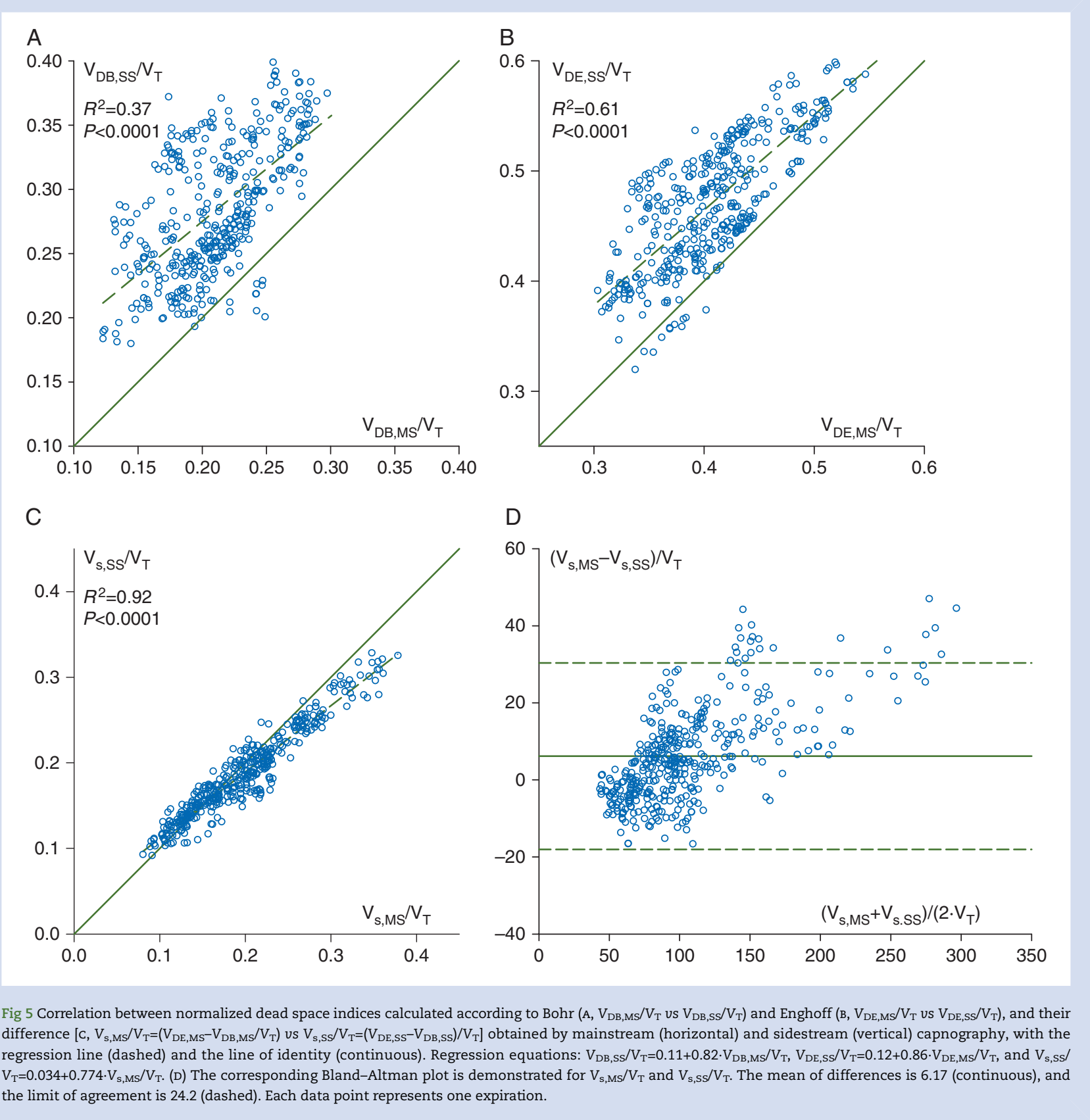

phase II slopes in the volume domain $\left(R^{2}=0.02, P<0.002\right)$, with a similar underestimation by sidestream capnography $\left[\mathrm{S}_{\text {II,V,SS }} / \mathrm{S}_{\text {II,V,MS }}=0.44(0.008), P<0.0001\right]$. Significant correlation but poor agreement was found between the two types of $\alpha$ angle $\left(R^{2}=0.89, P<0.0001\right)$, with $\alpha_{S S}$ slightly but consistently overestimating $\alpha_{\mathrm{MS}}[1.04(0.001), P<0.0001]$. Although $V_{\mathrm{DF}, \mathrm{MS}}$ and $\mathrm{V}_{\mathrm{DF}, \mathrm{SS}}$ correlated moderately $\left(R^{2}=0.56, P<0.0001\right)$, their agreement was rather poor, and the sidestream method overestimated the mainstream values $\left[\mathrm{V}_{\mathrm{DF}, \mathrm{SS}} / \mathrm{V}_{\mathrm{DF}, \mathrm{MS}}=1.3(0.013), \mathrm{P}<0.0001\right]$.

Figure 5 illustrates the correlations between respiratory dead space indices measured by the two methods. Moderate, but statistically significant correlation was found between the normalized dead space parameters $\mathrm{V}_{\mathrm{DB}, \mathrm{MS}} / \mathrm{V}_{\mathrm{T}}$ and $\mathrm{V}_{\mathrm{DB}, \mathrm{SS}} / \mathrm{V}_{\mathrm{T}}\left(\mathrm{R}^{2}=0.37\right.$, $P<0.0001)$, with overestimation of mainstream Bohr's dead space by the sidestream method $\left[\mathrm{V}_{\mathrm{DB}, \mathrm{SS}} / \mathrm{V}_{\mathrm{DB}, \mathrm{MS}}=1.37\right.$ (0.01), $P<0.0001]$. In the measurement of the Enghoff dead space, the two methods exhibited good correlation $\left(R^{2}=0.61, P<0.0001\right)$ and a slight overestimation by the sidestream capnograph $\left[\mathrm{V}_{\mathrm{DE}, \mathrm{SS}} /\right.$ $V_{D E, M S}=1.16(0.004), P<0.0001$ ]. Given that $P_{\mathrm{CO}_{2}}$ shows excellent agreement between the two techniques $\left[R^{2}=0.95\right.$ and mainstream/sidestream ratio=1.01 (0.02), $P=0.2$ ], the dissociations between physiological dead space parameters can be ascribed to the discrepancies in $P_{\overline{\mathrm{E} C O}}\left[R^{2}=0.77\right.$ and mainstream/sidestream ratio=1.12 (0.08), $P<0.0001$ ]. The overestimations of $V_{D E}$ and $V_{D B}$ by the sidestream technique resulted in a strong correlation in their difference (i.e. the lung volume with the intrapulmonary shunt; $R^{2}=0.92, P<0.0001$ between $V_{S, S S} / V_{T}$ and $\left.V_{S, M S} / V_{T}\right)$. This relationship was associated with good agreement between the 

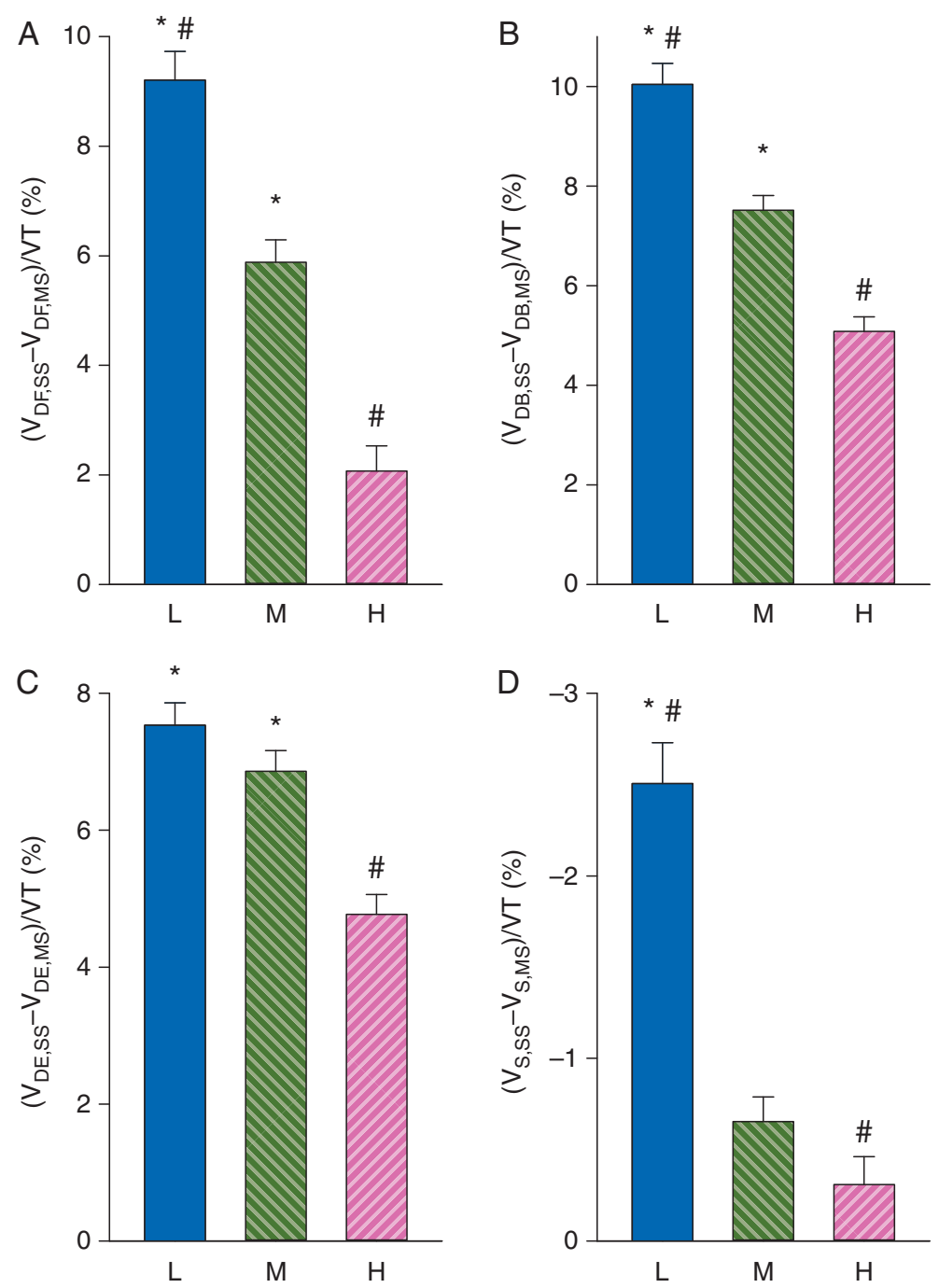

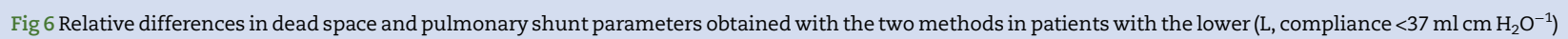
and higher $\left(\mathrm{H}\right.$, compliance $>53 \mathrm{ml} \mathrm{cm} \mathrm{H} \mathrm{O}^{-1}$ ) quartiles and medium $(\mathrm{M})$ interquartile range. ${ }^{*} \mathrm{P}<0.05$ us $\mathrm{H} ;{ }^{*} \mathrm{P}<0.05$ us $\mathrm{M}$.

Table 1 Mainstream capnographic parameter values, obtained with or without sidestream suctioning, and the corresponding P-values of

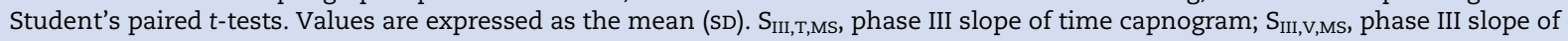
volumetric capnogram; $\mathrm{S}_{\mathrm{IIT}, \mathrm{MS}}$, phase II slope of time capnogram; $\mathrm{S}_{\mathrm{II}, \mathrm{V}, \mathrm{MS}}$, phase II slope of volumetric capnogram; $\mathrm{V}_{\mathrm{DF}, \mathrm{MS}} / \mathrm{V}_{\mathrm{T}}$, normalized Fowler dead space; $\mathrm{V}_{\mathrm{DB}, \mathrm{MS}} / \mathrm{V}_{\mathrm{T}}$, normalized Bohr dead space; $\mathrm{V}_{\mathrm{DE}, \mathrm{MS}} / \mathrm{V}_{\mathrm{T}}$, normalized Enghoff dead space; $\mathrm{V}_{\mathrm{s}, \mathrm{MS}} / \mathrm{V}_{\mathrm{T}}$, normalized difference between the Enghoff and Bohr dead spaces; $V_{T}$, tidal volume

\begin{tabular}{llllllllll}
\hline $\begin{array}{l}\text { Sidestream } \\
\text { suctioning }\end{array}$ & $\begin{array}{l}\mathrm{S}_{\mathrm{III}, \mathrm{T}, \mathrm{MS}} \\
\left(\mathrm{kPa} \mathrm{s}^{-1}\right)\end{array}$ & $\begin{array}{l}\mathrm{S}_{\mathrm{III}, \mathrm{V}, \mathrm{MS}} \\
\left(\mathrm{kPa} \mathrm{litre}^{-1}\right)\end{array}$ & $\begin{array}{l}\mathrm{S}_{\mathrm{II}, \mathrm{T}, \mathrm{MS}} \\
\left(\mathrm{kPa} \mathrm{s}^{-1}\right)\end{array}$ & $\begin{array}{l}\mathrm{S}_{\mathrm{II}, \mathrm{V}, \mathrm{MS}} \\
\left(\mathrm{kPa} \mathrm{litre}^{-1}\right)\end{array}$ & $\mathrm{V}_{\mathrm{DF}, \mathrm{MS}} / \mathrm{V}_{\mathrm{T}}$ & $\mathrm{V}_{\mathrm{DB}, \mathrm{MS}} / \mathrm{V}_{\mathrm{T}}$ & $\mathrm{V}_{\mathrm{DE}, \mathrm{MS}} / \mathrm{V}_{\mathrm{T}}$ & $\mathrm{V}_{\mathrm{s}, \mathrm{MS}} / \mathrm{V}_{\mathrm{T}}$ & $\mathrm{V}_{\mathrm{T}}(\mathrm{ml})$ \\
\hline On & $0.106(0.108)$ & $1.82(0.92)$ & $29.13(5.42)$ & $62.96(14.31)$ & $0.196(0.037)$ & $0.198(0.04)$ & $0.401(0.059)$ & $0.198(0.067)$ & $586(116)$ \\
Off & $0.109(0.104)$ & $1.85(0.92)$ & $29.03(5.36)$ & $62.19(14.23)$ & $0.195(0.036)$ & $0.198(0.04)$ & $0.403(0.058)$ & $0.199(0.065)$ & $590(116)$ \\
P-value & 0.4 & 0.19 & 0.39 & 0.18 & 0.21 & 0.11 & 0.13 & 0.4 & 0.003 \\
\hline
\end{tabular}

shunt volumes, with the sidestream method only slightly underestimating the mainstream values $\left[\mathrm{V}_{\mathrm{s}, \mathrm{SS}} / \mathrm{V}_{\mathrm{s}, \mathrm{MS}}=0.97\right.$ (0.004), $P<0.0001]$. The limit of agreement was $24 \mathrm{ml}$.

To reveal the effect of lung stiffness on the difference between the dead space and pulmonary shunt parameters determined by the mainstream and sidestream methods, Fig. 6 depicts the differences between mainstream and sidestream values as a function of $C$. Decreasing compliance resulted in an increasing overestimation of dead space and shunt parameters assessed by using the sidestream technique $(P<0.0001)$. 
In the supplemental measurements assessing the potential biasing effect of sidestream sampling flow on the mainstream parameters, no statistically significant differences were found in any of the mainstream capnogram parameters obtained with or without suctioning (Table 1; P>0.11), whereas a 3.64 (1.22) ml difference was found in $V_{T}(P<0.004)$.

\section{Discussion}

The results of the present study revealed that the sidestream capnography led to a dynamic distortion of the $\mathrm{CO}_{2}$ concentration curve compared with the mainstream approach regarded as a reference technique. ${ }^{32}$ Thus, the sidestream method biased the solid indices obtained from capnogram regions in which rapid changes in $\mathrm{CO}_{2}$ concentration occur (i.e. phase II slopes, the transition from phase II to III, the end-tidal portion, $\mathrm{V}_{\mathrm{CO}_{2}}$, and derived parameters, such as Fowler's and Bohr's dead space). However, the sidestream technique does provide a good approximation of capnogram parameters characterizing periods of low rates of change in $\mathrm{CO}_{2}$ (phase III slopes) and intrapulmonary shunt.

The differences between the sidestream and mainstream techniques can be explained by physical principles. The transport delay of the gas in the sampling tube is a well-described characteristic of the sidestream measurement system. ${ }^{17}$ This phenomenon introduces a predictable time lag in the detection of the $\mathrm{CO}_{2}$ concentration and gives rise to axial mixing of the gas residing in the sampling tube. ${ }^{2} 101119$ Axial in-line diffusion in both space and time occurs during the transport, depending on the $\mathrm{CO}_{2}$ gradient. ${ }^{32}$ This blurring process equilibrates the concentration differences between the gas compartments. ${ }^{26}$ Theoretically, the biasing effects of this adverse process can be diminished by shortening the sampling tube, increasing the suction flow rate, or both. Shortening the sampling tube (from 3 to $1.5 \mathrm{~m}$ ) in five additional patients led to fairly proportional improvements in the sidestream estimates to the ratio of the tube lengths $\left(\mathrm{S}_{\mathrm{II}, \mathrm{T}, \mathrm{SS}} / \mathrm{S}_{\mathrm{II}, \mathrm{T}, \mathrm{MS}}\right.$ of 37.4 and $60.2 \% ; \mathrm{V}_{\mathrm{DF}, \mathrm{SS}} / \mathrm{V}_{\mathrm{DF}, \mathrm{MS}}$ of 154.2 and $128.5 \%$ with long and short tubes, respectively). Likewise, increasing the sampling flow rate decreased the difference between sidestream and mainstream estimates $\left(\mathrm{S}_{\mathrm{II}, \mathrm{T}, \mathrm{SS}} / \mathrm{S}_{\mathrm{II}, \mathrm{T}, \mathrm{MS}}\right.$ of 47 and $76 \% ; S_{\text {III,T,SS }} / S_{\text {III,T,MS }}$ of 146 and $99 \%$ for suction rates of 100 and $350 \mathrm{ml} \mathrm{min}^{-1}$, respectively). These results suggest the possibility of improving the accuracy of shape factor estimates by using sidestream capnography.

A further factor contributing to the distortion of the sidestream capnogram is the variable sampling flow rate resulting from the alternating positive airway pressure during mechanical ventilation. ${ }^{19} 20$ Given that this phenomenon acts during inspiratory-expiratory phase transitions, it ultimately modifies the ascending and descending limbs of the capnograms. ${ }^{19} 20$

The physical principles described above are of less importance in the assessment of the capnogram phase III slope. The reason for the good correlation and agreement (Fig. $3 \mathrm{~A}$ and $\mathrm{B}$ ) is the relatively steady-state $\mathrm{CO}_{2}$ concentration (Fig. 1) and constant gas sampling flow during this period (Fig. 2). In the only previous study where the sidestream and mainstream phase III slopes were compared, substantially greater differences were observed in infants, which can be attributed to the higher ventilation rate $(\sim 32 \mathrm{bpm}) .{ }^{26}$

The initial part of the capnogram, comprising the phase II slopes, angle $\alpha$, and $V_{\mathrm{DF}}$, coincides with a high rate of change in the $\mathrm{CO}_{2}$ concentration and with sudden pressure alterations in the breathing circuit causing variable sampling flow rate ${ }^{20}$ in the tube of the sidestream capnograph. Consequently, in agreement with previous results on ventilated infants, ${ }^{26}$ the phase II slope of the sidestream capnogram is lower than that obtained by the mainstream technique (Fig. 1, bottom panel, and Fig. 4B). This reduction in $\mathrm{S}_{\mathrm{II}, \mathrm{T}, \mathrm{SS}}$ of necessity infers weak relationships between the anatomical dead spaces, $V_{\mathrm{DF}, \mathrm{MS}}$ and $\mathrm{V}_{\mathrm{DF}, \mathrm{SS}}$ (Fig. 4D), and the sidestream-derived $\alpha_{S S}$ (Fig. 4C).

The ventilation-perfusion mismatch can be divided into alveolar dead space ventilation and shunt perfusion. ${ }^{314}$ We obtained fairly weak correlations and agreements of both the normalized Bohr and Enghoff dead space fractions. The correlation analyses revealed that these dissociations can be ascribed to the discrepancies in the $P \overline{\mathrm{E}}_{\mathrm{CO}_{2}}$, resulting from the dynamic distortion of the sidestream capnogram (e.g. Fig. 1). Taking the difference between the Enghoff and Bohr dead spaces eliminates these discrepancies, which explains the excellent correlations and good agreement between $\mathrm{V}_{\mathrm{s}, \mathrm{MS}}$ and $\mathrm{V}_{\mathrm{s}, \mathrm{SS}}$ (Fig. $5 \mathrm{C}$ and $\mathrm{D}$ ). The differences between the two estimates in the dead space and shunt parameters depend on the level of $C$, with the greatest deviations in patients with low compliance (Fig. 6). Around the ventilation frequency, the respiratory system impedance is dominated by the elastic forces. Given that low compliance involves higher airway pressures, variations in sampling flow rate are expected to be augmented within the respiratory cycle in the presence of increased stiffness. This implies that the use of dead space parameters determined by the sidestream technique might result in false interpretations. Conversely, the assessment of the shunt fraction is feasible by using sidestream capnography, although a slight underestimation is expected in patients with a less compliant respiratory system.

Our measurements demonstrate that the most frequently used capnogram parameter, the $\mathrm{PET}_{\mathrm{CO}_{2}}$, is underestimated by a value with clinically minimal relevance $(0.025 \mathrm{kPa})$. This concordance between the two techniques supports the conclusions of previous studies. ${ }^{23} 25$

As a methodological aspect, we assessed whether gas sampling to the sidestream capnograph affects the shape of the mainstream capnogram resulting from the juxtaposed position of the mainstream sensor. However, the lack of differences in any of the mainstream parameters revealed that this effect has negligible impact on the mainstream parameters. This lack of sensitivity can also be anticipated from the amount of aspirated volume being about two orders of magnitude smaller than the $\mathrm{V}_{\mathrm{T}}$.

In conclusion, we provide evidence that sidestream capnography allows reliable measurement of $\mathrm{PET}_{\mathrm{CO}_{2}}$, time and volumetric phase III slopes, and the intrapulmonary shunt fraction. Thus, sidestream capnography is suitable for quantification of the unevenness of the alveolar ventilation and the ventilationperfusion mismatch. However, reliable assessments of the phase II slope, the anatomical and physiological dead spaces, and the rate of elimination of $\mathrm{CO}_{2}$ necessitate the combined application of mainstream volumetric capnography and sophisticated bedside information technology tools.

\section{Authors' contributions}

Study design: F.P., B.B.

Patient recruitment: Z.C., B.B.

Custom-made software design for data collection: G.H.F., J.T.

Data collection: A.L.B., Z.C.

Data analysis: A.L.B., F.P., G.H.F., B.B.

Interpretation of data: A.L.B., G.H.F., J.T., B.B.

Writing up the paper: A.L.B., F.P., B.B.

All authors contributed to revising the manuscript critically for important intellectual content. 


\section{Acknowledgements}

The authors wish to thank Edit Vigh and Kitti Nevery for contributing to the patient recruitment and data collection.

\section{Funding}

Hungarian Scientific Research Grant (OTKA K81179 and K115253); European Union and the State of Hungary; European Social Fund (in the framework of TÁMOP 4.2.6 'National Excellence Program' and TÁMOP-4.2.2.D-15/1/KONV-2015-0024).

\section{References}

1. Ortega R, Connor C, Kim S, Djang R, Patel K. Monitoring ventilation with capnography. N Engl J Med 2012; 367: e27

2. Thompson JE, Jaffe MB. Capnographic waveforms in the mechanically ventilated patient. Respir Care 2005; 50: 100-8; discussion 108-9

3. Tusman G, Sipmann FS, Bohm SH. Rationale of dead space measurement by volumetric capnography. Anesth Analg 2012; 114: 866-74

4. Bhavani-Shankar K, Moseley H, Kumar AY, Delph Y. Capnometry and anaesthesia. Can J Anaesth 1992; 39: 617-32

5. Walsh BK, Crotwell DN, Restrepo RD. Capnography/capnometry during mechanical ventilation: 2011. Respir Care 2011; 56: 503-9

6. American Society of Anesthesiologists. Standards for basic anesthetic monitoring. 2015. Available from http://www.asahq. org/ /media/Sites/ASAHQ/Files/Public/Resources/standardsguidelines/standards-for-basic-anesthetic-monitoring.pdf (accessed 14 March 2016)

7. Krauss B, Deykin A, Lam A, et al. Capnogram shape in obstructive lung disease. Anesth Analg 2005; 100: 884-8

8. Babik B, Csorba Z, Czovek D, Mayr PN, Bogats G, Petak F. Effects of respiratory mechanics on the capnogram phases: importance of dynamic compliance of the respiratory system. Crit Care 2012; 16: R177

9. Ioan I, Demoulin B, Duvivier C, et al. Frequency dependence of capnography in anesthetized rabbits. Respir Physiol Neurobiol 2014; 190: 14-9

10. Strömberg NO, Gustafsson PM. Ventilation inhomogeneity assessed by nitrogen washout and ventilation-perfusion mismatch by capnography in stable and induced airway obstruction. Pediatr Pulmonol 2000; 29: 94-102

11. Anderson CT, Breen PH. Carbon dioxide kinetics and capnography during critical care. Crit Care 2000; 4: 207-15

12. Blanch L, Lucangelo U, Lopez-Aguilar J, Fernandez R, Romero PV. Volumetric capnography in patients with acute lung injury: effects of positive end-expiratory pressure. Eur Respir J 1999; 13: 1048-54

13. Tusman G, Suarez-Sipmann F, Bohm SH, et al. Monitoring dead space during recruitment and PEEP titration in an experimental model. Intensive Care Med 2006; 32: 1863-71

14. Tusman G, Sipmann FS, Borges JB, Hedenstierna G, Bohm SH. Validation of Bohr dead space measured by volumetric capnography. Intensive Care Med 2011; 37: 870-4
15. Tusman G, Bohm SH, Sipmann FS, Maisch S. Lung recruitment improves the efficiency of ventilation and gas exchange during one-lung ventilation anesthesia. Anesth Analg 2004; 98: 1604-9

16. Brunner JX, Westenskow DR. How the rise time of carbon dioxide analysers influences the accuracy of carbon dioxide measurements. Br J Anaesth 1988; 61: 628-38

17. Breen PH, Mazumdar B, Skinner SC. Capnometer transport delay: measurement and clinical implications. Anesth Analg 1994; 78: 584-6

18. Schena J, Thompson J, Crone RK. Mechanical influences on the capnogram. Crit Care Med 1984; 12: 672-4

19. Epstein RA, Reznik AM, Epstein MA. Determinants of distortions in $\mathrm{CO}_{2}$ catheter sampling systems: a mathematical model. Respir Physiol 1980; 41: 127-36

20. Farmery AD, Hahn CE. A method of reconstruction of clinical gas-analyzer signals corrupted by positive-pressure ventilation. J Appl Physiol 2001; 90: 1282-90

21. Jaffe MB. Mainstream or sidestream capnography? Respironics White Paper 2002. Available from http://www. oem.respironics.com/Downloads/Main\%20vs\%20Side.pdf (accessed 14 March 2016)

22. Teixeira Neto FJ, Carregaro AB, Mannarino R, Cruz ML, Luna SP. Comparison of a sidestream capnograph and a mainstream capnograph in mechanically ventilated dogs. J Am Vet Med Assoc 2002; 221: 1582-5

23. McEvedy BA, McLeod ME, Kirpalani H, Volgyesi GA, Lerman J. End-tidal carbon dioxide measurements in critically ill neonates: a comparison of side-stream and mainstream capnometers. Can J Anaesth 1990; 37: 322-6

24. Pekdemir M, Cinar O, Yilmaz S, Yaka E, Yuksel M. Disparity between mainstream and sidestream end-tidal carbon dioxide values and arterial carbon dioxide levels. Respir Care 2013; 58: $1152-6$

25. Sakata DJ, Matsubara I, Gopalakrishnan NA, et al. Flowthrough versus sidestream capnometry for detection of end tidal carbon dioxide in the sedated patient. J Clin Monit Comput 2009; 23: 115-22

26. Pascucci RC, Schena JA, Thompson JE. Comparison of a sidestream and mainstream capnometer in infants. Crit Care Med 1989; 17: 560-2

27. Fowler W. The respiratory dead space. Am J Physiol 1948; 54: 405-16

28. Bohr C. Über die Lungenatmung. Skan Arch Physiol 1891; 53: 236-8

29. Enghoff H. Volumen inefficax: Bemerkungen zur Frage des schädlichen Raumes. Upsala Läkareforen Forhandl 1938; 44: 191-218

30. Bland M. How can I decide the sample size for a study of agreement between two methods of measurement? 2004. Available from https://www-users.york.ac.uk/ mb55/meas/ sizemeth.htm (accessed 14 March 2016)

31. Bland JM, Altman DG. Statistical methods for assessing agreement between two methods of clinical measurement. Lancet 1986; 1: 307-10

32. Gravenstein JS, Jaffe MB, Gravenstein N, Paulus DA. Technical Perpectives. Capnography. Cambridge: Cambridge University Press, 2011; 381-96 
II. 


\title{
Sevoflurane Relieves Lung Function Deterioration After Cardiopulmonary Bypass
}

\author{
Adam L. Balogh, MD*,†, Ferenc Peták, PhD ${ }^{\dagger, 1}$, \\ Gergely H. Fodor, MD, PhD , Roberta Sudy, MD*, , \\ Barna Babik, MD, PhD* \\ *Department of Anesthesiology and Intensive Therapy, University of Szeged, Szeged, Hungary \\ ${ }^{\dagger}$ Department of Medical Physics and Informatics, University of Szeged, Szeged, Hungary
}

Objective: To investigate sevoflurane's potential to alleviate the detrimental pulmonary changes after cardiopulmonary bypass (CPB).

Design: Prospective, randomized clinical investigation.

Setting: University hospital.

Participants: One hundred ninety patients undergoing elective cardiac surgery.

Interventions: Ninety-nine patients under intravenous anesthesia were administered 1 minimal alveolar concentration sevoflurane for 5 minutes after being weaned from CPB (group SEV); intravenous anesthesia was maintained in the other 91 patients (group CTRL).

Measurements and Main Results: Measurements were performed with open chest: before CPB, after CPB, and after intervention. The lungs' mechanical impedance and capnogram traces were recorded, arterial and central venous blood samples were analyzed, and lung compliance was documented. Airway resistance, tissue damping, and elastance were obtained from the impedance spectra. The capnogram phase III slope was determined using linear regression. The partial pressure of oxygen in the arterial blood/fraction of inspired oxygen ratio and shunt fraction were calculated from blood gas parameters. After CPB, sevoflurane induced bronchodilation, reflected in marked drops in airway resistance and smaller improvements in lung tissue viscoelasticity indicated by decreases in tissue damping and elastance. These changes were reflected in a decreased capnogram phase III slope and shunt fraction and increased partial pressure of oxygen in the arterial blood/fraction of inspired oxygen ratio and lung compliance. The more severe deteriorations that occurred after CPB, the greater improvements by sevoflurane were observed. Conclusions: Sevoflurane can alleviate CPB-induced bronchoconstriction, compromised lung tissue mechanics, and enhanced intrapulmonary shunt. This benefit has particular importance in patients with severe CPB-induced lung function deterioration.

(c) 2017 Elsevier Inc. All rights reserved.

Key Words: inhalation anesthesia; extracorporeal circulation; respiratory mechanics; capnography; ventilation, heterogeneity

Q1 VOLATILE ANESTHETICS have marked relaxation potential on the airway smooth muscle, resulting in complex pulmonary consequences. Their bronchodilator activity against an elevated bronchial tone caused by exogenous constrictor agonists has been proved consistently in experimental studies. $^{1-3}$ Airway dilation by volatile agents also has been

\footnotetext{
${ }^{1}$ Address reprint requests to Ferenc Peták, $\mathrm{PhD}$, Department of Medical Physics and Informatics, University of Szeged, H-6720 Szeged, Korányi fasor 9, Hungary.

E-mail address: petak.ferenc@med.u-szeged.hu (F. Peták).
}

confirmed after endogenous release of constrictor mediators in clinical investigations; elevations in the airway tone in these previous clinical studies were induced by administering thiopental and succinylcholine and/or performing endotracheal intubation. ${ }^{4,5}$

Another relevant trigger of perioperative bronchoconstriction is cardiopulmonary bypass (CPB) applied during open heart surgery. ${ }^{6,7}$ The use of this technique induces welldescribed multimodal detrimental changes in the lungs. ${ }^{8}$ The systemic inflammatory response is initiated by contact activation, ischemia-reperfusion, and endotoxemia, which are 
followed by the activation of complement, cytokine, and coagulation/fibrinolysis cascades, ${ }^{9-11}$ which in turn result in leukocyte activation. ${ }^{12}$ Free oxygen radicals, plateletactivating factor, and leukotrienes increase vascular permeability and interstitial edema. ${ }^{13}$ Furthermore, mast cells and basophils release bronchoactive mediators, such as histamine and serotonin. ${ }^{14,15}$ The subsequent overall pulmonary dysfunction can be manifested in important clinical pathologies, such as airway constriction, atelectasis, hypoxemia, elevated right heart afterload, and reduced systemic venous return.

Sevoflurane is among the most commonly used volatile anesthetics with beneficial pharmacokinetic properties, includ-

Q2 ing an advantageous bronchial effect compared with other volatile anesthetics. ${ }^{4}$ The effects of sevoflurane on lung function have been investigated extensively in humans and animal models. However, in these studies simple bronchial challenges were applied, mainly inducing specific bronchoconstriction of cholinergic or histaminergic origin. ${ }^{1,16,17}$ Even though the beneficial pulmonary profile of sevoflurane after $\mathrm{CPB}$ can be anticipated, the only previous study to investigate its effects on the lungs after this complex challenge was limited to demonstrating beneficial changes in leukocyte counts and interleukin levels. ${ }^{18}$ Furthermore, the effect of sevoflurane on lung functional changes, particularly increased interstitial edema and ventilation heterogeneity after $\mathrm{CPB}$, have not been investigated. The authors therefore aimed to characterize the therapeutic potential of this volatile agent against adverse pulmonary changes induced by CPB by assessing airway and lung tissue mechanics, ventilation heterogeneity, ventilation/perfusion mismatch, and gas exchange. The authors hypothesized that after deleterious lung function changes to $\mathrm{CPB}$, the expected bronchodilation by sevoflurane is associated with improvements in lung tissue viscoelasticity and diminished ventilation heterogeneities, which may enhance oxygenation.

\section{Methods}

\section{Patients}

The protocol was approved by the Human Research Ethics Committee, University of Szeged, Hungary (No. WHO 2788). Patients undergoing elective open heart surgery were enrolled in the study between September 2014 and November 2015; the process is shown in Figure 1. Inclusion criteria were an ejection fraction $>30 \%$, a body mass index $<35 \mathrm{~kg} / \mathrm{m}^{2}$, and a lack of endocarditis. Written, informed consent was obtained from the patients participating in the study, who then were randomly assigned to the sevoflurane group (SEV) or the control group (CTRL). Measurement data of 190 participants (SEV [n = 99], CTRL [n $=91$ ]; 107 males, 83 females, 63 y of age [range 32-85 y]) were included in the analysis. Table 1 summarizes the demographic, anthropometric, and clinical characteristics of the patients.
Anesthesia and Surgery

The patients were premedicated with intramuscular morphine $(0.07 \mathrm{mg} / \mathrm{kg})$ and midazolam $(0.07 \mathrm{mg} / \mathrm{kg}) 1$ hour before the surgery. Anesthesia was induced with intravenous (IV) Q3 midazolam $(30 \mu \mathrm{g} / \mathrm{kg})$, sufentanil $(0.4-0.5 \mu \mathrm{g} / \mathrm{kg})$, and propofol $(0.3-0.5 \mathrm{mg} / \mathrm{kg})$ and was maintained with an IV infusion of propofol $(50 \mu \mathrm{g} / \mathrm{kg} / \mathrm{min})$. Neuromuscular blockade was achieved with IV boluses of rocuronium $(0.6 \mathrm{mg} / \mathrm{kg}$ for induction and $0.2 \mathrm{mg} / \mathrm{kg}$ every $30 \mathrm{~min}$ for maintenance).

A cuffed tracheal tube with an internal diameter of 7,8 , or $9 \mathrm{~mm}$ was used for tracheal intubation, and patients were ventilated with a Dräger Zeus anesthesia machine (Dräger, Lübeck, Germany) in volume-controlled mode with descending flow. Ventilation frequency was set to 12 to 14 breaths/ minute, and a tidal volume of $7 \mathrm{~mL} / \mathrm{kg}$ and a positive endexpiratory pressure of $4 \mathrm{cmH}_{2} \mathrm{O}$ were applied. Mechanical ventilation was initiated with a fraction of inspired oxygen $\left(\mathrm{F}_{\mathrm{I}} \mathrm{O}_{2}\right)$ of 0.5 that was set to 0.8 after CPB.

Before $\mathrm{CPB}$, the membrane oxygenator was primed with $1,500 \mathrm{~mL}$ of lactated Ringer's solution. Heparin was administered at a dose of $300 \mathrm{U} / \mathrm{kg}$, with the anticoagulation time maintained at 300 seconds. Moderate hypothermia was induced routinely (esophageal temperature of $32^{\circ} \mathrm{C}$ ). During $\mathrm{CPB}$, mechanical ventilation was stopped, and the ventilator was disconnected without applying positive airway pressure. Before restoring ventilation, the lungs were inflated 3 to 5 times to a peak airway pressure of $30 \mathrm{cmH}_{2} \mathrm{O}$ to facilitate lung recruitment.

\section{Forced Oscillatory Measurements}

Changes in the airway and tissue mechanical properties from CPB and sevoflurane were assessed by measuring the low-frequency forced oscillatory input impedance of the lungs, as detailed previously. ${ }^{6}$ Briefly, a T-piece with 2 collapsible segments was attached to the distal tracheal tube, with one end connected to the respirator and the other end to a loudspeakerin-box system. This apparatus made it possible to switch the patient from the respirator to the forced oscillatory setup during the measurements. These were performed by introducing pseudorandom pressure excitations generated by the loudspeaker into the trachea during short (15 s) apneic pauses introduced into the mechanical ventilation. The forcing signal consisted of 15 integer multiple components of the $0.4 \mathrm{~Hz}$ fundamental frequency, between 0.4 and $6 \mathrm{~Hz}$. A $28 \mathrm{~mm}$ ID screen pneumotachograph connected to a differential pressure transducer (ICS model 33NA002D; IC Sensors, Milpitas, CA) was used to measure tracheal airflow. An identical pressure transducer was used to detect airway opening pressure. Lung input impedance was computed from the power spectra of airway opening pressure and tracheal airflow and then ensemble-averaged under each condition. The mean lung impedance data were fitted using a well-validated 4-parameter model $^{19}$ containing a frequency-independent airway resistance (Raw) and inertance (Iaw) and a constant-phase tissue compartment characterized by the coefficients of damping $(G)$ and 
Table 1

Demographic, Anthropometric, and Clinical Characteristics of the Patients.
CTRL $(\mathrm{n}=91)$

$\begin{array}{cc}54 / 37 & 53 / 46 \\ 65 \pm 14 & 63 \pm 14 \\ 167 \pm 9 & 168 \pm 10 \\ 79 \pm 16 & 82 \pm 16\end{array}$

Age, y

Height, cm

Weight, $\mathrm{kg}$

Surgery

AVR/AVP

$\mathrm{AVR}+\mathrm{CABG}$

MVM/MVP

Other

Respiratory comorbidities

Asthma

Emphysema

NOTE. Anthropometric data are presented as mean \pm standard deviation. Abbreviations: AVR/AVP, aortic valve replacement/plasty; CABG, coronary artery bypass grafting; MVR/MVP, mitral valve replacement/plasty; Other, left atrial myxoma removal, tricuspid valve plasty, atrial septal defect closure, ascending aorta aneurysm repair. elastance $(\mathrm{H})$ such that the difference between measured and modeled impedance values were minimal. Lung tissue hysteresivity was calculated as $\eta=\mathrm{G} / \mathrm{H}$. Raw represents the flow resistance of the bronchial tree, and Iaw is related to the mass of the gas in the airways. The tissue parameters characterize the resistive $(\mathrm{G})$ and elastic properties of the lung parenchyma $(H)$, and $\eta$ reflects the coupling between the resistive and elastic properties.

\section{Recording and Analyses of the Expiratory Capnogram}

Changes in carbon dioxide $\left(\mathrm{CO}_{2}\right)$ partial pressure in the exhaled gas during mechanical ventilation were measured with a calibrated mainstream capnograph (Novametrix Capnogard; Andover, MA). The measured signals were digitized at a sampling frequency of $102.4 \mathrm{~Hz}$ and stored on a computer.

Custom-made software was used to determine the capnogram parameters. The phase III slope of the time capnogram ( $\left.\mathrm{S}_{\text {III }}\right)$ was assessed by fitting a linear regression line to the last 
$160 \%$ of phase III. ${ }^{20-22}$ Likewise, the phase II slope $\left(\mathrm{S}_{\text {II }}\right)$ was obtained by fitting a regression line to the points within $20 \%$ of time around the inflexion point of phase II. ${ }^{23}$

\section{Analyses of Blood Gas}

The partial pressure of oxygen in the arterial blood $\left(\mathrm{PaO}_{2}\right)$ was determined from arterial blood gas samples for the $\mathrm{PaO}_{2}$ / $\mathrm{F}_{\mathrm{I}} \mathrm{O}_{2}$ ratio and the arterial-to-end-tidal $\mathrm{CO}_{2}$ gradient $\left(\mathrm{P}_{\mathrm{a}}\right.$ $\mathrm{ET} \mathrm{CO}_{2}$ ). The intrapulmonary shunt fraction (Qs/Qt) was determined using the Berggren equation ${ }^{24}$ : Qs $/ \mathrm{Qt}=\left(\mathrm{CcO}_{2}\right.$ $\left.-\mathrm{CaO}_{2}\right) /\left(\mathrm{CcO}_{2}-\mathrm{CvO}_{2}\right)$, where $\mathrm{CcO}_{2}, \mathrm{CaO}_{2}$, and $\mathrm{CvO}_{2}$ are the oxygen contents of the pulmonary capillary and arterial and central venous blood, respectively. $\mathrm{CcO}_{2}$ was calculated according to the alveolar gas equation, assuming the oxygen saturation of hemoglobin in the pulmonary capillaries to be $100 \%: \mathrm{CcO}_{2}=1.34 \mathrm{~mL} / \mathrm{g} \times \mathrm{Hb}+\mathrm{Sol} \times$ $\left(\mathrm{F}_{\mathrm{I}} \mathrm{O}_{2} \times 713 \mathrm{mmHg}-\mathrm{PaCO}_{2} / 0.8\right)$, where $1.34 \mathrm{~mL} / \mathrm{g}$ is Hüfner's constant, $\mathrm{Hb}$ is the hemoglobin concentration in Q6 grams, Sol is $0.0031 \mathrm{~mL} / 100 \mathrm{~mL} / \mathrm{mmHg}, 713 \mathrm{mmHg}$ is the total dry gas pressure, $\mathrm{PaCO}_{2}$ is the partial pressure of $\mathrm{CO}_{2}$ in the arterial blood, and 0.8 is the respiratory exchange ratio.

\section{Measurement Protocol}

The scheme of the experimental protocol is outlined in Figure 2. When stable hemodynamic and respiratory mechanical conditions had been reached after sternotomy, baseline measurements were performed 5 minutes before starting CPB. Measurements included recordings of four 15-second capnogram traces; analyses of arterial and central venous blood gas samples (Radiometer ABL TM 505; Radiometer, Copenhagen, Denmark); registration of the dynamic respiratory compliance

Q7 displayed by the ventilator (C); and collection of $4 \mathrm{ZL}$ data epochs. The same set of data was gathered 5 minutes after weaning the patient from $\mathrm{CPB}$, when stable circulatory and ventilator conditions were reestablished. Subsequently, in group SEV, 1 age-related minimal alveolar concentration $(\mathrm{MAC})^{25}$ of sevoflurane was achieved by setting the vaporizer to $1.4 \%$ to $1.9 \%$ and the fresh gas flow to $16 \mathrm{~L} / \mathrm{min}$, and maintained for 5 minutes with a fresh gas flow of $2 \mathrm{~L} / \mathrm{min}$. This interval was chosen based on a previous study, in which respiratory mechanics were found to reach a steady-state condition after administering 1 MAC sevoflurane for 5 minutes after the peak effect an allergen provocation in rabbits. ${ }^{16}$ Ventilation was maintained without intervention in the patients in group CTRL for a matching period. The third data collection step was taken in the same manner, as detailed earlier in both groups of patients.

\section{Statistical Analyses}

Sample size was estimated for a 2-way repeated measures analysis of variance on $\mathrm{H}$ as the primary outcome variable with an expected effect size of 0.2 (ie, an approximately $20 \%$ change after sevoflurane); a power of 0.8 ; and 2-sided alpha error of $0.05 .^{26}$ The estimation resulted in a required sample size of 97 for each group.

Two-sample $t$ tests were applied to compare mean age, height, and weight among the protocol groups. The chi-square test was used to test the independence of group allocation and sex and the distribution of surgery types within each group.

Scatters in measured variables are expressed as standard error of the mean. The normality of the data was tested using the Kolmogorov-Smirnov test with a Lilliefors correction. Two-way repeated measures analysis of variance with the inclusion of an interaction term was used for all measured variables, with the protocol stage as within-subject factor (before CPB, after CPB, and after intervention) and group allocation as between-subject factor (group SEV or group CTRL) to establish the effects of CPB and the subsequent administration of sevoflurane. The Holm-Sidak multiple comparison procedure was adopted to compare the variables in the various study groups at different protocol stages. When comparing 2 samples, the Student $t$ test was used for normality and the Mann-Whitney rank sum test otherwise. The statistical tests were performed with a SigmaPlot statistical software package, Version 13 (Systat, San Jose, CA). All reported p values are 2 -sided.
Fig 2. Timeline for the experimental protocol. Measurements were performed with open chest condition at the following 3 stages of cardiac surgery: before starting $\mathrm{CPB}, 5$ minutes after weaning from CPB, and after 5 minutes of intervention (administration of sevoflurane at 1 MAC [group SEV] or unaltered anesthesia management [group CTRL]). At each stage, arterial and central venous blood gas samples were analyzed, the dynamic lung compliance displayed by the ventilator was documented, four 15-second capnogram traces were recorded, and 4 impedance measurements (ZL) were performed. 

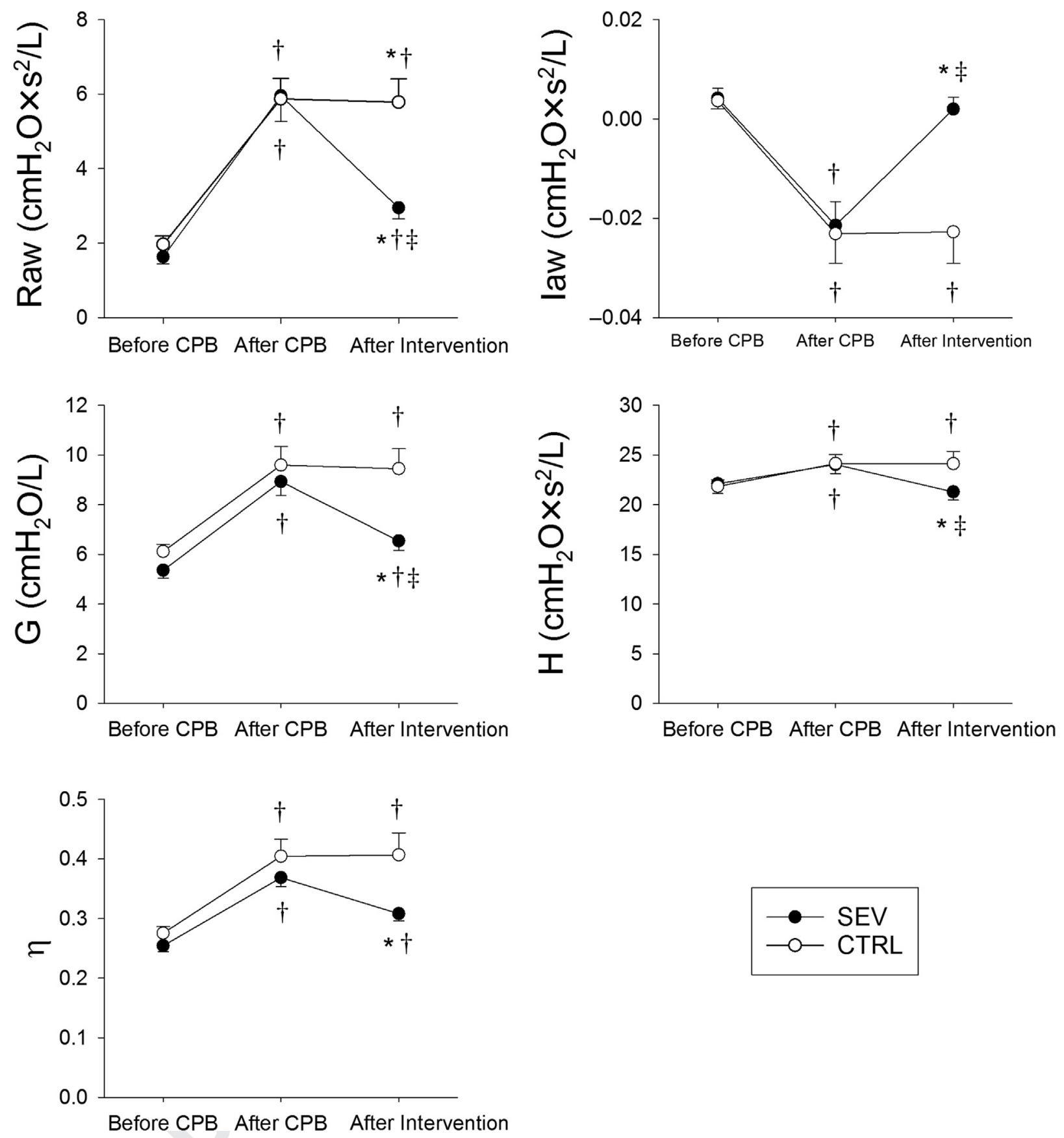

Fig 3. Forced oscillatory airway (Raw: airway resistance; Iaw: airway inertance) and tissue (G: tissue damping; H: tissue elastance; $\eta$ : tissue hysteresivity) parameters in the group treated with sevoflurane at $1 \mathrm{MAC}$ for 5 minutes (SEV) and the control group with intravenous anesthesia maintained (CTRL). Error bars represent standard error of the mean. * $\mathrm{p}<0.05$ versus condition "after $\mathrm{CPB}$ " within a group; ${ }^{\dagger} \mathrm{p}<0.05$ versus condition "before $\mathrm{CPB}$ " within a group; ${ }^{\ddagger} \mathrm{p}<0.05$ between protocol groups within a stage.

\section{Results}

No significant difference was found between the protocol groups in age, height, or weight. The distribution of sex, surgery types, and respiratory comorbidities were independent of group allocation (Table 1).

Airway and lung tissue mechanical parameters in both protocol groups at the different stages of the study protocol are demonstrated in Figure 3. The CPB-induced changes in any of the measured parameters in group CTRL were not significantly different from those in group SEV. CPB induced Q9 a significant change in all the mechanical parameters, with the most pronounced elevations in Raw (pooled changes of $287 \% \pm 17 \%)$, marked decreases in Iaw $(-0.025 \pm 0.002$ $\left.\mathrm{cmH}_{2} \mathrm{O} \times \mathrm{s}^{2} / \mathrm{L}\right)$, and increases in $\mathrm{G}(98 \% \pm 27 \%)$, whereas rises in $\mathrm{H}$ and $\eta$ were smaller $(15 \% \pm 2.3 \%$ and $86 \% \pm$ $32 \%$, respectively; $\mathrm{p}<0.0005$ for all). Sevoflurane induced marked drops in Raw $(-43 \% \pm 1.9 \%, \mathrm{p}<0.001)$; rises in Iaw $\left(-0.024 \pm 0.003 \mathrm{cmH}_{2} \mathrm{O} \times \mathrm{s}^{2} / \mathrm{L}\right)$; reductions in $\mathrm{G}$ $(-23 \% \pm 2.9 \%, \mathrm{p}<0.001$ for all $)$; and moderate decreases 

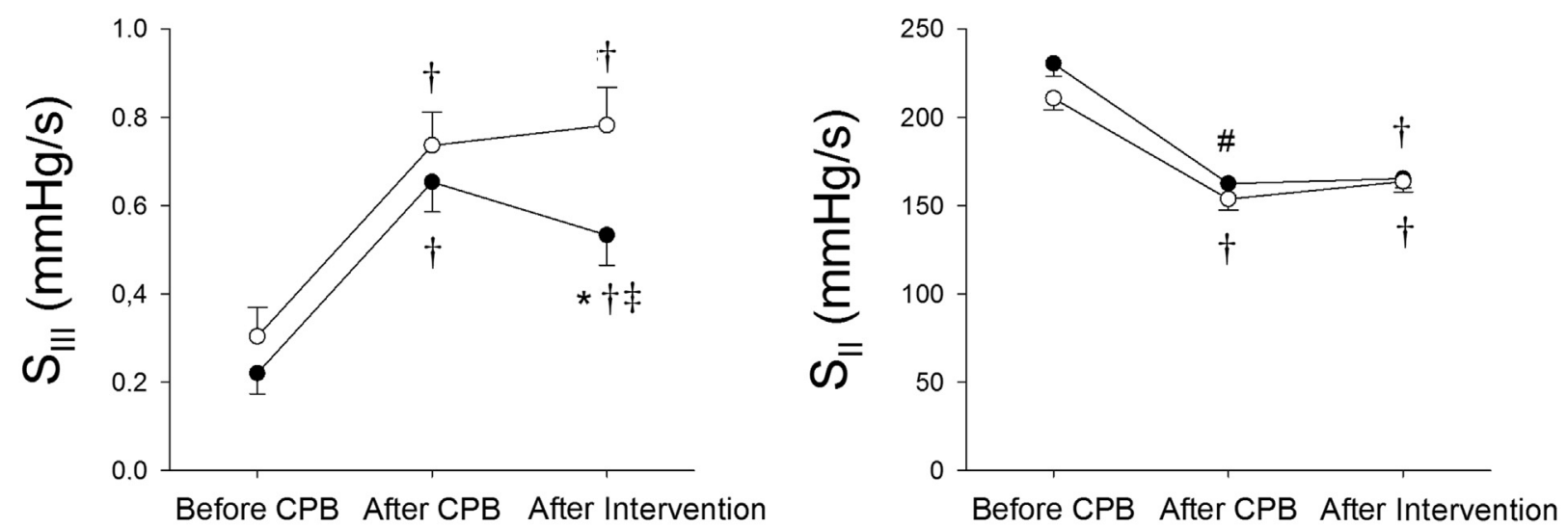

Before CPB After CPB After Intervention
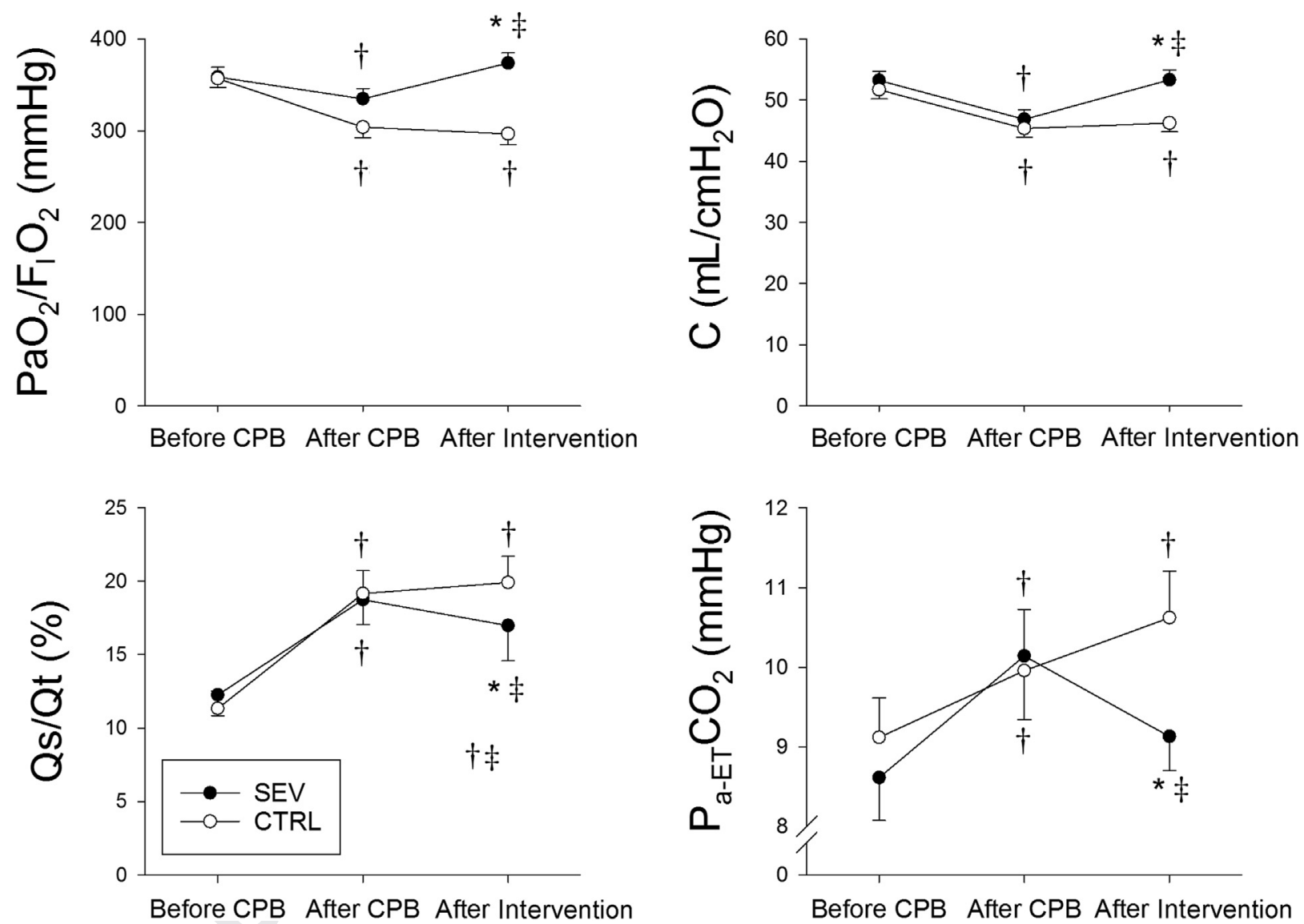

Fig 4. Phase III ( $\left.\mathrm{S}_{\mathrm{III}}\right)$ and phase II slopes ( $\left.\mathrm{S}_{\mathrm{II}}\right)$ of time capnograms, lung compliance (C), $\mathrm{PaO}_{2} / \mathrm{F}_{\mathrm{I}} \mathrm{O}_{2}$ ratio, intrapulmonary shunt fraction (Qs/Qt), and arterial to end-tidal $\mathrm{CO}_{2}$ gradient $\left(\mathrm{P}_{\mathrm{a}-\mathrm{ET}} \mathrm{CO}_{2}\right)$ in the group treated with sevoflurane at $1 \mathrm{MAC}$ for 5 minutes (SEV) and the control group (CTRL). Error bars represent the standard error of the mean. *p $<0.05$ versus condition "after CPB" within a group; ${ }^{\dagger} \mathrm{p}<0.05$ versus condition "before CPB" within a group; ${ }^{\ddagger} \mathrm{p}<0.05$ between protocol groups within a stage.

in $\mathrm{H}(-10 \% \pm 2.0 \%, \mathrm{p}<0.001)$ and $\eta(9.0 \% \pm 4.0 \%, \mathrm{p}<$ 0.02). There was no evidence of a statistically significant detectable change in any of the parameters in the corresponding time-matched changes in group CTRL.

Capnogram phase slopes, lung compliance, and parameters associated with oxygenation are demonstrated in Fig 4. The phase III slope of the capnogram exhibited markedly significant increases after CPB in both protocol groups, with pooled Q10 changes of $0.46 \pm 0.04 \mathrm{mmHg} / \mathrm{s}(\mathrm{p}<0.0001)$. After application of sevoflurane, $\mathrm{S}_{\mathrm{III}}$ decreased $(-0.15 \pm$ $0.036 \mathrm{mmHg} / \mathrm{s}, \mathrm{p}<0.02$ ), whereas $\mathrm{S}_{\mathrm{III}}$ did not change significantly in group CTRL. No significant difference was found in $\mathrm{S}_{\text {II }}$ between the protocol groups at any stage $(\mathrm{p}>$ $0.13)$. The phase II slope decreased markedly after CPB $(28 \%$ $\pm 1.5 \%, \mathrm{p}<0.0001)$ and increased slightly at the last stage in both groups $(9.8 \% \pm 1.8 \%, \mathrm{p}<0.02)$. The changes in the $\mathrm{PaO}_{2} / \mathrm{F}_{\mathrm{I}} \mathrm{O}_{2}$ ratio, $\mathrm{C}$, Qs/Qt, and $\mathrm{P}_{\mathrm{a}-\mathrm{ET}} \mathrm{CO}_{2}$ subsequent to $\mathrm{CPB}$ did not differ significantly between the protocol groups. The 

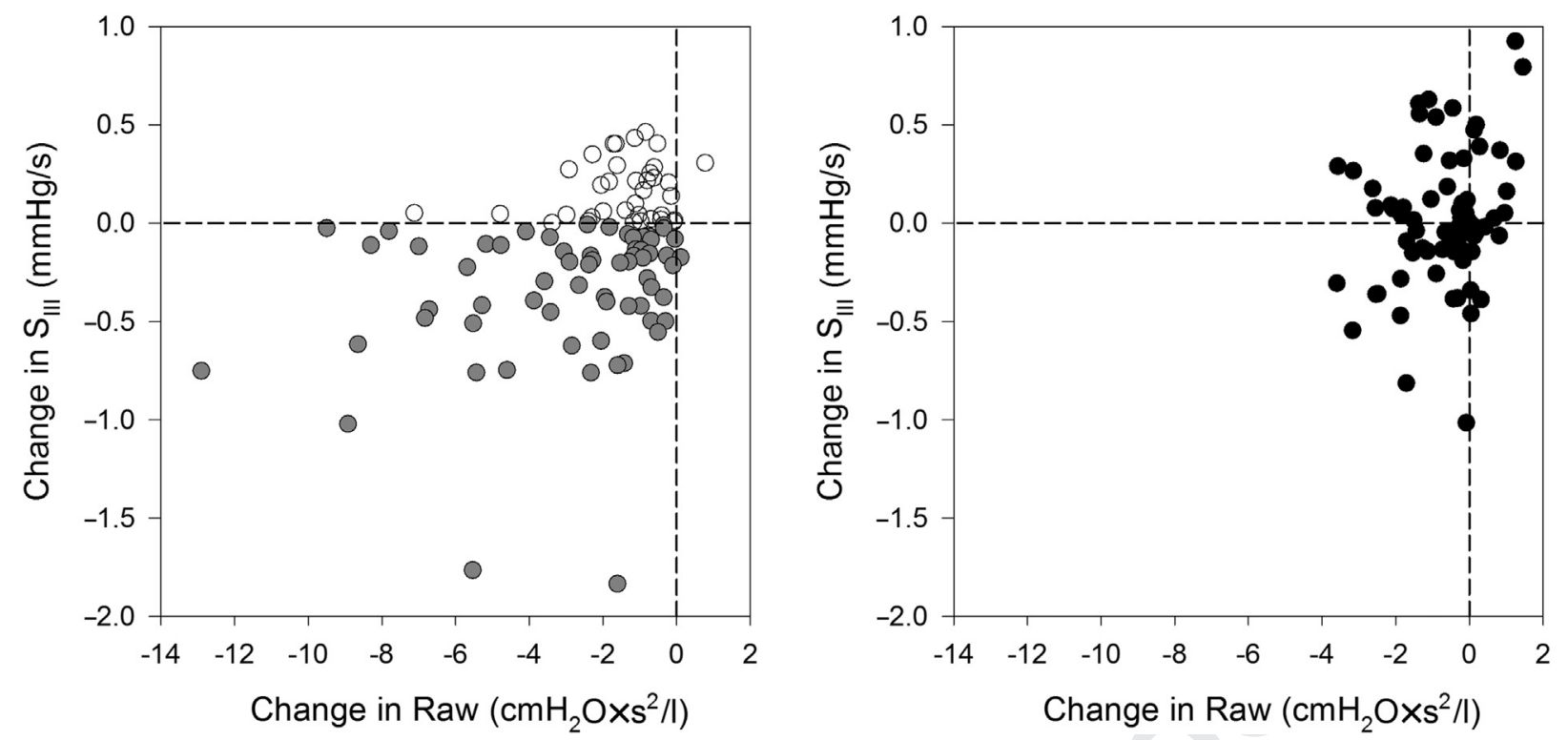

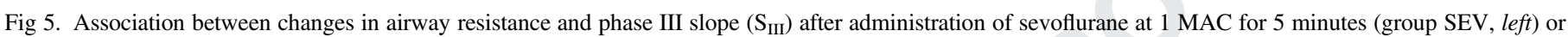

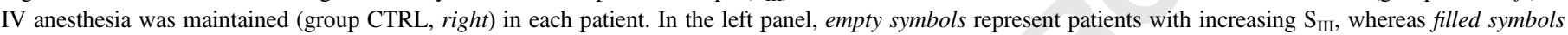
represent patients with decreasing $\mathrm{S}_{\text {III }}$ from sevoflurane.

$\mathrm{PaO}_{2} / \mathrm{F}_{\mathrm{I}} \mathrm{O}_{2}$ ratio and $\mathrm{C}$ exhibited significant decreases after $\mathrm{CPB}$ (pooled changes of $-9.3 \% \pm 2.1 \%$ and $-13 \% \pm 1.0 \%$, respectively), whereas Qs/Qt and $\mathrm{P}_{\mathrm{a}-\mathrm{ET}} \mathrm{CO}_{2}$ increased (119\% $\pm 9 \%$ and $32 \% \pm 9 \%$, respectively; $p<0.0001$ for all). Sevoflurane reversed the decreases in the $\mathrm{PaO}_{2} / \mathrm{F}_{\mathrm{I}} \mathrm{O}_{2}$ ratio and $\mathrm{C}(15 \% \pm 1.7 \%$ and $17 \% \pm 1.4 \%$, respectively; $\mathrm{p}<0.0001$ for both) and reduced Qs/Qt and $\mathrm{P}_{\mathrm{a}-\mathrm{ET}} \mathrm{CO}_{2}(-20 \% \pm 1.5 \%$ and $-9.7 \% \pm 3.3 \%$, respectively; $\mathrm{p}<0.03)$. The corresponding changes in the $\mathrm{PaO}_{2} / \mathrm{F}_{\mathrm{I}} \mathrm{O}_{2}$ ratio, $\mathrm{C}$, and Qs/Qt in group CTRL were not significant.

Figure 5 depicts the associations between the changes in Raw and $\mathrm{S}_{\text {III }}$ after the interventions. Sevoflurane decreased Raw in all but 1 patient, whereas the changes in $\mathrm{S}_{\mathrm{III}}$ were far less uniform; the administration of sevoflurane resulted in further elevations in $S_{\mathrm{III}}$ in 36 of 99 cases. In contrast, 28 of the 91 patients in group CTRL exhibited additional elevations in Raw during the corresponding period, and $\mathrm{S}_{\mathrm{III}}$ increased in 35 cases.

The association of post-CPB values of the $\mathrm{PaO}_{2} / \mathrm{F}_{\mathrm{I}} \mathrm{O}_{2}$ ratio and $\mathrm{P}_{\mathrm{a}-\mathrm{ET}} \mathrm{CO}_{2}$ and their sevoflurane-induced changes are demonstrated in Figure 6. No statistically significant correlation was observed between the $\mathrm{PaO}_{2} / \mathrm{F}_{\mathrm{I}} \mathrm{O}_{2}$ ratio and its change after sevoflurane $\left(\mathrm{R}^{2}=0.05\right)$, whereas a strong negative correlation was found between $\mathrm{P}_{\mathrm{a}-\mathrm{ET}} \mathrm{CO}_{2}$ and its change after sevoflurane $\left(\mathrm{R}^{2}=0.51, \mathrm{p}<0.001\right)$.

Fig 6. Association between post-CPB values of the $\mathrm{PaO}_{2} / \mathrm{F}_{\mathrm{I}} \mathrm{O}_{2}$ ratio (left) and $\mathrm{P}_{\mathrm{a}-\mathrm{ET}} \mathrm{CO}_{2}$ (right) and their sevoflurane-induced changes. Each symbol represents a patient; dashed lines denote linear regressions. 


\section{Discussion}

The results of this study demonstrated the ability of sevoflurane to reverse detrimental changes in lung function induced by extracorporeal circulation in a large cohort of cardiac surgery patients. Administration of sevoflurane led to marked airway dilations uniformly in almost all the patients, resulting in improved function of the lung as an oxygenator. Conversely, this beneficial profile of sevoflurane was reflected in distinctly different changes in the capnogram parameter related to ventilation heterogeneities $\left(\mathrm{S}_{\mathrm{III}}\right)$. Even though the parameters presented improved unanimously after the administration of sevoflurane, none of them showed significant changes in group CTRL during the matching period.

\section{Airway and Lung Tissue Mechanics}

Sevoflurane induced significant improvements in the airway and tissue mechanics compromised by CPB. This finding is in accordance with previous results, where the beneficial profile of sevoflurane was demonstrated against bronchoconstriction induced by exogenous cholinergic agonists ${ }^{1,2}$ or after a release of endogenous mediators. ${ }^{3}$ Because Raw mainly reflects the flow resistance of the central conducting airways, ${ }^{27}$ the marked drops in this parameter likely are a reflection of the prominent dilation of proximal airway regions. This idea is supported by the complete return of Iaw to pre-CPB levels in group SEV, which may have resulted from the rise of bronchial volume as a consequence of bronchodilation ${ }^{27}$ and from the homogenization of airway calibers. ${ }^{28}$ The drops in lung tissue parameters $\mathrm{G}$ and $\mathrm{H}$ after the administration of sevoflurane may reflect an improvement in the parenchymal viscoelasticity because sevoflurane is reported to have pulmonary anti-inflammatory effects. ${ }^{29,30}$ However, such a process was not likely to evolve due to the relatively short time frame $(5 \mathrm{~min})$. Another, more probable, mechanism responsible for the improvement in tissue parameters may be due to alveolar recruitment secondary to bronchodilation and homogenization of alveolar ventilation. Accordingly, the drops in $\mathrm{G}$ can be explained by decreasing time constant inequalities arising from the heterogenous constriction of small airways. Because sevoflurane induced greater drops in $G$ than in $H$, their ratio $\eta$ decreased after the administration of sevoflurane, supporting the notion of lung homogenization. ${ }^{31}$ The improved lung aeration from sevoflurane also is supported by the increases in a routinely assessed mechanical parameter reflecting overall lung tissue stiffness (C).

\section{Ventilation and Oxygenation}

The phase III slope of the capnogram is determined by the ventilation and perfusion of the lungs, although the latter process only accounts for $\sim 20 \%$ of the change in $\mathrm{S}_{\mathrm{III}}{ }^{32}$ Furthermore, the slope of $\mathrm{CO}_{2}$ concentration during alveolar emptying is governed primarily by Raw. ${ }^{23}$ Accordingly, an increment in $\mathrm{S}_{\text {III }}$ mainly reflects the maldistribution of ventilation, as observed in asthma, ${ }^{33}$ in obstructive lung disease, ${ }^{21}$ or after $\mathrm{CPB},{ }^{23}$ whereas bronchodilator therapy ${ }^{34}$ or an optimized ventilation strategy ${ }^{20,22,35}$ decreases $S_{\text {III. }}$. Considering these earlier findings, the decrement in the mean $\mathrm{S}_{\mathrm{III}}$ in the study presented here implies the reduction of ventilation heterogeneity from sevoflurane. This result is in accordance with the beneficial lung mechanical changes, as previously described.

The lack of difference in the change in $S_{I I}$ between the protocol groups can be explained by the dependence of this parameter on various lung mechanical properties. In a previous study, the change in $\mathrm{S}_{\mathrm{II}}$ exhibited a negative correlation with the change in Raw and a positive correlation with the change in $\mathrm{C}^{23}$ Because sevoflurane induced changes in both of these mechanical parameters, their effects on $S_{\text {II }}$ may have been counterbalanced.

The improvement of ventilation from sevoflurane was manifested in better ventilation-perfusion matching as reflected by the decreased $\mathrm{Qs} / \mathrm{Qt}$ and a related, easier accessible parameter, $\mathrm{P}_{\mathrm{a}-\mathrm{ET}} \mathrm{CO}_{2}$. Several studies have investigated the effect of sevoflurane on the intrapulmonary shunt fraction, but they were focused on the potential inhibition of hypoxic pulmonary vasoconstriction by this volatile agent during one lung ventilation. Abe et al reported a decrease in Qs/Qt after switching from sevoflurane to propofol, ${ }^{36}$ whereas Beck et al observed similar changes in Qs/Qt among patients receiving either sevoflurane or propofol. ${ }^{37}$ The discrepancies in these findings can be attributed to the dual action of sevoflurane; although it inhibits hypoxic pulmonary vasoconstriction via vascular smooth muscle relaxation, it also decreases ventilation-perfusion mismatch by facilitating a more uniformly distributed ventilation. In the study presented here, the striking bronchodilation from sevoflurane opened shunted alveolar regions with sustained perfusion in both lungs. The resultant improvement in ventilation-perfusion matching most likely outweighed the potential loss of protective hypoxic pulmonary vasoconstriction, as reflected in the decreased Qs/ $\mathrm{Qt}$ and $\mathrm{P}_{\mathrm{a}-\mathrm{ET}} \mathrm{CO}_{2}$. These beneficial changes ultimately resulted in better oxygenation, as reflected by the increased $\mathrm{PaO}_{2} / \mathrm{F}_{\mathrm{I}} \mathrm{O}_{2}$ ratio. A further noteworthy observation is that the higher the $\mathrm{P}_{\mathrm{a}-\mathrm{ET}} \mathrm{CO}_{2}$ after $\mathrm{CPB}$, the greater its improvement to sevoflurane. Even though this relationship is less apparent for the absolute changes in $\mathrm{PaO}_{2} / \mathrm{F}_{\mathrm{I}} \mathrm{O}_{2}$ to sevoflurane, this is of greater importance in patients with low $\mathrm{PaO}_{2} / \mathrm{F}_{\mathrm{I}} \mathrm{O}_{2}$ after CPB. These findings indicate the particular benefit of sevoflurane in patients with severely compromised gas exchange.

\section{Effect of Sevoflurane on Ventilation Heterogeneity}

Despite the association between airway caliber and $\mathrm{S}_{\mathrm{III}}{ }^{23}$ the magnitude of the decrement in $\mathrm{S}_{\mathrm{III}}$ after the administration of sevoflurane did not match that in Raw. Thus, the authors sought to elucidate the origin of this discrepancy by investigating the association between the changes in Raw and in $\mathrm{S}_{\mathrm{III}}$ after the post-CPB intervention in both protocol groups. Whereas Raw decreased spontaneously in about two-thirds of the patients in group CTRL after CPB, bronchodilation was observed in all the patients but 1 in group SEV. Despite this uniform change in Raw in the latter group, $S_{\text {III }}$ exhibited 
diverse changes, with further elevations in more than one-third of the patients. This suggests that in these cases, airway dilation resulted in a more heterogenous alveolar emptying.

\section{Limitations and Future Directions}

Because the low-frequency forced oscillation technique requires general anesthesia and mechanical ventilation, this study was limited to the assessment of intraoperative changes in pulmonary mechanics, ventilation, and oxygenation. Systematic evaluation of the duration of the pulmonary effects of sevoflurane and its possible postoperative benefits (eg, shorter extubation time and intensive care unit stay, lower frequency and severity of respiratory morbidities) may be a subject of a future investigation. Additional research may focus on the characterization of the preventive potential of sevoflurane administered into the oxygenator during CPB in patients with airway susceptibilities. Another possible direction for forthcoming research is the investigation of the potential respiratory benefit of sevoflurane in intensive care unit patients with respiratory complications, in whom its administration can be achieved by using the anesthetic conserving device (AnaConDa; Sendana Medical, Kildare, Ireland).

In conclusion, the results of the study presented here demonstrated that bronchoconstriction with subsequent development of atelectasis and intrapulmonary shunt triggered by $\mathrm{CPB}$ can be effectively alleviated with the application of sevoflurane. This benefit may be of particular importance in patients with airway hyper-responsiveness, in which severe bronchoconstriction is likely to develop after CPB. In such cases, switching anesthesia management from a total intravenous approach to an inhalational technique may be recommended. The potential increase in ventilation heterogeneity after sevoflurane may necessitate the elevation of positive end expiratory pressure and/or applying recruitment maneuvers.

\section{References}

1 Habre W, Petak F, Sly PD, et al. Protective effects of volatile agents against methacholine-induced bronchoconstriction in rats. Anesthesiology 2001;94:348-53.

2 Myers CF, Fontao F, Janosi TZ, et al. Sevoflurane and desflurane protect cholinergic-induced bronchoconstriction of hyperreactive airways in rabbits. Can J Anaesth 2011;58:1007-15.

3 Wiklund CU, Lindsten U, Lim S, et al. Interactions of volatile anesthetics with cholinergic, tachykinin, and leukotriene mechanisms in isolated guinea pig bronchial smooth muscle. Anesth Analg 2002;95: $1650-5$, table of contents.

4 von Ungern-Sternberg BS, Saudan S, Petak F, et al. Desflurane but not sevoflurane impairs airway and respiratory tissue mechanics in children with susceptible airways. Anesthesiology 2008;108:216-24.

5 Rooke GA, Choi JH, Bishop MJ. The effect of isoflurane, halothane, sevoflurane, and thiopental/nitrous oxide on respiratory system resistance after tracheal intubation. Anesthesiology 1997;86:1294-9.

6 Babik B, Asztalos T, Petak F, et al. Changes in respiratory mechanics during cardiac surgery. Anesth Analg 2003;96:1280-7. table of contents.

7 Albu G, Babik B, Kesmarky K, et al. Changes in airway and respiratory tissue mechanics after cardiac surgery. Ann Thorac Surg 2010;89:1218-26.
8 Wan S, LeClerc JL, Vincent JL. Inflammatory response to cardiopulmonary bypass: Mechanisms involved and possible therapeutic strategies. Chest 1997;112:676-92.

9 Steinberg JB, Kapelanski DP, Olson JD, et al. Cytokine and complement levels in patients undergoing cardiopulmonary bypass. J Thorac Cardiovasc Surg 1993;106:1008-16.

10 Chenoweth DE, Cooper SW, Hugli TE, et al. Complement activation during cardiopulmonary bypass: Evidence for generation of C3a and C5a anaphylatoxins. N Engl J Med 1981;304:497-503.

11 Tanaka K, Takao M, Yada I, et al. Alterations in coagulation and fibrinolysis associated with cardiopulmonary bypass during open heart surgery. J Cardiothorac Anesth 1989;3:181-8.

12 Laffey JG, Boylan JF, Cheng DC. The systemic inflammatory response to cardiac surgery: Implications for the anesthesiologist. Anesthesiology 2002;97:215-52.

13 Downing SW, Edmunds Jr. LH. Release of vasoactive substances during cardiopulmonary bypass. Ann Thorac Surg 1992;54:1236-43.

14 Fayaz KM, Pugh S, Balachandran S, et al. Histamine release during adult cardiopulmonary bypass. Anaesthesia 2005;60:1179-84.

15 Neuhof C, Walter O, Dapper F, et al. Bradykinin and histamine generation with generalized enhancement of microvascular permeability in neonates, infants, and children undergoing cardiopulmonary bypass surgery. Pediatr Crit Care Med 2003;4:299-304.

16 Lele E, Petak F, Carnesecchi S, et al. The protective effects of volatile anesthestics against the bronchoconstriction induced by an allergic reaction in sensitized rabbit pups. Anesth Analg 2013;116:1257-64.

17 Schutz N. Effects of volatile anaesthetic agents on enhanced airway tone in sensitized guinea pigs. Br J Anaesth 2004;92:254-60.

18 Cho EJ, Yoon JH, Hong SJ, et al. The effects of sevoflurane on systemic and pulmonary inflammatory responses after cardiopulmonary bypass. J Cardiothorac Vasc Anesth 2009;23:639-45.

19 Hantos Z, Daroczy B, Suki B, et al. Input impedance and peripheral inhomogeneity of dog lungs. J Appl Physiol (1985) 1992;72:168-78.

20 Blanch L, Lucangelo U, Lopez-Aguilar J, et al. Volumetric capnography in patients with acute lung injury: Effects of positive end-expiratory pressure. Eur Respiratory J 1999;13:1048-54.

21 Krauss B, Deykin A, Lam A, et al. Capnogram shape in obstructive lung disease. Anesth Analg 2005;100:884-8, table of contents.

22 Babik B, Csorba Z, Czovek D, et al. Effects of respiratory mechanics on the capnogram phases: Importance of dynamic compliance of the respiratory system. Crit Care 2012;16:R177.

23 Csorba Z, Petak F, Nevery K, et al. Capnographic parameters in ventilated patients: Correspondence with airway and lung tissue mechanics. Anesth Analg 2016;122:1412-20.

24 Berggren S. The oxygen deficit of arterial blood caused by non-ventilating parts of the lung. Acta Physiol Scand 1942;11:1-92.

25 Nickalls RW, Mapleson WW. Age-related iso-MAC charts for isoflurane, sevoflurane and desflurane in man. Br J Anaesth 2003;91:170-4.

26 Bausell RB, Li Y-F. Power analysis for experimental research: A practical guide for the biological, medical, and social sciences. New York: Cambridge University Press; 2002.

27 Peslin R, Fredberg JJ. Oscillation mechanics of the respiratory system: Comprehensive physiology. Hoboken, NJ: John Wiley \& Sons, Inc; 2011. 145-177.

28 Lanteri CJ, Petak F, Gurrin L, et al. Influence of inertance on respiratory mechanics measurements in mechanically ventilated puppies. Pediatr Pulmonol 1999;28:130-8.

29 Suter D, Spahn DR, Blumenthal S, et al. The immunomodulatory effect of sevoflurane in endotoxin-injured alveolar epithelial cells. Anesth Analg 2007;104:638-45.

30 Sugasawa Y, Yamaguchi K, Kumakura S, et al. Effects of sevoflurane and propofol on pulmonary inflammatory responses during lung resection. J Anesth 2012;26:62-9.

31 Lutchen KR, Hantos Z, Petak F, et al. Airway inhomogeneities contribute to apparent lung tissue mechanics during constriction. J Appl Physiol (1985) 1996;80:1841-9. 
32 Tusman G, Areta M, Climente C, et al. Effect of pulmonary perfusion on the slopes of single-breath test of CO2. J Appl Physiol (1985) 2005;99: $650-5$.

33 You B, Peslin R, Duvivier C, et al. Expiratory capnography in asthma: Evaluation of various shape indices. Eur Respir J 1994;7: 318-23.

34 Blanch L, Fernandez R, Saura P, et al. Relationship between expired capnogram and respiratory system resistance in critically ill patients during total ventilatory support. Chest 1994;105:219-23.
35 Böhm SH, Maisch S, von Sandersleben A, et al. The effects of lung recruitment on the phase III slope of volumetric capnography in morbidly obese patients. Anesth Analg 2009;109:151-9.

36 Abe K, Shimizu T, Takashina M, et al. The effects of propofol, isoflurane, and sevoflurane on oxygenation and shunt fraction during one-lung ventilation. Anesth Analg 1998;87:1164-9.

37 Beck DH, Doepfmer UR, Sinemus C, et al. Effects of sevoflurane and propofol on pulmonary shunt fraction during one lung ventilation for thoracic surgery. Br J Anaesth 2001;86:38-43.
15

17

19

21

23

25

27 